DOE/ORO/2036

\title{
TESTING AND EVALUATION OF ELECTROKINETIC DECONTAMINATION OF CONCRETE
}

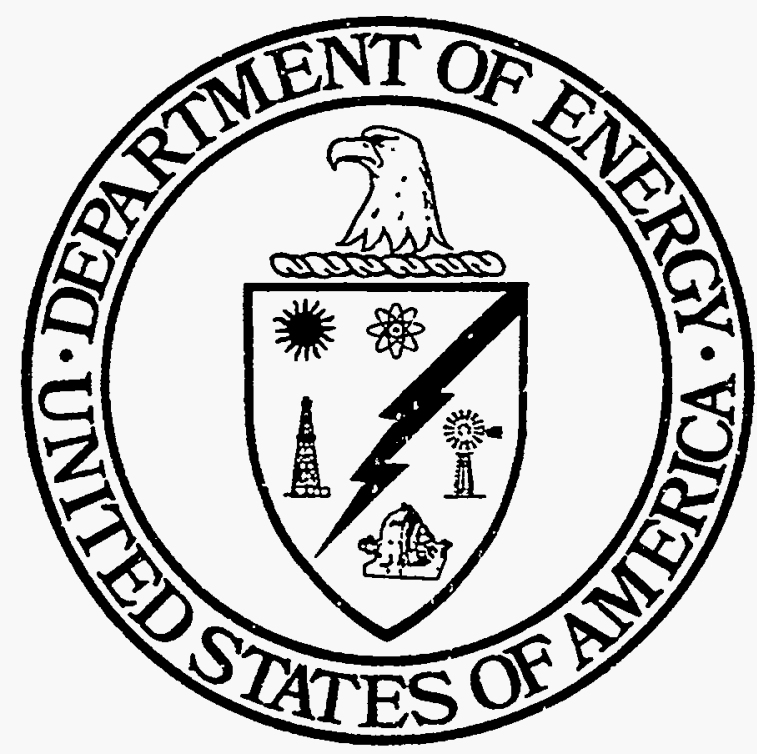

RECEIVED OCT 161998

$\mathbf{O S T}$

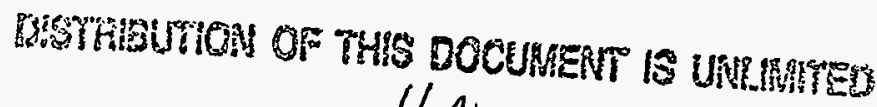

UN

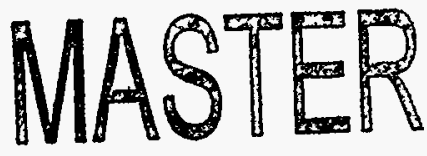

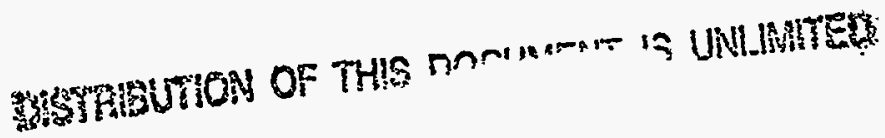




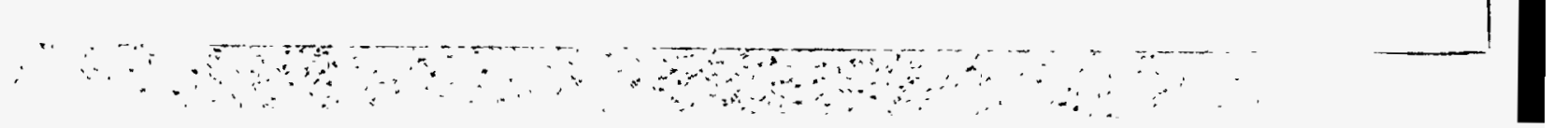




\title{
TESTING AND EVALUATION OF ELECTROKINETIC DECONTAMINATION OF CONCRETE
}

\author{
D. W. DePaoli, M. T. Harris, M. R. Ally, I. L. Morgan,* \\ N. Cate, M. E. Ellis, K. Heath, D. W. Hovist \\ Chemical Technology Division \\ Oak Ridge National Laboratory \\ G. W. Kabalka, C. L. Anderson, C. Tang \\ Department of Chemistry \\ University of Tennessee
}

Technical Report for Period

September 1994 - November 1995

Date Published: October 1996

Prepared for the

U. S. Department of Energy

Office of Technology Development

Office of Environmental Management

B\&R Code: EW 4010000

Prepared by

Oak Ridge National Laboratory

P. O. Box 2008

Oak Ridge, Tennessee 37831

managed by

Lockheed Martin Energy Research Corp.

for the

U. S. Department of Energy

under contract DE-AC05-96OR22464

*Former staff member of the Chemical Technology Division, ORNL

$\uparrow$ Formerly a staff member of the Chemical Technology Division; now a staff member of Robotics and Processing Division, ORNL 



\section{CONTENTS}

LIST OF FIGURES $\ldots \ldots \ldots \ldots \ldots \ldots \ldots \ldots \ldots \ldots \ldots \ldots \ldots \ldots \ldots \ldots \ldots \ldots$

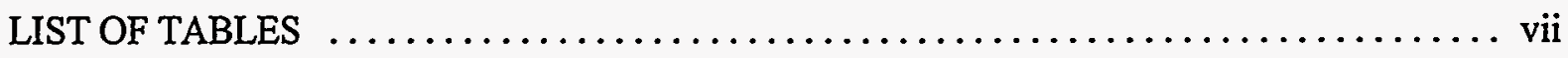

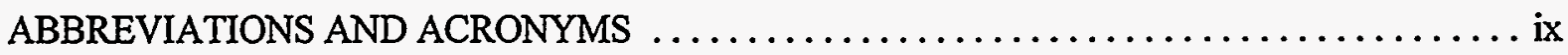

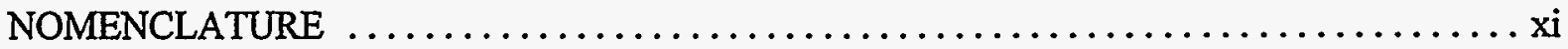

EXECUTTVE SUMMARY $\ldots \ldots \ldots \ldots \ldots \ldots \ldots \ldots \ldots \ldots \ldots \ldots \ldots \ldots \ldots \ldots \ldots \ldots \ldots \ldots \ldots \ldots$

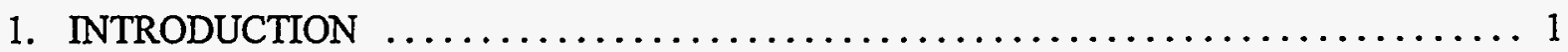

1.1 SYNOPSIS OF CONCRETE DECONTAMINATION NEEDS $\ldots \ldots \ldots \ldots \ldots \ldots \ldots \ldots$

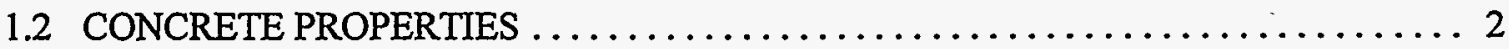

1.3 SCOPE AND STATUS OF ELECTROKINETIC DECONTAMINATION

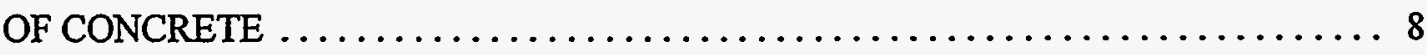

2. REVIEW OF ELECTROKINETIC DECONTAMINATION $\ldots \ldots \ldots \ldots \ldots \ldots \ldots \ldots \ldots$

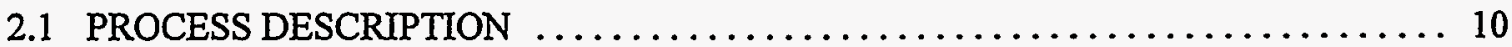

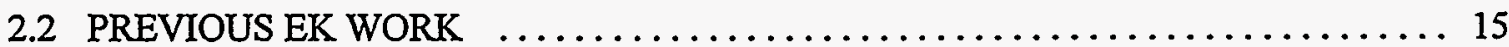

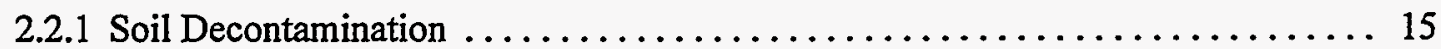

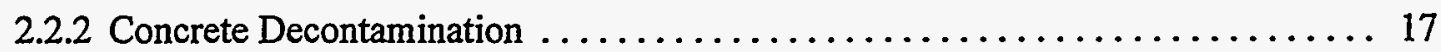

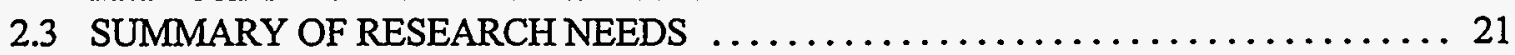

3. INVESTIGATION OF ELECTROKINETIC DECONTAMINATION

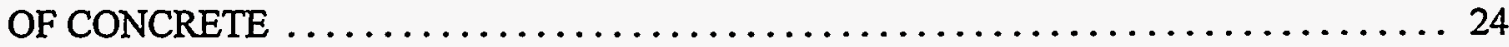

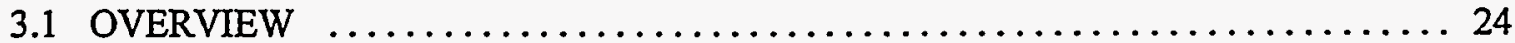

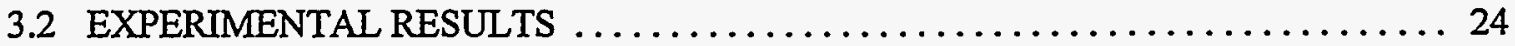

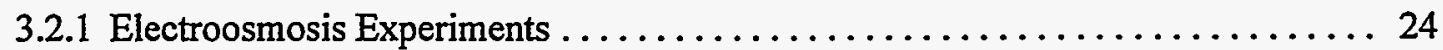

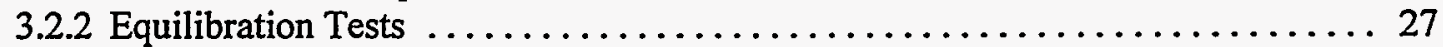

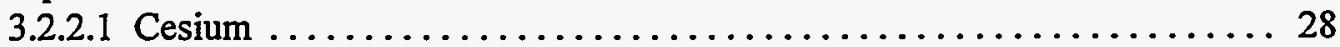

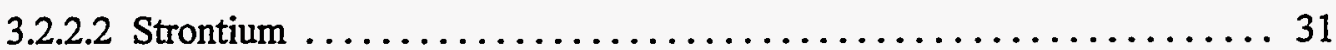

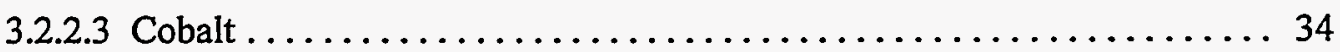

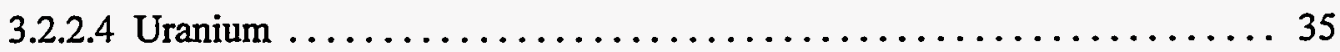

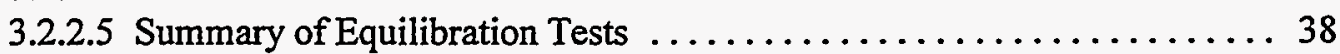

3.2.3 Dynamic Loading/Desorption Experiments $\ldots \ldots \ldots \ldots \ldots \ldots \ldots \ldots \ldots \ldots . \ldots \ldots$

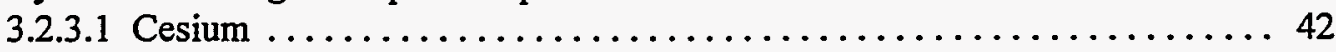

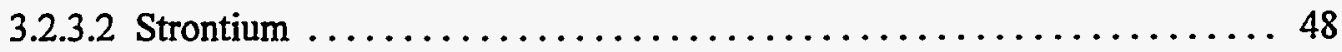

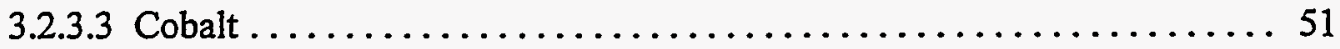

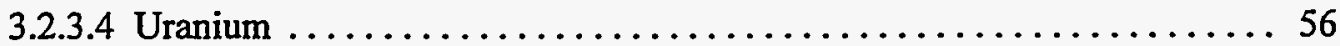

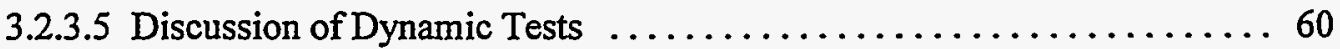

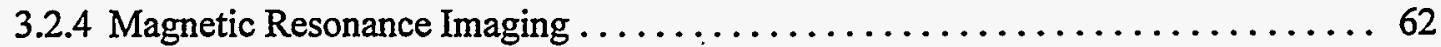

3.2.5 Zeta Potential Measurements ........................... 64

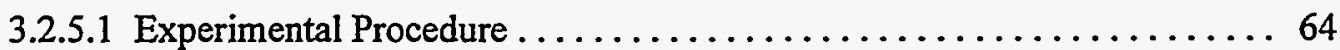

3.2.5.2 Results ...................................... 65 


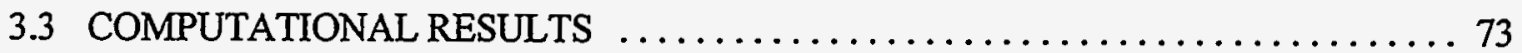

3.3.1 Liquid Penetration of Pores . . . . . . . . . . . . . . . . . . . 73

3.3.2 Contaminant Transport by EK .............................. 79

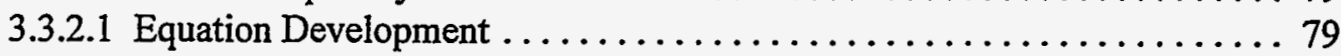

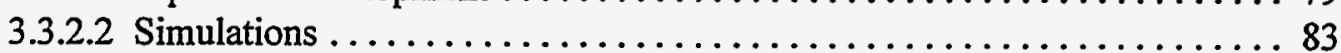

3.3.2.3 Comparison of Computational and Dynamic Experiment Results ..... 89

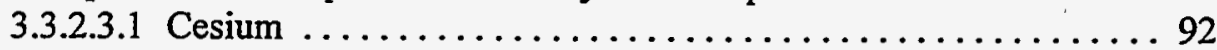

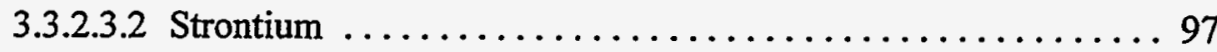

3.3.2.4 Discussion of Modeling Results ................. 102

4. EVALUATION OF THE ELECTROKINETIC DECONTAMINATION

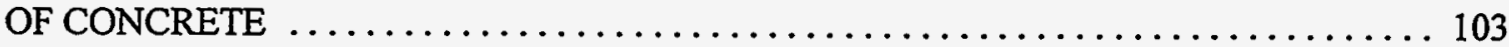

5. CONCLUSIONS AND RECOMMENDATIONS $\ldots \ldots \ldots \ldots \ldots \ldots \ldots \ldots \ldots \ldots \ldots$

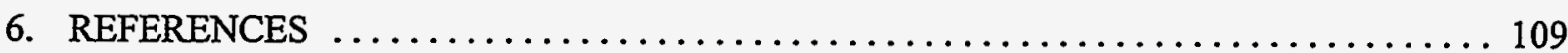




\section{DISCLAIMER}

Portions of this document may be illegible in electronic image products. Images are produced from the best available original document. 


\section{LIST OF FIGURES}

Figure Page

1.1 Estimation of water penetration rate using Darcy's Law $\ldots \ldots \ldots \ldots \ldots \ldots \ldots$

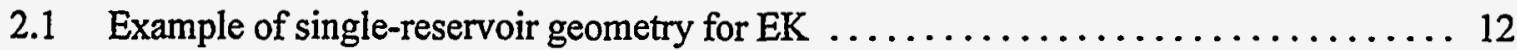

2.2 Example of dual-reservoir geometry for EK $\ldots \ldots \ldots \ldots \ldots \ldots \ldots \ldots \ldots \ldots \ldots \ldots$

3.1 Loading of cesium on concrete in $0.016 \mathrm{M}$ sodium hydroxide $\ldots \ldots \ldots \ldots \ldots 29$

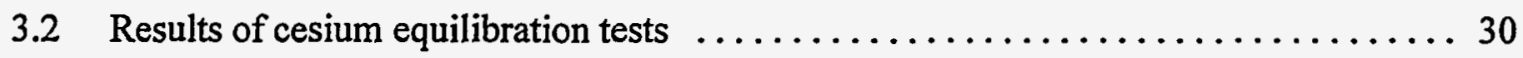

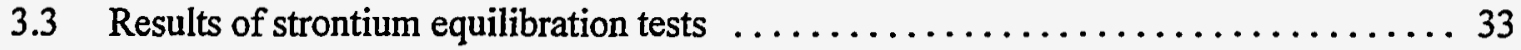

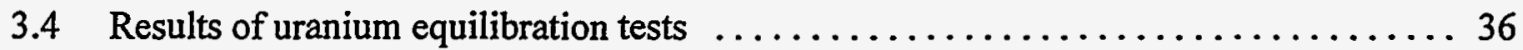

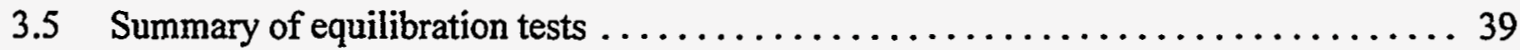

3.6 Schematic of dynamic electrokinetic experiment $\ldots \ldots \ldots \ldots \ldots \ldots \ldots \ldots \ldots \ldots$

3.7 Results of first dynamic test with cesium $\ldots \ldots \ldots \ldots \ldots \ldots \ldots \ldots \ldots \ldots \ldots$

3.8 Comparison of cesium dynamic tests $\ldots \ldots \ldots \ldots \ldots \ldots \ldots \ldots \ldots \ldots \ldots \ldots \ldots \ldots \ldots \ldots \ldots \ldots \ldots$

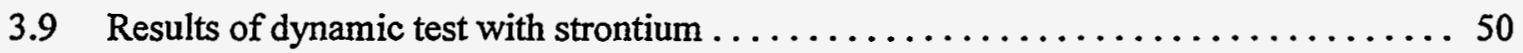

3.10 Results of tests to obtain three-dimensional images of water trapped in a 1.91-cm-diam,

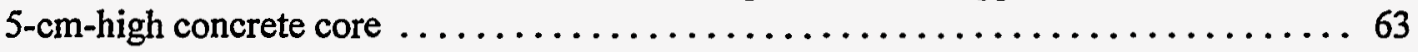

3.11 Effects of $\mathrm{pH}$ and $[\mathrm{NaOH}]$ on dynamic change in zeta potential of concrete $(0.2 \mathrm{mg}$

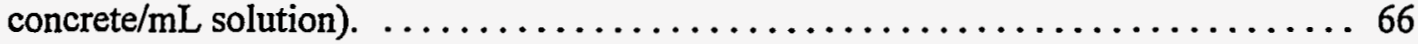

3.12 Effects of $\mathrm{pH}$ and $[\mathrm{NaCl}]$ on dynamic change in zeta potential of concrete $(0.2 \mathrm{mg}$

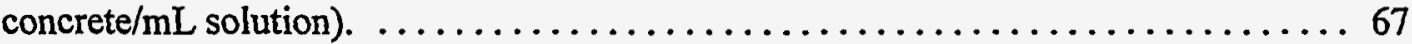

3.13 Effect of $[\mathrm{NaOH}]$ on zeta potential of concrete $\ldots \ldots \ldots \ldots \ldots \ldots \ldots \ldots \ldots \ldots \ldots \ldots \ldots$

3.14 Effect of $\mathrm{pH}$ on zeta potential of concrete $(0.2 \mathrm{mg}$ concrete/mL solution) $\ldots \ldots \ldots 69$

3.15 Effect of concentration of concrete particles in suspension on zeta potential $\ldots \ldots \ldots 71$

3.16 Effect of concentration of concrete particles in suspension

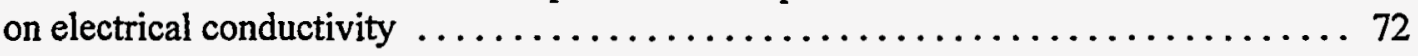

3.17 Schematic of system in force balance of liquid in a closed-end pore $\ldots \ldots \ldots \ldots \ldots 74$

3.18 Comparison between forces acting on liquid in a pore $\ldots \ldots \ldots \ldots \ldots \ldots \ldots$

3.19 Penetration of cylindrical closed-end pores $\ldots \ldots \ldots \ldots \ldots \ldots \ldots \ldots \ldots \ldots \ldots 77$

3.20 Schematic of system used in the simulation of dynamic experiments . . . . . . . 84

3.21 Effect of number of collocation points on computed $\mathrm{UO}_{2}\left(\mathrm{CO}_{3}\right)_{2}{ }_{4}$ concentrations

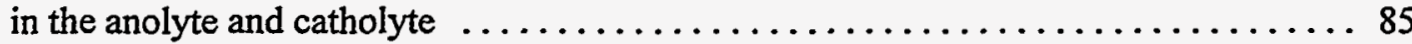

3.22 Computed $\mathrm{UO}_{2}\left(\mathrm{CO}_{3}\right)_{2}{ }^{4}$ concentration profile in concrete for 12 collocation points 
3.23 Computed $\mathrm{UO}_{2}\left(\mathrm{CO}_{3}\right)_{2}{ }^{4-}$ concentration profile in concrete for 22 collocation points

3.24 Computed $\mathrm{UO}_{2}\left(\mathrm{CO}_{3}\right)_{2}{ }^{4}$ concentration profile in concrete for 32 collocation points

3.25 Computed electrokinetic transport of $\mathrm{Cs}^{+}$ions through a concrete core:

(a) without electroosmosis; (b) with electroosmosis

3.26 Computed electrokinetic transport of $\mathrm{UO}_{2}\left(\mathrm{CO}_{3}\right)_{3}{ }^{4}$ ions through a concrete core: (a) without electroosmosis; (b) with electroosmosis

3.27 Comparison of computed and experimental cesium concentrations in anolyte and catholyte.

3.28 Comparison of computed and experimental $\mathrm{pH}$ levels during cesium transport.

3.29 Comparison of computed and experimental voltage drops across concrete disk during cesium transport

3.30 Comparison of computed and experimental strontium concentrations in anolyte and catholyte

3.31 Comparison of computed and experimental $\mathrm{pH}$ levels during strontium transport. ... 100

3.32 Comparison of computed and experimental voltage drops across concrete disk during strontium transport 


\section{LIST OF TABLES}

1.1 Typical compositions of portland cements $\ldots \ldots \ldots \ldots \ldots \ldots \ldots \ldots \ldots \ldots$

1.2 Dominant species in cement pore solutions $\ldots \ldots \ldots \ldots \ldots \ldots \ldots \ldots \ldots \ldots$

3.1 Measurement of electroosmotic flow of distilled water across glass frit $\ldots \ldots \ldots \ldots 25$

3.2 Results of first dynamic loading/desorption test with cesium $\ldots \ldots \ldots \ldots \ldots \ldots 4$

3.3 Results of second dynamic loading/desorption test with cesium $\ldots \ldots \ldots \ldots \ldots \ldots$

3.4 Results of dynamic loading/desorption test with strontium $\ldots \ldots \ldots \ldots \ldots \ldots \ldots$

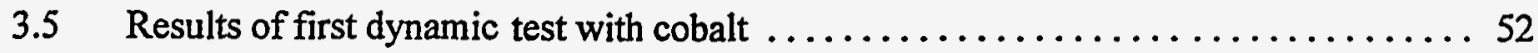

3.6 Results of second dynamic test to study electromigration of cobalt-EDTA complex

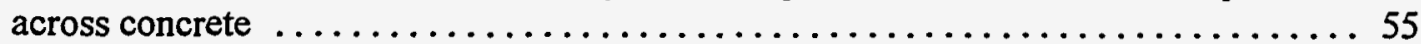

3.7 Results of first dynamic test with uranium $\ldots \ldots \ldots \ldots \ldots \ldots \ldots \ldots \ldots \ldots$

3.8 Results of second dynamic test with uranium $\ldots \ldots \ldots \ldots \ldots \ldots \ldots \ldots \ldots \ldots$

3.9 Results of third dynamic test with uranium $\ldots \ldots \ldots \ldots \ldots \ldots \ldots \ldots \ldots \ldots \ldots \ldots \ldots \ldots$

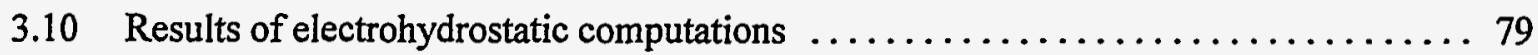

3.11 Initial concentrations of ions for simulation of cesium dynamic experiment $\ldots \ldots \ldots 93$

3.12 Parameter values for simulation of cesium dynamic experiment $\ldots \ldots \ldots \ldots \ldots \ldots 9$

3.13 Initial concentrations of ions for simulation of strontium dynamic experiment .....98

3.14 Parameter values for simulation of strontium dynamic experiment . . . . . . . 98 
AA atomic absorption spectroscopy

dc direct current

DOE U.S. Department of Energy

dpm disintegrations per minute

EDTA ethylenediaminetetraacetic acid

EK electrokinetic decontamination

HANF Hanford Site

ICP inductively coupled plasma (emission spectroscopy)

ICPP Idaho Chemical Processing Plant

INEL Idaho National Engineering Laboratory

MRI magnetic resonance imaging

NMR nuclear magnetic resonance

NRC U.S. Nuclear Regulatory Commission

ORNL Oak Ridge National Laboratory

ORR Oak Ridge Reservation

PCB polychlorinated biphenyl

ppm parts per million by weight (i.e., micrograms per gram)

TTP technical task plan 



\section{NOMENCLATURE}

( $A=$ electrical current, $L=$ length, $M=$ mass, $\mathrm{mol}=$ amount of substance, $t=$ time, $T=$ temperature)

$A_{c} \quad$ area of concrete disk, dimensionless

c concentration, $\mathrm{ML}^{-3}$

$c_{i} \quad$ concentration of species $i, \mathrm{ML}^{-3}$

d diameter of concrete disk, $\mathrm{L}$

$D_{l} \quad$ diffusivity of species $i, \mathrm{~L}^{2} \mathrm{t}^{-1}$

$D_{l}$ diffusivity of reference species, $\mathrm{L}^{2} \mathrm{t}^{-1}$

Da Damkohler number, defined as $\left(\mathrm{L}^{2} \mathrm{R}^{0}\right) /\left(\mathrm{D}_{1} \mathrm{c}_{\mathrm{ref}}\right)$, dimensionless

F Faraday constant, $\mathrm{A} \mathrm{mol}^{-1} \mathrm{t}$

$g$ gravitational acceleration, $\mathrm{L} \mathrm{t}^{2}$

$h_{\text {pore }} \quad$ total pore length, $\mathrm{L}$

$h_{2} \quad$ liquid penetration depth, $\mathrm{L}$

$E_{o} \quad$ scaled normal component of electrical field, dimensionless

$G \quad$ Green's function, dimensionless

$H$ pressure difference in liquid head, $\mathrm{L}$

$\mathcal{H}$ scaled local mean curvature, dimensionless

$i \quad$ electrical current, $\mathrm{A}$,

$\bar{i}_{x} \quad$ scaled electrical current density for straight pore, dimensionless

$\bar{i}_{y} \quad$ scaled dimensionless effective electrical current density, dimensionless

$k$ permeability, $\mathrm{L}^{2}$

$k_{i}^{\prime} \quad$ film mass transfer coefficient for species $i, t^{-1}$

$K \quad$ scaled reference pressure, dimensionless

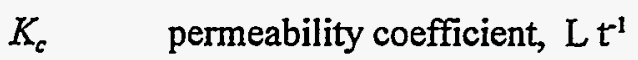

$K_{d} \quad$ distribution coefficient, $\mathrm{L}^{3} \mathrm{M}^{-1}$

$L \quad$ length, $\mathrm{L}$

$m$ mass, $\mathrm{M}$

$n \quad$ scaled unit normal, dimensionless

$N_{e} \quad$ electrical Bond number, dimensionless

$N_{g} \quad$ gravitational Bond number, dimensionless 


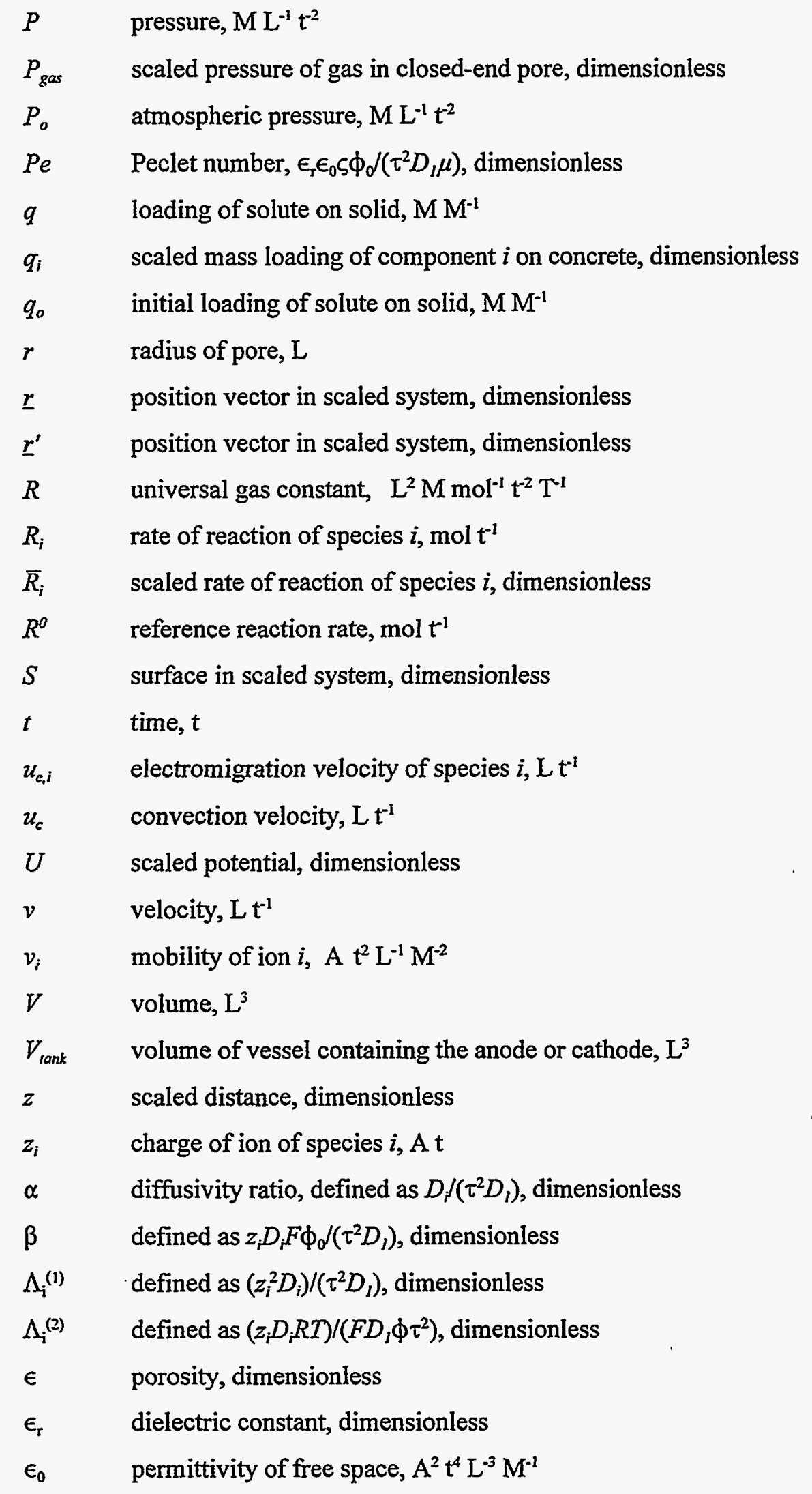




$\begin{array}{ll}\zeta & \text { zeta potential, } M \mathrm{~L}^{2} \mathrm{~A}^{-1} \mathrm{t}^{-3} \\ \theta & \text { contact angle between liquid and pore wall, dimensionless } \\ \kappa & \text { effective conductivity of pore liquid, } \mathrm{A}^{2} \mathrm{t}^{3} \mathrm{M}^{-1} \mathrm{~L}^{-2} \\ \kappa_{\text {surface }} & \text { surface conductivity, } \mathrm{A}^{2} \mathrm{t}^{3} \mathrm{M}^{-1} \mathrm{~L}^{-2} \\ \lambda_{c} & \text { ratio of transport by electromigration and electroosmosis, dimensionless } \\ \mu & \text { viscosity, } M \mathrm{~L}^{-1} \mathrm{t}^{-1} \\ \rho & \text { liquid density, } M \mathrm{~L}^{-3} \\ \rho_{\mathrm{b}} & \text { bulk density of concrete, } M \mathrm{~L}^{-3} \\ \sigma & \text { surface tension, } M \mathrm{t}^{-2} \\ \tau & \text { tortuosity, dimensionless } \\ \phi & \text { electrical potential, } M \mathrm{~L}^{2} \mathrm{~A}^{-1} \mathrm{t}^{-3} \\ \Phi & \text { scaled electrical potential, dimensionless } \\ \phi_{0} & \text { reference potential, } M L^{2} \mathrm{~A}^{-1} t^{-3}\end{array}$




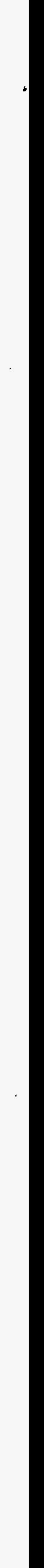




\section{EXECUTIVE SUMMARY}

The technical task plan (TTP) 152002, "Accelerated Testing of Concrete Decontamination Methods," was submitted by Oak Ridge National Laboratory to meet the needs of the Decontamination and Decommissioning Integrated Demonstration Program. The goals and objectives of the TTP are to (1) describe the nature and extent of concrete contamination within the Department of Energy (DOE) complex and emerging and commercial technologies applicable to these problems; (2) to match technologies to the concrete problems and recommend up to four demonstrations; (3) to initiate recommended demonstrations; and (4) to continue investigation and evaluation of the application of electrokinetic decontamination processes to concrete. This document presents findings of experimental and theoretical studies of the electrokinetic decontamination (EK) process and their implications for field demonstrations. This effort is an extension of the work performed under TTP 142005, "Electroosmotic Concrete Decontamination." The goals of this task were to determine the applicability of EK for treating contaminated concrete and, if warranted, to evaluate EK as a potential technology for demonstration.

This task included experiments and theoretical work aimed at developing a fundamental understanding of the processes controlling EK of concrete. A numerical model incorporating these mechanisms was developed, allowing the estimation of contaminant removal under a given set of operating conditions. This model will facilitate the evaluation and optimization of EK processes for different site conditions. Experiments were performed to determine model parameters and to verify model performance. These experiments also included qualitative evaluation of the importance of electroosmosis; sorption isotherms of cesium, cobalt, strontium, and uranium, which are representative concrete contaminants at DOE facilities; and dynamic loading/desorption experiments for the same contaminants. 
This investigation has determined that electroosmosis will not be significant in most applications of EK to concrete and that electromigration will be the primary transport mechanism. The basic nature of concrete will dominate the interactions of contaminants with concrete, leading to precipitate formation for many metal species. The loading of contaminants on concrete was measured to be in the following order: $\mathrm{U}, \mathrm{Co}>\mathrm{S} \mathrm{r}>\mathrm{Cs}$. Dynamic experiments conducted by applying an electrical potential across a concrete disk showed that the mobilities of these contaminants in concrete were in reverse order of the loading. The results indicate that cesium may be removed completely and relatively quickly by EK, strontium may be removed less quickly, and uranium and cobalt will be removed much more slowly. It will be necessary to develop specialized lixiviants containing complexants for the removal of precipitating contaminants such as uranium and cobalt. The one-dimensional EK model developed for this task was successful in estimating the contaminant transport in the dynamic experiments. Thus, it provides a tool for the prediction and optimization of EK.

The results of this work indicate that EK is not yet a mature technology. Several technical issues must be resolved before it can be applied successfully at each particular site. These issues include the physicochemical interactions between concrete, contaminants, and lixiviants; system geometry; and operating conditions. The model developed for this effort provides valuable information regarding the optimal system geometry and operating parameters for a given set of conditions. The modeling results and a limited number of experiments indicate that a significant effort would be required to develop this technology for application to concrete decontamination problems at DOE sites.

It is recommended that if other decontamination technologies are shown to be deficient, particularly in terms of the capability to treat deep contamination or that in cracks, and if such problems are of sufficient importance to DOE, further development and demonstration work should be undertaken with EK. Such work should be a comprehensive effort, with bench-scale testing conducted first to determine the interactions of the contaminants, the lixiviant, and the concrete. The demonstrations, of 
necessity, would involve an attempt to measure a mass balance, with core samples being taken before and after treatment. It is recommended that a demonstration be conducted at a relatively "simple" contamination site, that is, one with a single, mobile contaminant (such as cesium) if possible. 


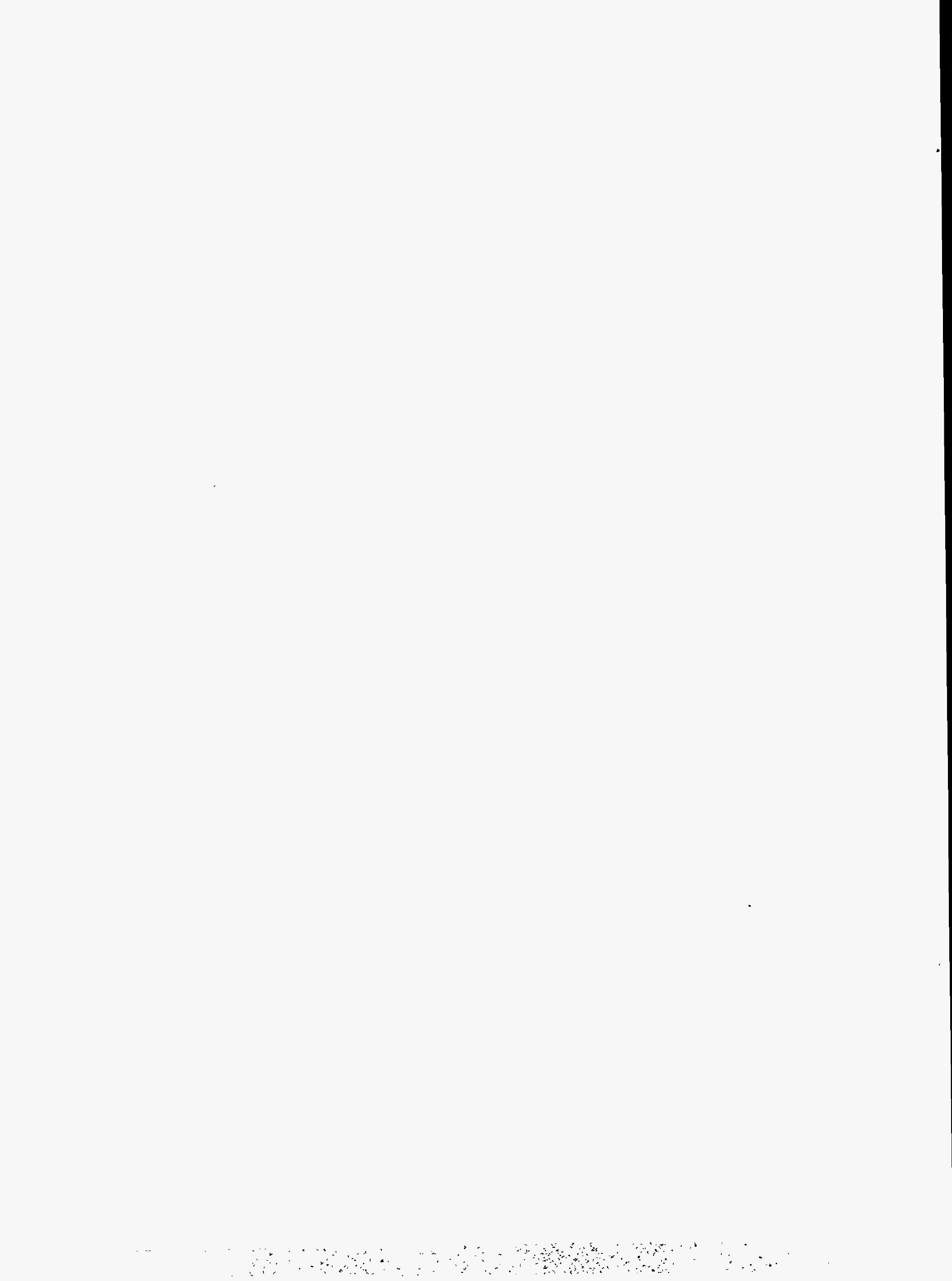




\section{INTRODUCTION}

\subsection{SYNOPSIS OF CONCRETE DECONTAMINATION NEEDS}

Concrete was used widely in the construction of DOE facilities because of its structural strength, shielding qualities, and reasonable cost.

Concrete in these facilities has been contaminated with a variety of hazardous chemicals, heavy metals, and radionuclides. Estimates of the nature and extent of contamination have been made through a survey of existing information (Dickerson et al. 1995). The total area of contaminated concrete within the DOE complex is estimated in the range of $7.9 \times 10^{8} \mathrm{ft}^{2}$, or approximately 18,000 acres. The volume of contaminated concrete is estimated at $6.7 \times 10^{6} \mathrm{ft}^{3}$. These estimates are low but are expected to increase (possibly double) as additional characterization information becomes available. As indicated in the Baseline Environmental Remediation database, approximately $86 \%$ of the contaminated process buildings have identified radiological contamination (Dickerson et al. 1995). The most frequently occurring radiological contaminants within the DOE complex are ${ }^{137} \mathrm{Cs}$ and ${ }^{238} \mathrm{U}$ (and its daughters), closely followed by ${ }^{60} \mathrm{Co}$ and

${ }^{90} \mathrm{Sr}$. With additional characterization data from the sites, the order of contaminant frequency may be expected to change; however, it is likely that ${ }^{137} \mathrm{Cs},{ }^{238} \mathrm{U},{ }^{60} \mathrm{Co}$, and ${ }^{90} \mathrm{Sr}$ will remain as the most commonly occurring isotopes. The extent of contaminated concrete varies widely, from loose and fixed surface contamination to that within joints and cracks. In some cases, contamination may have penetrated more deeply into the concrete (e.g., reactor pools where the concrete was exposed to contamination under a hydrostatic head). Nonradiological contaminants require special considerations when they occur; of specific interest are PCBs and mercury, which have been detected in concrete at depths of greater than 4 in. in some cases. 


\subsection{CONCRETE PROPERTIES}

Construction-grade concrete is composed of a cement binder and aggregate. The aggregate is generally in the form of small rocks of mixed composition. For structural strength, the concrete is usually poured around or over a metallic grid system, commonly called reinforcing bar or rebar. The grid system is composed of either steel rods wired together at their intersections or wire mesh similar to that produced for use as fencing material. Although commonly perceived as a static, nonporous, and inert material, concrete is very porous and provides a complex and dynamic medium for chemical reactions. For example, the hydration reactions that transform freshly poured concrete into a relatively solid mass have been observed to continue for several hundred years.

Typical compositions of portland cements are shown in Table 1.1 (Connor 1990). One property of particular importance in dealing with contaminated concrete is the specific surface area. The large surface area $\left(3220 \mathrm{~cm}^{2} / \mathrm{g}\right)$ involved here results in a complex and active system for interaction with contaminants (Bostick et al. 1993). The concrete structure is composed of three phases: a solid phase containing calcium and silica hydration products; voids; and pore water, either free or sorbed on pore walls. The free pore water contains dissolved salts from the concrete materials; typical ions present are listed in Table 1.2 (Roy and Scheetz 1991).

Properties of concrete that affect contaminant transport and will be of concern in EK include porosity, permeability, degree of saturation, and $\mathrm{pH}$. Porosity values vary according to the method used for estimation; concrete typically falls within a porosity range of 0.2 to 0.6 (Ramachandran 1984). Permeability is a property that relates the rate of water penetration into concrete as a function of pressure drop, as described by Darcy's law. Darcy's law may be written in a single dimension as

$$
v=\frac{k}{\mu} \frac{\Delta P}{L}=K_{c} \frac{H}{L},
$$


Table 1.1. Typical compositions of portland cements

\begin{tabular}{|c|c|c|c|c|c|c|c|c|c|}
\hline $\begin{array}{l}\text { Cement } \\
\text { type }\end{array}$ & Designation & $\begin{array}{c}3 \mathrm{CaO} \cdot \mathrm{SiO}_{2} \\
(\mathrm{wt} \%)\end{array}$ & $\begin{array}{c}2 \mathrm{CaO} \cdot \mathrm{SiO}_{2} \\
(\mathrm{wt} \%)\end{array}$ & $\begin{array}{c}3 \mathrm{CaO} \cdot \mathrm{Al}_{2} \mathrm{O}_{3} \\
(\mathrm{wt} \%)\end{array}$ & $\begin{array}{c}4 \mathrm{CaO} \cdot \mathrm{Al}_{2} \mathrm{O}_{3} \cdot \mathrm{Fe}_{2} \mathrm{O}_{3} \\
(\mathrm{wt} \%)\end{array}$ & $\begin{array}{c}\mathrm{CaO} \\
(\mathrm{wt} \%)\end{array}$ & $\begin{array}{l}\mathrm{CaSO}_{4} \\
(\mathrm{wt} \%) \\
\end{array}$ & $\begin{array}{c}\text { Specific } \\
\text { gravity }\end{array}$ & $\begin{array}{c}\text { Specific } \\
\text { surface area } \\
\left(\mathrm{cm}^{2} / \mathrm{g}\right)\end{array}$ \\
\hline I & $\begin{array}{l}\text { Normal portland; } \\
\text { general use }\end{array}$ & 45 & 27 & 11 & 8 & 0.5 & 3.1 & 3.17 & 3220 \\
\hline II & $\begin{array}{l}\text { Moderate heat } \\
\text { evolution }\end{array}$ & 44 & 31 & 5 & 13 & 0.4 & 2.8 & & \\
\hline III & High early strength & 53 & 19 & 11 & 9 & 0.7 & 4 & & \\
\hline IV & Low heat evolution & 28 & 49 & 4 & 12 & 0.2 & 3.2 & & \\
\hline V & Rapid hardening & 66 & 11 & 8 & 9 & & & 3.13 & 4340 \\
\hline
\end{tabular}


Table 1.2. Dominant species in cement pore solutions

\begin{tabular}{lll} 
Cation & Anion & Neutral species \\
\hline $\mathrm{Ca}^{2+}$ & $\mathrm{Cl}^{-}$ & $\mathrm{H}_{4} \mathrm{SiO}_{4}$ \\
$\mathrm{Mg}^{2+}$ & $\mathrm{SO}_{4}^{2-}$ & $\mathrm{H}_{2} \mathrm{CO}_{3}$ \\
$\mathrm{Na}^{+}$ & $\mathrm{HCO}_{3}^{-}$ & \\
$\mathrm{K}^{+}$ & $\mathrm{Fe}(\mathrm{OH})_{4}^{-}$ & \\
$\mathrm{H}^{+}$ & $\mathrm{Al}^{-}(\mathrm{OH})_{4}^{-}$ & \\
$\mathrm{MgOH}^{+}$ & $\mathrm{H}_{3} \mathrm{SiO}_{4}^{-}$ & \\
& $\mathrm{H}_{2} \mathrm{SiO}_{4}^{2-}$ \\
& $\mathrm{OH}^{-}$ \\
& $\mathrm{CO}_{3}^{2-}$ \\
\end{tabular}

Source: Roy and Scheetz 1991. 
where $v$ is the velocity of water penetration, $k$ is the permeability of the concrete to water flow, $\mu$ is the viscosity of water, and $\Delta P$ is the pressure difference across a sample of width $L$. Darcy's law is equivalently stated in terms of head, in which case $K_{c}$ is the permeability coefficient and $H$ is the pressure difference in water head. The permeability of concrete is a function of many variables, including the water/cement ratio, mixing and curing procedures, aggregate size and porosity, the presence of admixtures, and coatings. Structural concrete generally ranges in permeability $(k)$ from $10^{-17}$ to $10^{-13} \mathrm{~cm}^{2}$, or in permeability coefficient $\left(K_{c}\right.$ ) from $10^{-12}$ to $10^{-8} \mathrm{~cm} / \mathrm{s}$ (Ramachandran 1984; Roy 1989 ). Figure 1.1 presents results of calculations using Darcy's law, showing the water penetration rate in millimeters per year as a function of the concrete permeability and the pressure drop. Examples may be used to illustrate the variability of penetration depth for various conditions. For instance, the annual penetration rate for a $10-\mathrm{cm}$-thick floor made of relatively impermeable concrete having $k=1 \times 10^{-16} \mathrm{~cm}^{2}$ in a tank of $10 \mathrm{~m}$ of water would be approximately $0.3 \mathrm{~mm}$. Thus, over 20 years, the water penetration would be expected to be approximately $0.6 \mathrm{~cm}$. In contrast, solution maintained at a depth of $1 \mathrm{~cm}$ on a 1 -cm-thick sample of very permeable concrete having $k=1 \mathrm{x}$ $10^{-13} \mathrm{~cm}^{2}$ would also penetrate at the same rate of $0.3 \mathrm{~mm}$ per year. While these example calculations illustrate that concrete is relative impervious to infiltration of contaminant-containing solutions, it should be stressed that this analysis can only be used for the approximation of contaminant penetration; for instance, other factors that are not considered that could accelerate transport include an initial fast penetration of the surface pores and diffusional transport that will extend the depth of contamination in saturated media.

The degree of saturation of concrete will affect electrokinetic decontamination (EK) processes not only in providing an avenue for diffusional transport of contaminants, but also by determining the electrical conductivity of the concrete. As would be expected, electrical conductivity increases with increasing water content. Because concrete has a great affinity for water, the micropores (those smaller than about $0.01 \mu \mathrm{m}$ ) are generally filled with water, and water condensation occurs in larger capillaries for relative humidities greater than approximately $40 \%$ (Kong et al. 1983). Thus, resistive barriers to EK likely exist, for the most 


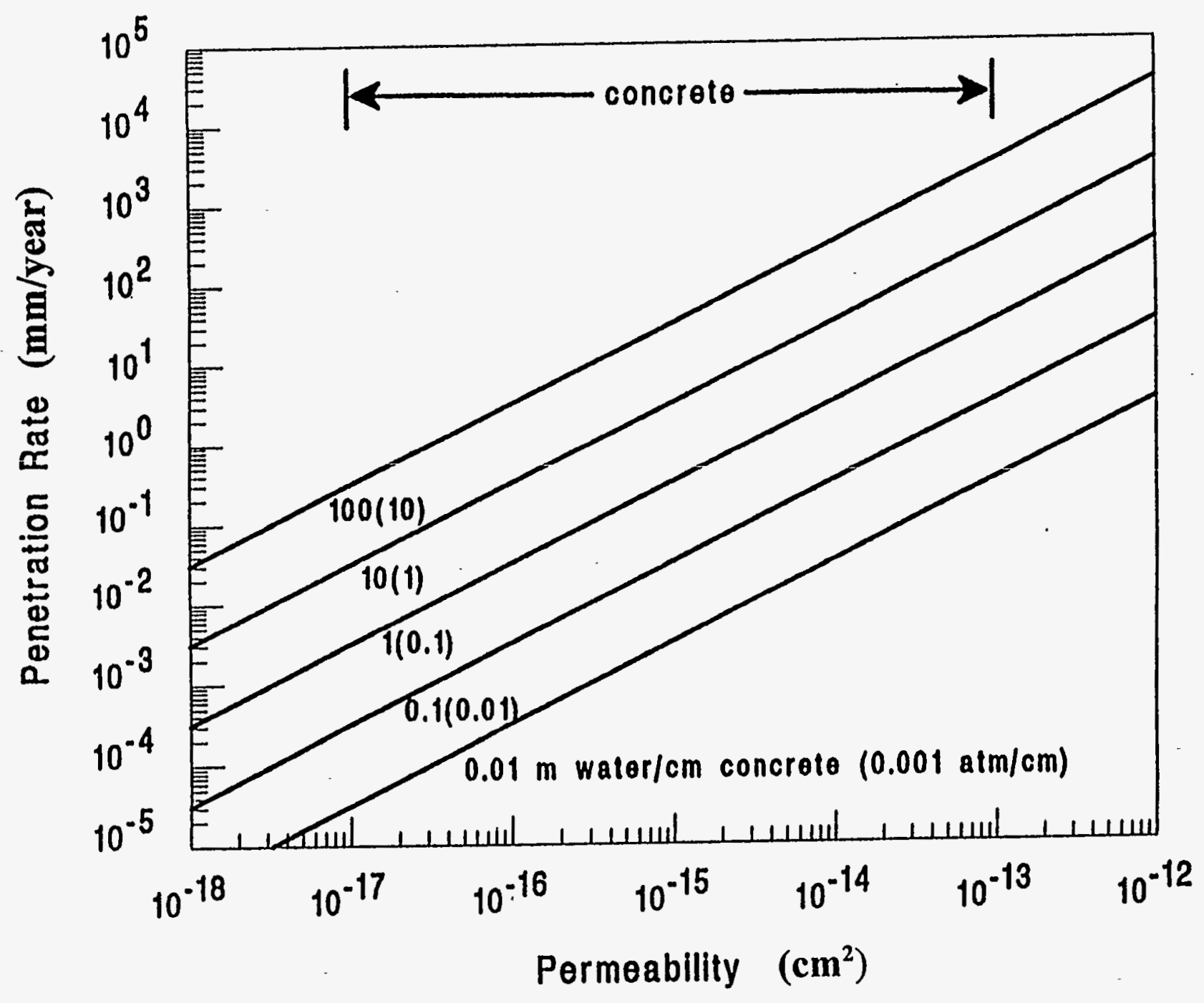

Fig. 1.1. Estimation of water penetration rate using Darcy's law. 
part, in larger pores near the surface of the concrete (Morgan and Gilbert 1994).

Typically, the pH in the pore space is greater than 13 (Roy and Scheetz 1991). This is important since many metals are insoluble at this $\mathrm{pH}$ level and, therefore, precipitate as solids within the pores (Cocke and Mollah 1991). Other mechanisms by which contaminants may become incorporated into the cement matrix include chemisorption, chemical incorporation, and ion exchange. These processes will retard the penetration of contaminants into concrete. For instance, precipitating contaminants are expected to be present near the surface. Such species may be relatively accessible for removal; however, it is necessary for the lixiviants used for chemical extraction or electrokinetic remediation to be effective in solubilizing the contaminants at high $\mathrm{pH}$ levels.

The above factors indicate that, in many cases, concrete contamination is likely to be limited to the upper surface. This is supported by studies conducted by the U.S. Nuclear Regulatory Commission (NRC) that were aimed at estimating the amount of contaminated concrete that must be removed at NRC sites (U.S. NRC 1994). The results indicated that radioactive contamination was confined to the top inch of concrete. The radionuclides were found to have infiltrated farther into concrete from wet areas than from dry areas. Different species exhibited different mobilities; the order of relative depth of contamination for the four species reported was ${ }^{137} \mathrm{Cs}>{ }^{60} \mathrm{Co}>\mathrm{Th}>\mathrm{U}$. Morgan and Gilbert (1994) also indicated that uranium and technetium contamination in the wet concrete of the solar ponds at the Hanford Site (HANF) was limited to the upper $0.5 \mathrm{in}$. In contrast, Slater et al. (1976) reported significant concentrations of chloride ion at depths of 3 in. and greater, while PCBs and mercury at the Y-12 site are reported to have reached 6 in. in depth (Dickerson et al. 1995). 


\subsection{SCOPE AND STATUS OF ELECTROIKINETIC DECONTAMINATION OF CONCRETE}

Electrokinetic decontamination is viewed as an emerging technology that may be advantageous for use in the decontamination of concrete since it may generate less secondary waste than previously tried methods, including high-pressure water, chemical treatment, or mechanical scabbling processes (Archibald 1995).

Although it is conceivable that EK, if found to be successful, could be applied to a wide range of concrete contamination problems, it would primarily be aimed at two major types of decontamination: deep contamination of bulk concrete, and contamination in cracks and crevices. It is applicable to ionic species and those contaminants which can be made to exist in ionic form in aqueous solution by reaction or complexation; thus, most metals are target species, while it is not likely that PCB contamination can be removed by EK. In addition, it does not appear likely that tritium contamination can be fully removed by EK because of the high water content of concrete. Since the technology depends on application of electrolyte solutions to the concrete surface (see Sect. 2.1 for description of the technology), it is more suitable for horizontal surfaces and tanks or pools; however, it is possible that process modifications could be made to apply the technology to vertical surfaces as well.

EK is not yet a mature technology for use in the decontamination of concrete. Several topics must be addressed in order to determine its feasibility for application and to evaluate its performance relative to other decontamination techniques. These include the following:

1. EK must be shown to be capable of reliably reducing the levels of contaminants in concrete to sitespecific regulatory guidelines. In addition to evaluating the performance in removing contaminants, considerations must be made for possible technical difficulties, unknown quantities associated with 
construction and operation, the ease of undertaking additional remedial actions if required, and the ability to monitor the effectiveness of the technology.

2. An evaluation of the secondary waste streams resulting from EK treatment is needed. Factors to be considered are the type and volume of associated secondary wastes, the magnitude of risk from untreated waste or from treatment residuals, the adequacy and reliability of controls such as containment systems and institutional controls necessary to manage treatment residuals and untreated waste, and the feasibility of treating secondary waste to meet disposal criteria.

3. An evaluation of the costs associated with full-scale remediation using EK is needed. Factors to be considered include processing time, direct and indirect capital costs, equipment installation costs, operating costs, maintenance costs, demobilization costs, and others.

4. An assessment must be made of the long- and short-term risks posed by application of EK to human health and the environment. Factors to be considered include short-term risks that might be posed during implementation of the process, the effectiveness and reliability of protective measures, and potential environmental impacts of the process. 


\section{REVIEW OF ELECTROKINETIC DECONTAMINATION}

Electrokinetic decontamination is a proposed nondestructive technique for the removal of contaminants from concrete through the application of electrical potential. It is attractive because of several possible advantages, including low capital and operating costs, reduced exposure potential and secondary waste production, and potential for use in treatment for removal of contamination deep in concrete or in cracks. This technology has been demonstrated with mixed results in a limited number of applications; thus, there is a need for a better understanding of the controlling mechanisms for process design and optimization. This section describes the EK process, explores the possible mechanisms for contaminant migration during EK, reviews previous electrokinetic work on soils and concrete, and summarizes the research necessary to evaluate and develop the technology for concrete decontamination.

\subsection{PROCESS DESCRIPTION}

Electrokinetic remediation of concrete involves the contacting of a lixiviant solution (i.e., a solution that solubilizes the contaminants) with the concrete surface in combination with the application of an electrical field. As the lixiviant is transported into the concrete, the contaminant ions are mobilized from a bound or sorbed state on the concrete pore surfaces into the pore solution and are then transported through the pore liquid toward an oppositely charged electrode. Contaminants are removed in the solution at the concrete surface. As part of this process, oxidation and reduction reactions occur at the electrodes. In aqueous solution, hydrogen ions and oxygen gas are often produced from water by the oxidation reaction at the anode and hydroxyl ions and hydrogen gas are often produced by the reduction reaction at the cathode.

This process may be applied in two geometries: (1) single reservoir, and (2) dual reservoir. The primary distinction between these two classifications is the control over the liquid environment surrounding 
the two electrodes. In the single-reservoir approach, a reservoir containing a lixiviant solution is placed on the concrete surface and a counter electrode is provided by a convenient connection, such as reinforcing bars in the concrete or a grounding rod connected to the soil below a concrete pad. An example of this singlereservoir approach is shown in Fig. 2.1 (Morgan and Gilbert 1994). While the single-reservoir approach is simpler in design, a major limitation exists in that both the application of the lixiviant solution and the removal of the contaminant must occur in the same reservoir since there is no means to control the solution at the counter electrode. This geometry may be applied in a few different approaches: application with a single polarity for transport of mobile ions to the surface; application with a single polarity to force lixiviant of a given charge into the concrete and concurrent removal of an oppositely charged contaminant complex; or application with one polarity to force a charged lixiviant into the concrete, followed by a reversal of polarity to remove a contaminant complex of the same charge. A dual-reservoir geometry involves the application of lixiviant from one or both of two liquid reservoirs containing oppositely charged electrodes. Electrical current in the form of ions flows from one electrode to the other through the concrete. In this geometry, oppositely charged contaminants may be collected in the two reservoirs, and charged lixiviants could be forced through concrete, forming charged contaminant complexes that would move toward one of the two reservoirs. While this approach is simply applied to concrete samples in the laboratory, in situ application is less straightforward. Figure 2.2 shows a design example of a dual-reservoir approach applied to concrete floors (Morgan and Gilbert 1994).

Several mechanisms, including capillary forces and electrohydrodynamics, diffusion, electrophoresis, electromigration, and electroosmosis, contribute to electrokinetic processes. An understanding of each of these mechanisms and their relative importance in concrete is necessary for evaluation and optimization of EK. Capillary forces and electrohydrodynamics are important in the wetting and filling of the concrete pores with liquid. These are of importance during the initial application of EK since the concrete pores must be filled for the lixiviant solution to contact the contaminants and for significant electrical conductivity. 


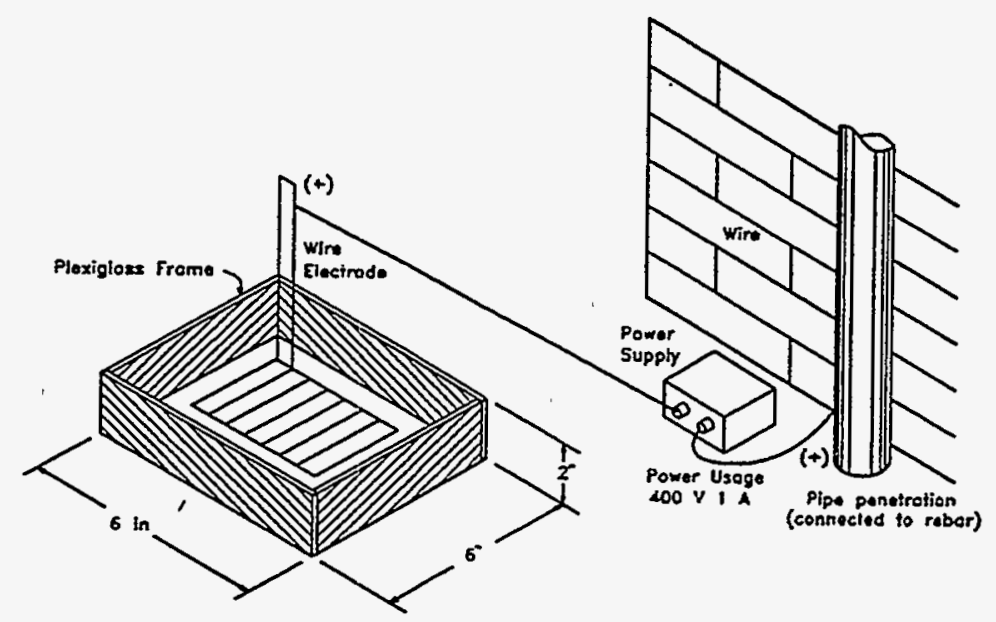

Fig. 2.1. Example of single-reservoir geometry for EK.

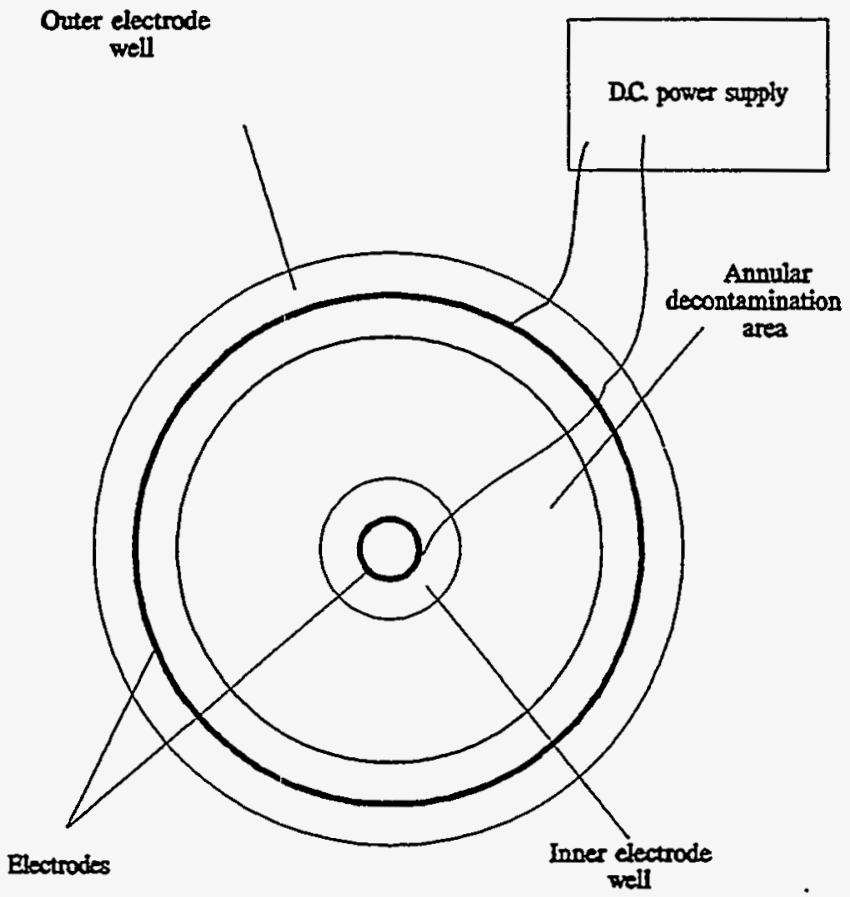

Fig. 2.2. Example of dual-reservoir geometry for EK. 
Theoretical and experimental work on these mechanisms is detailed in Sect. 3. Diffusion, which occurs as the result of concentration gradients in the solution and along solid surfaces, acts to move contaminants from high-concentration zones to those of lower concentration; therefore, an EK process must be operated such that the rate of transport by electrical mechanisms is sufficient to overcome diffusional transport. Electrophoresis, electromigration, and electroosmosis involve motion in response to a potential gradient, Electrophoresis refers to the motion of charged particles; the term electromigration is used for the transport of ions; and electroosmosis is movement of liquid relative to a stationary surface such as a capillary pore. Electrophoresis is not expected to be a dominant transport mechanism in EK; however, it could be significant under circumstances in which colloidal precipitates are formed. Electromigration and electroosmosis, which are potentially significant mechanisms for contaminant transport during EK, are described further in the following paragraphs.

Electromigration is the motion of ions through a solution toward an oppositely charged electrode (see, e.g., Atkins 1982). The force imposed on an ion has a magnitude equal to the product of the charge on the ion and the potential gradient. This force is counteracted by viscous drag forces that are functions of the solution viscosity, ionic radius, and ion solvation. The speed of ion transport is commonly defined by a quantity, termed the ionic mobility, that takes into account the drag forces and is the proportionality between the potential gradient and the ion velocity.

Electroosmosis is the bulk motion of liquid through a porous medium or bed of small particles with an applied electric field (see, e.g., Gucker and Meldrum 1950; Sheludko 1966; Bockris and Reddy 1977). It may be considered to be the converse of electrophoresis; in electrophoresis, charged particles are transported through a liquid, while in electroosmosis the liquid is transported relative to stationary charged surfaces. The key to the magnitude and direction of electroosmotic flow is the charge at the solid surfaces. If ions of one sign are part of or sorbed on a surface, ions of the opposite sign will accumulate in the liquid near the surface. This forms an electrical double layer - the total charge of the double layer is zero, but 
there is a separation of charges. The charges on the surface and within an immobile hydration shell are stationary, while those outside the shear boundary at the edge of the hydration shell are free to move. Motion of these mobile charges may be induced by an applied electric field. Thus, electroosmotic flow may be understood as resulting from the motion of these mobile charges, which, in turn, causes motion of the bulk fluid. The direction of electroosmotic flow will be in the direction of the electrode having the same polarity as the surface charge. For example, for a positively charged surface, the mobile charges will be negative ions; therefore, flow will be toward the positive electrode (the anode). The magnitude of electroosmotic flow is governed by two primary factors: the pore size and the zeta potential. The effect of pore size is straightforward; for small pores, flow at the surface affects a significant fraction of the liquid volume and, hence, electroosmotic flow is relatively large, while the surface flow for large pores is much less significant. The zeta potential, defined as the potential at the shear boundary, incorporates the effects of many factors, including solution chemistry and concentration. The zeta potential may be experimentally measured through the electrophoretic movement of small particles; measurements for concrete under various conditions are described in Sect. 3.2.5. Three particularly important factors in EK that will affect the zeta potential and, in turn, the electroosmotic flow are $\mathrm{pH}$, adsorbing ions, and electrolyte concentration. EK may affect concrete pore solution $\mathrm{pH}$ and, as such, may change the magnitude and sign of the surface charge, thereby significantly affecting the magnitude and direction of electroosmotic flow. The sorption of ions may have similar effects. The concentration of electrolytes, either salts naturally present in concrete pores or lixiviants, will have a significant effect on electroosmosis. Higher electrolyte concentrations cause a decrease in the zeta potential and the thickness of the electrical double layer. Therefore, electroosmotic flow can be expected to be low for concrete pores containing dissolved salts and for EK processes using electrolyte solutions. 


\subsection{PREVIOUS EK WORK}

Electrokinetics has been extensively investigated for the in situ remediation of contaminated soils, while much less study has been performed on application of the technique to concrete. A brief review of the results of the soil work is included to provide insight into the successful application of EK and to afford a basis for comparison with concrete decontamination.

\subsubsection{Soil Decontamination}

Processes aimed at utilizing electroosmotic flow for soil applications have been in practice since the 1930s. Soil pore water is often of low ionic strength, leading to a significant zeta potential. Importantly, fine soils of lower permeability that are less amenable to pressure-driven flow generally have greater electroosmotic flow due to smaller pores. Thus, electroosmotic processes can be used to move water through tight soils such as clays more efficiently than conventional processes. Electroosmotic processes have been used for dewatering of soils in construction applications such as the stabilization of slopes and excavations (e.g., Casagrande 1952, 1983). In addition, processes using electroosmotic flow to flush contaminated soil with water have been successfully tested as means of removing nondissociating organic compounds such as gasoline components and trichloroethylene from tight soils (Acar et al. 1992; Bruell et al. 1992; Segall and Bruell 1992; Shapiro and Probstein 1993). However, these and other studies (e.g., Lockhart 1983a, 1983b, 1983c) have shown that electroosmotic flow is not constant in an application; rather, changes in $\mathrm{pH}$, conductivity, and, in the case of dewatering, saturation of the soil pore water due to chemical and electrochemical reactions generally lead to variable flow. For instance, Acar and coworkers (1992) found that significant electroosmotic flow was not induced in bench-scale tests with clays until after 5 to $10 \mathrm{~h}$ of operation, while Hamed and coworkers (1991) noted a similar startup time, followed by a sharp increase and a more gradual decrease of an order of magnitude in electroosmotic flow rate. Jacobs and coworkers (1994) 
similarly reported a small initial electroosmotic flow that stopped after one-quarter of a pore volume. Thus, it should be realized that no electrokinetic process is purely electroosmotic; rather, because electrical current in these systems requires the electromigration of ions, other effects will become significant.

Electromigration makes it possible to develop efficient electrokinetic techniques for the removal of ionic species from soils. Recently, a significant amount of work in bench-scale study (e.g., Hamed et al. 1991; Bibler et al. 1993; Hicks and Tondorf 1994; Jacobs et al. 1994; Khan and Alam 1994; Runnels and Patterson 1994), theory and analysis (e.g., Acar et al. 1990; Alshawabkeh and Acar 1992; Thornton and Shapiro 1994), and field-scale application (e.g., Lageman et al. 1989; Bibler and Meaker 1994; Lomasney 1994; Trombly 1994) has been conducted regarding the removal of metals and dissociating organics from soils. The concept of decontamination by electromigration of ions is simple - ions travel toward oppositely charged electrodes; however, the process is complicated by chemical factors, particularly pH. Typically, electrolysis reactions take place in the electrode compartments: an oxidation reaction at the positively charged anode,

$$
2 \mathrm{H}_{2} \mathrm{O} \Rightarrow \mathrm{O}_{2}+4 \mathrm{H}^{+}+4 e^{-}
$$

and a reduction reaction at the negatively charged cathode,

$$
4 \mathrm{H}_{2} \mathrm{O}+4 e^{-} \Rightarrow 2 \mathrm{H}_{2}+4 \mathrm{OH}^{-} \text {. }
$$

Because of the production of $\mathrm{H}^{+}$at the anode and $\mathrm{OH}^{-}$at the cathode, these reactions affect the $\mathrm{pH}$ distribution in the system. If the buffering capacity of the soil is not high, an acid front is generated that moves through the soil toward the cathode. This causes dissolution and transport of metal ions. In a system without process modifications, a base front can move in the opposite direction from the cathode. A result of this situation is a low $\mathrm{pH}$ in the solution near the anode, a high $\mathrm{pH}$ in the soil near the cathode, and a steep $\mathrm{pH}$ gradient in an intermediate soil zone. For metal species that are soluble at low $\mathrm{pHs}$ and insoluble at high 
$\mathrm{pHs}$, the metals are depleted in the region near the anode but deposited at the $\mathrm{pH}$-front. As illustrated by Hicks and Tondorf (1994), for a metal species such as zinc, which is insoluble at moderately high pH levels but forms negatively charged soluble hydroxides when the $\mathrm{pH}$ is increased further, this can lead to a focusing of the contamination; that is, in addition to the zone near the anode, the zone near the cathode is cleaned since the metal hydroxides are moved toward the anode. The result is a zone of high metals concentration in the region of the $\mathrm{pH}$ jump. This condition is not desirable since there is no means for removing the metal precipitates. Several modified processes have been devised to control the $\mathrm{pH}$. Lageman and coworkers (1989) presented a system with circulation loops involving undisclosed purification and conditioning of both the anolyte and the catholyte. Khan and Alam (1994) used a hydraulic gradient to flow solution from the anode to the cathode, with removal and treatment of the catholyte and recycle in the anolyte. Bibler and coworkers (1993) controlled the $\mathrm{pH}$ at about 6 throughout the soil by flowing saturated calcium oxide through the anode reservoir and $2 M$ acetic acid through the cathode reservoir. Jacobs and coworkers (1994) purged the catholyte with a tap-water wash, and Acar and Alshawabkeh (1993) added acetic acid to the catholyte. In each of these improved systems, the $\mathrm{pH}$ of the pore water is maintained acidic throughout the soil, serving to keep metal contaminants dissolved for transport to the cathode. A possible additional benefit of processes that neutralize the electrolysis products is the ability to maintain the conductivity of the pore water at a low value, thus enhancing electroosmotic flow.

\subsubsection{Concrete Decontamination}

The application of EK to concrete has many similarities to, as well as many differences from, its application to soils. The similarities are relatively straightforward: the overall systems of oppositely charged electrodes and lixiviant solution are essentially duplicates; the primary mechanisms (electroosmosis, electromigration, etc.) are the same; and the technique is applied in situ to a porous medium in each case. Several characteristics of concrete that differentiate it from soils, in general, are lower permeability, higher 
$\mathrm{pH}$ and buffering capacity, higher ionic strength of pore water, and, usually, a more complicated chemistry.

Electrokinetic techniques were applied to concrete as early as the mid-1970s for the removal of chloride ions from concrete structures to decrease corrosion (Slater et al. 1976; Vennesland and Opsahl 1986). In this application, metal reinforcements within the concrete are connected to the negative lead of a power supply and an electrode at the surface is connected to the positive lead. Chloride ions within the concrete are transported to the surface by electromigration and are either converted to molecular chlorine at the anode or captured by sorbent material. Slater and coworkers (1976) demonstrated the removal of chloride in field experiments conducted on bridge decks. Platinized titanium electrodes were placed at the surface in $0.1 M$ calcium hydroxide solution containing anion-exchange resin; the reinforcing bars serving as the cathodes were at depths of 2 in. and greater. Each of $\operatorname{six} 3.7-\mathrm{m}^{2}\left(40-\mathrm{ft}^{2}\right)$ test areas was treated by applying a de current of 100 to $120 \mathrm{~V}$, resulting in currents of 28 to $100 \mathrm{~A}$ (current densities, 7.6 to $27 \mathrm{~A} / \mathrm{m}^{2}$ ). The treatment was shown to reduce chloride concentrations throughout the bulk concrete between the rebar and the surface; during a 24 -h treatment, the average chloride concentration was reduced $53 \%$ (from $0.41 \mathrm{wt} \%$ to $0.19 \mathrm{wt} \%$ ) for the top inch of concrete, $71 \%$ (from $0.20 \mathrm{wt} \%$ to $0.06 \mathrm{wt} \%$ ) for the concrete in the 1 - to 2 -in.-depth range, and $67 \%$ (from $0.054 \mathrm{wt} \%$ to $0.019 \mathrm{wt} \%$ ) for the concrete in the 2- to 3-in.depth range. A general correlation between treatment time and chloride removal was noted. The technique successfully reduced chloride concentrations such that active corrosion of the rebar had not resumed in the 3 months following treatment. No adverse effect on the concrete was noted. In their European patent, Vennesland and Opsahl (1986) pointed out practical problems with the method of Slater et al. (1976), including large energy requirements $\left(100 \mathrm{~m}^{2}\right.$ would require a supply of power at about $100 \mathrm{~V}$ and $1350 \mathrm{~A}$, or $135 \mathrm{~kW}$ ), a limitation to horizontal surfaces, and a limitation to the upper zone of concrete. The patent addresses these limitations by applying graphite electrodes to the concrete surface, covered by a viscous, nonliquid electrolyte medium (examples named are retarded gunite and conductive paints or gels) into which the chloride ions are driven and sorbed. The proposed operating voltage range is 3 to $15 \mathrm{~V}$. No performance 
data on this approach were presented. Electrokinetic methods have since been used to accelerate the transport of chloride ions into concrete in tests used to characterize the resistance of concrete to chloride penetration (Andrade et al. 1994).

Aside from the removal of chloride ions, the application of EK to in situ decontamination of concrete has been limited to scoping studies within the DOE complex. EK scoping studies have been conducted at the Idaho National Engineering Laboratory's (INEL's) Idaho Chemical Processing Plant (ICPP), on the Oak Ridge Reservation (ORR) at the K-25 site, and on the solar ponds at HANF.

At the ICPP, EK was applied to radioactively contaminated concrete lids that were used to cover a settling basin (Archibald, 1995). The basin had been filled with radioactively contaminated water and left in place for 20 to 25 years. The liquid in the basin had risen to approximately 2 to 3 in. above the bottom of the 4-in.-thick lids. Radiological contamination in the water consisted primarily of Cs, with smaller amounts of $\mathrm{U}, \mathrm{Pu}, \mathrm{Sr}, \mathrm{Ce}, \mathrm{Co}, \mathrm{Eu}$, and $\mathrm{Am}$. Two $1.9-\mathrm{m}^{2}$ plots were tested using $\mathrm{EK}$, one by a "dry" process and the other by a "wet" process. These processes were operated using the "electroosmotic pulse technology" of Dry-Tec of North America, in which a voltage is applied across the concrete with the aim of inducing electroosmotic flow. In each process, the lids were placed in reservoirs containing 11 gal of demineralized water and copper-coated steel rods that were used as cathodes (i.e., negative electrodes). In the "dry" test, rebar lifting rings that were cast into the concrete lid were used as the cathodes; in the "wet" test, cathodes consisting of $1 / 8$-in. titanium bars were placed in a reservoir of demineralized water sealed to the upper surface of the lid. A common supply provided electrical power to both systems simultaneously at approximately $39 \mathrm{~V}$. Conductivity was nearly constant in both test cells over 3 weeks of operation, with a current of $1 \mathrm{~A}$ in the dry test and $265 \mathrm{~mA}$ in the wet test. This difference in conductivity is understandable since the rebar anode in the dry test was directly connected to the concrete, while the anodes in the wet test were immersed in less conductive solution. Samples taken from the unstirred reservoirs during the test showed a general increase in cesium concentration. Measurements taken after the tests indicated that contact 
beta-gamma measurements were reduced 80 and $83 \%$ for the wet and dry tests, respectively, while lesser reductions were noted in smearable beta/gamma/alpha. Radioactive contamination was measured on the cathodes and in the catholyte reservoirs after the test, giving further support that contamination was driven out of the concrete. Approximately 21 gal of wastewater was produced. Although this test provided apparently positive results for EK, several deficiencies limit the conclusions that can be derived, including the following: (1) inconsistencies in core sampling results prevented material balances from being made; (2) since the solutions were not stirred except in the case of the final samples, the transient data are not reliable; (3) no control tests (identical tests without power applied) were conducted to determine the level of decontamination due solely to EK; (4) because the power supply was shared between the two tests, different current levels were maintained; and (5) the use of demineralized water indicates that the aim of the tests was to drive electroosmotic flow - the use of an electrolyte solution as the anolyte may have been more effective by providing greater conductivity and, possibly, by affecting ion-exchange/sorption equilibria.

At the ORR K-25 site, the Isotron Corporation of New Orleans, Louisiana, tested its version of EK teçhology for removal of uranium from (1) concrete dust from scabbling using steel-shot blasting, (2) concrete made by casting the concrete dust in portland cement, and (3) concrete slabs in a highcontamination area (Lomasney 1993). The results of the tests on concrete dust and on dust cast in portland cement provided significant details, particularly regarding the relative effectiveness of different lixiviant solutions in solubilizing uranium. Solutions containing carbonate and/or citrate ions were shown to be most effective at uranium solubilization, particularly with the addition of peroxide. The peroxide was considered to be useful in oxidizing the estimated 20 to $25 \%$ of the uranium existing in the quadrivalent oxidation state to the hexavalent state. The bench-scale work indicated that there was a significant effect on the efficiency of the EK process due to the casting of concrete in portland cement; thus, it was necessary to conduct investigations on actual concrete floors. Preliminary results indicated that the EK process could remove significant amounts of uranium contamination from concrete. For instance, uranium concentration was 
shown to increase with time in the anolyte for tests with several geometric configurations and with several proprietary lixiviant mixtures. In addition, tests showed an increase in the concentration of uranium in solution for electrokinetic treatment vs treatment by contact with the lixiviant solution alone. However, a lack of characterization data available before testing prevented determination of the percentage of uranium removal.

Bench-top EK studies were also conducted at the ORR K-25 site by ORNL (Bostick et al. 1993). These tests indicated the potential for contaminant removal by EK; greater than $90 \%$ removal of uranium, based on surface radiation measurements, was achieved in some tests. Significantly greater removal was achieved when peroxide was added to the lixiviant. The process was also demonstrated by ORNL at solar ponds at HANF (Morgan and Gilbert 1994). The demonstration at HANF was limited to a 3-day operation. In the longest run $(8 \mathrm{~h})$, which was conducted with a single-reservoir geometry, the electrical potential was held at $320 \mathrm{~V}$ and the current increased from $120 \mathrm{~mA}$ to $200 \mathrm{~mA}$ in the first $2.25 \mathrm{~h}$. Uranium concentration increased in solution at the surface. Surface radiation readings were decreased from $18,000 \mathrm{dpm} / 100 \mathrm{~cm}^{2}$ to $8,000 \mathrm{dpm} / 100 \mathrm{~cm}^{2}$. A two-reservoir geometry using a one-piece cell was tested at $1 \mathrm{~A}$ and $100 \mathrm{~V}$ with no success in terms of uranium dissolution or decrease in surface radiation readings. It appears that this test suffered from short-circuit current flow along the concrete surface between the reservoirs. The results of the EK demonstration at HANF were inconclusive because of the short test duration, the absence of control experiments, and the lack of detailed preoperation and postoperation sampling,

\subsection{SUMMARY OF RESEARCH NEEDS}

Generally, the results of past DOE-sponsored electrokinetic concrete decontamination work can be summarized as follows:

1. On a laboratory scale, results suggest that large driving forces due to an electric field gradient can 
enable a lixiviant to penetrate a concrete substrate and, in turn, complex with a target contaminant. Reversal of the applied potential may bring the complexed contaminants back to the concrete surface for collection and disposal.

2. The lixiviants used for uranium removal are similar to those used for soil washing and in the mining industry for uranium extraction; that is, they are electrolyte solutions containing carbonate ions (Francis et al. 1995).

3. The methodology used previously has been empirical. Each vendor has reported vastly different process conditions such as voltages, treatment times, and current densities. For instance, Dry-Tec reported dc power applied at $\geq 39 \mathrm{~V}$ at currents of $265 \mathrm{~mA}$ to $1 \mathrm{~A}$; the demonstration at HANF used $400 \mathrm{~V} \mathrm{dc}$ with a current of $0.5 \mathrm{~A}$; and Isotron reported voltages of 11 to 160 . The choice of electrodes and their spacing has been on an ad hoc basis.

4. A complete contaminant balance for the electrolyte and the concrete before and after treatment to establish the extent of cleanup was not performed in each case. This discrepancy has been attributed to the lack of the necessary detailed characterization data prior to conducting field demonstrations. Funds have not been available to obtain the type of information required to complete the material balances.

Based on the data obtained from these previous investigations, further research is necessary to develop an understanding of the capabilities and limitations of EK of concrete, as well as to provide guidance in future implementations. Several items may be identified as research needs, as follows:

1. An examination must be made of the mechanisms driving the process to provide an understanding of 
the effects of various system design features and process variables on decontamination performance. With a continued empirical approach, it will not be possible to reconcile (or explain) the data from previous demonstrations or to improve on the process.

2. Further investigations must be made of the chemistry of concrete, lixiviants, and contaminants. The resulting information will be essential in determining the depth of contamination, the contaminant removal rate, and the amount of residual contamination.

3. Demonstrations must be conducted, along with an attempt to calculate a material balance.

4. Further demonstrations must be conducted to gather information regarding cost, secondary waste generation, cleanup capability, and potential problems in implementation. Some potential technical difficulties that have not been fully explored are: (1) the extent and consequences of corrosion when rebar is used as an anode; (2) possible concrete damage, such as cracking, due to gas production or buildup of corrosion products/precipitates (Kong et al., 1983); and (3) the possibility of driving contamination deeper into concrete. It seems reasonable that these factors should be determined most accurately through long-term operation under field conditions. 


\section{INVESTIGATION OF ELECTROKINETIC DECONTAMUNATION OF CONCRETE}

\subsection{OVERVIEW}

This investigation consisted of experiments and computational work aimed at developing a fundamental understanding of the mechanisms controlling the EK of concrete. Experimental work included measurements of electroosmotic flow and of the variation of the zeta potential of concrete; determination of sorption isotherms of $\mathrm{Cs}, \mathrm{Sr}, \mathrm{Co}$, and $\mathrm{U}$ on concrete; and study of the wetting of concrete with lixiviant solution using a novel application of magnetic resonance imaging. Computations were aimed at determining the wetting of pores with an applied electrical field and at developing a predictive model for contaminant removal by EK. In addition, experiments involving dynamic loading and desorption of concrete disks allowed verification of the computations and provided important information regarding practical application of EK.

\subsection{EXPERIMENTAL RESULTS}

\subsubsection{Electroosmosis Experiments}

Experiments undertaken to evaluate the importance of electroosmosis in EK were conducted by energizing electrodes placed in solution on opposite sides of fine glass frits and concrete disks.

The glass-frit experiments were conducted to investigate electroosmotic effects without the chemical complications of concrete. An apparatus based on a 1-in.-diam fine-porosity (approximately 10- $\mu \mathrm{m}$ pores) glass frit was assembled. This device connected two reservoirs that were $10 \mathrm{~cm}$ tall and $57 \mathrm{~mm}$ in diameter (capacity of each, approximately $250 \mathrm{~mL}$ ) by a glass tube holding the frit. Platinum-wire electrodes were placed in each reservoir, with approximately $2 \mathrm{~cm}$ of the 20 -gauge wire placed in proximity of the frit faces. 
Scales attached to the sides of each reservoir for volume measurement were calibrated by adding known volumes.

Typical results obtained with distilled water containing phenolphthalein indicator (conductivity, approximately $2 \mu \mathrm{mho} / \mathrm{cm}$ ) in both reservoirs are shown in Table 3.1. Significant electroosmotic flow

Table 3.1. Measurement of electroosmotic flow of distilled water across glass frit

\begin{tabular}{ccccc}
\hline $\begin{array}{c}\text { Time } \\
(\mathrm{min})\end{array}$ & $\begin{array}{c}\text { Voltage } \\
(\mathrm{kV})\end{array}$ & $\begin{array}{c}\text { Current } \\
(\mathrm{mA})\end{array}$ & $\begin{array}{c}\text { Volume of catholyte } \\
(\mathrm{mL})\end{array}$ & $\begin{array}{c}\text { Volume of anolyte } \\
(\mathrm{mL})\end{array}$ \\
\hline 0 & 2.7 & 7.5 & 100 & 100 \\
1 & 2.7 & 8.0 & 109 & 90 \\
2 & 2.7 & 8.1 & 117 & 82 \\
3 & 2.7 & 8.3 & 124 & 74 \\
5 & 2.7 & 8.5 & 139 & 61 \\
\hline
\end{tabular}

of distilled water was measured; for instance, the data of Table 3.1 correspond to an average flux of nearly $1.6 \mathrm{~mL} \mathrm{~min}^{-1} \mathrm{~cm}^{-2}$. No color change was noted in either vessel, indicating that the $\mathrm{pH}$ of the catholyte did not exceed approximately 9. When a similar test was conducted with $0.1 \mathrm{MKCl}$ in each reservoir, only approximately $5.5 \mathrm{~V}$ was required for a current flow of $16 \mathrm{~mA}$. No electroosmotic flow was measured within $20 \mathrm{~min}$ of operation, while the color of the catholyte changed to reddish-purple between $30 \mathrm{~s}$ and $1 \mathrm{~min}$ of operation, signaling that the $\mathrm{pH}$ had reached the phenolphthalein transition range of 8 to 9.8 . These experiments indicate that, as predicted by theory, electroosmotic flow is significant when an electrical potential is placed across a porous medium saturated with a solution of low conductivity. In contrast, when the solution is more conductive, electroosmotic flow is decreased greatly both because of the effect on the electrical double layer in the pores and because a significant potential drop cannot be maintained across the medium without a large current flow. The reason there is no large $\mathrm{pH}$ change in distilled water, as might be 
expected due to the electrolysis reactions, is that the $\mathrm{H}^{+}$and $\mathrm{OH}^{-}$are essentially the only charge carriers available in solution. Thus, these ions are transported across the frit (at differing rates due to their different mobilities), where they react to form water.

Similar electroosmosis tests were conducted with concrete by securing, with silicone caulk, 5-cm-diam concrete disks between two $30-\mathrm{mL}$ glass reservoirs having graduated tubes constructed from burets at the top. Significant electroosmotic flow toward the cathode, although somewhat smaller than that with the frit, was exhibited for a concrete disk that had been contacted with aqueous solutions for an undocumented periord. These uncontrolled experiments were conducted using distilled water and copper-wire electrodes at typical conditions of $600 \mathrm{~V}$ and $60 \mathrm{~mA}$. This power level resulted in heating of the concrete and solutions to the boiling point. It is not clear what factors, such as extended contact with water or the presence of copper ions that had corroded from the anode, were responsible for this large electroosmotic flow. Many experiments that have since been conducted with several new concrete disks have exhibited no measurable electroosmotic flow.

These results indicate that electroosmotic flow is strong for fine porous media with solutions of low conductivity such as distilled water; however, as predicted, flow decreases significantly as a small amount of electrolyte is added. Similarly, new concrete disks exhibit little electroosmotic flow even with distilled water, presumably due to dissolved salts in the concrete pores. Significant electroosmotic flow may be induced through some concrete disks that have been contacted with water or possibly with certain ions for a defined period. As discussed in Sect. 3.2.5, the zeta potential of concrete, a governing variable in electroosmotic flow, is a complicated function of solution chemistry. Thus, these experiments indicate that electroosmotic flow will not be significant in most applications of EK, and that it may also be somewhat unpredictable. 


\subsubsection{Equilibration Tests}

Equilibration tests were conducted to measure the sorption isotherms of $\mathrm{Cs}, \mathrm{Co}, \mathrm{Sr}$, and $\mathrm{U}$ on concrete. These contaminants were chosen for testing because of their prevalence in contaminated concrete throughout the DOE complex. Equilibration tests were performed with $0.016 \mathrm{MNaOH}$ (simulating $\mathrm{pH}$ conditions of concrete pore water) or distilled water (for contaminants that precipitate at high $\mathrm{pH}$ ) and with potential lixiviant solutions. The $0.016 M \mathrm{NaOH}$ solution had a pH of 12.2 , matching that of distilled water equilibrated with concrete dust (particle size, $<500 \mu \mathrm{m}$ ) overnight at a water/concrete mass ratio of 3 .

The tests were conducted by contacting solutions with crushed concrete. Structural concrete samples were collected from various destructive activities at ORNL. This concrete was crushed and sieved, and the $500-\mu \mathrm{m}$-to-1-mm fraction was used for all equilibration tests. Weighed concrete samples of approximately $1.0 \mathrm{~g}$ were placed in polyethylene centrifuge tubes with $10.0 \mathrm{~mL}$ of solution containing a single contaminant. Solution concentrations of $0,10,50,100,250$, and $500 \mathrm{ppm}$ of the contaminant metal were used, and samples were run in triplicate. Although preliminary tests indicated that equilibration was achieved within approximately $2 \mathrm{~h}$, tests were conservatively conducted by contacting the solution and concrete for at least $24 \mathrm{~h}$ using a shaker. After equilibration, the tubes were centrifuged and the supernatant was drawn off. This liquid was filtered using $0.2-\mu \mathrm{m}$ cartridge filters to remove any particulates. The samples were diluted, if necessary, for analysis and acidified to $\mathrm{pH} 2$ or lower. Analysis was performed using inductively coupled plasma (ICP) emission spectroscopy for $\mathrm{Co}, \mathrm{Sr}$, and $U$ and using atomic absorption spectroscopy (AA) for Cs. Difficulties in analyses during preliminary tests emphasized the need to prepare standard solutions for calibration in matrices matching the samples. This was done by equilibrating blank solutions with concrete at the same ratio of $10 \mathrm{~mL}$ to $1 \mathrm{~g}$ and then using these solutions, after filtering, to prepare standards.

The samples from the loading tests were contacted with $2.0-\mathrm{mL}$ samples of lixiviant solutions to determine the capability of the lixiviants for dissolution of the contaminants. The procedure for these desorption tests was the same as that for the loading tests. 


\subsubsection{Cesium}

Seven equilibration tests were conducted using cesium solutions; three were tests in which cesium was loaded onto new concrete from $0.016 \mathrm{M} \mathrm{NaOH}$, and four were tests in which the loaded concrete was contacted with a potential lixiviant solution. The cesium solutions $(0,10,50,100,250$, and $500 \mathrm{ppm})$ used in the tests were generated by diluting a 5000-ppm standard solution prepared from cesium chloride and distilled water with $0.016 \mathrm{MNaOH}$ solution. A small amount of white precipitate was formed during the 24-h contact of the solutions with concrete; however, since cesium hydroxide is very soluble and because a similar precipitate formation was noted in contact of water with concrete, this is not believed to contain cesium.

Results of the cesium loading tests are shown in Fig. 3.1. Two data sets, those from series 4 and 6 , are in very good agreement; however, the data from series 1 lie on a curve that indicates a loading approximately half that of the other two runs. The reason for this discrepancy is not known. The source of the concrete was the same for the three series, and the experimental procedure was identical. In addition, all three data sets show little scatter within replicate points. The loading behavior of cesium on concrete is well represented by a Freundlich isotherm. The isotherm for series $I$ is

$$
q=1.84 c^{0.622}
$$

while that for the consistent series 4 and 6 is

$$
q=4.07 c^{0.668}
$$

where $q$ is the loading of cesium on concrete, in $\mathrm{mg} / \mathrm{g}$, and $c$ is the concentration of cesium in solution, in $\mathrm{mg} / \mathrm{mL}$.

The results of all cesium equilibration tests are shown in Fig. 3.2. This figure includes the information from desorption tests as well as that from the loading test shown in Fig. 3.1. The data for 0.01 MEDTA 


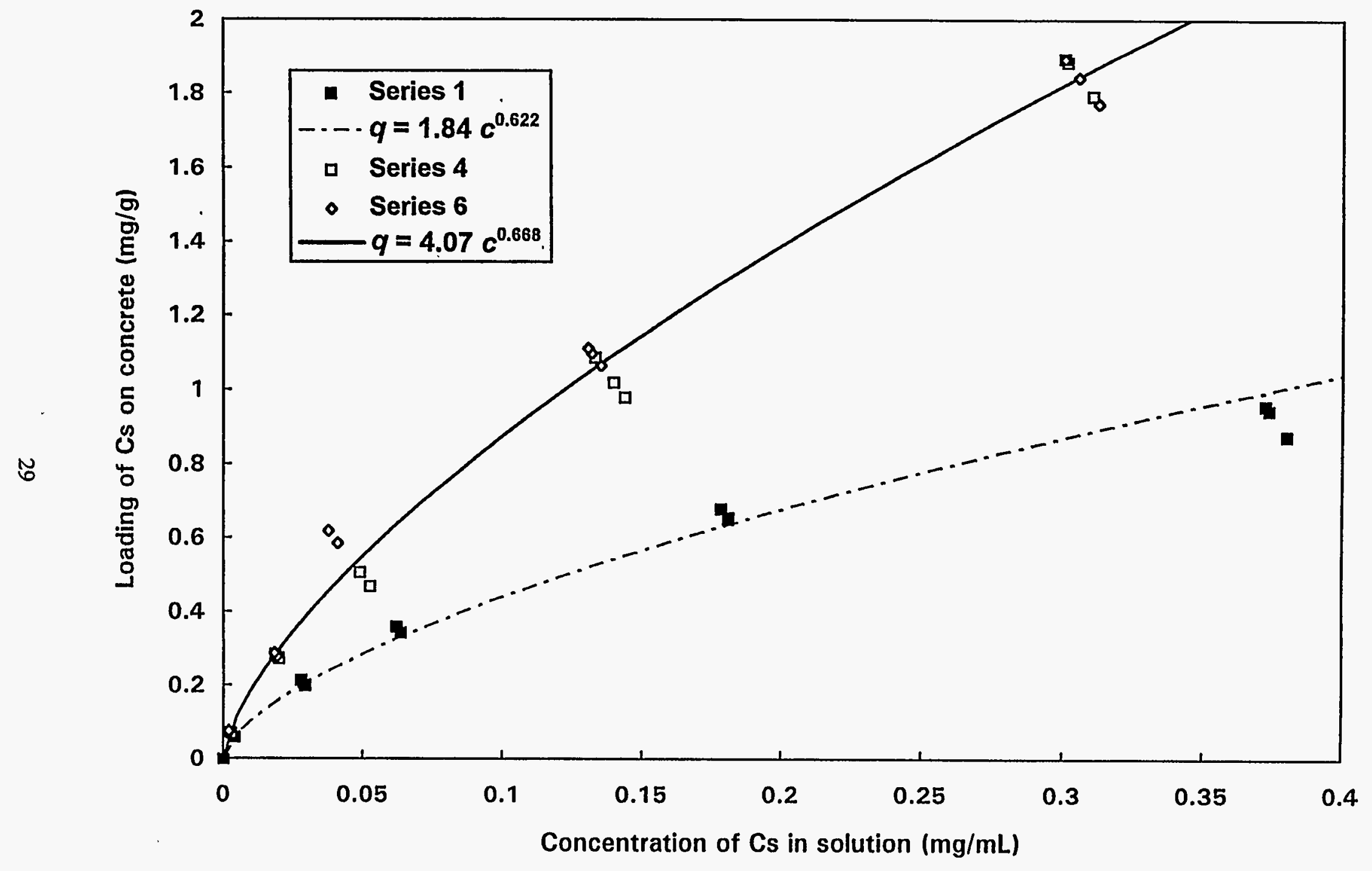

Fig. 3.1. Loading of cesium on concrete in $0.016 M$ sodium hydroxide. 


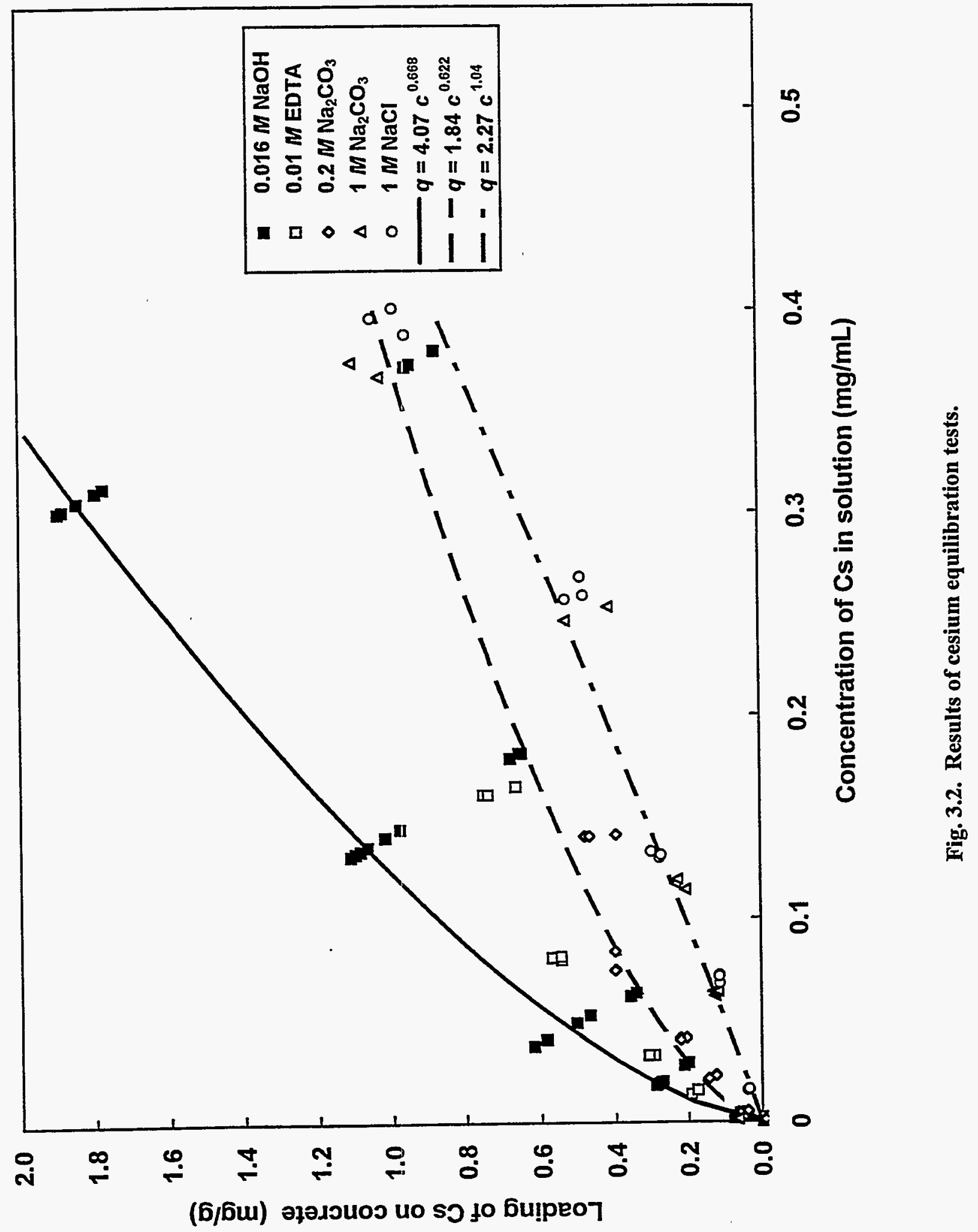


were from tests conducted with loaded concrete from series 1 , and the data for $0.2 \mathrm{M}$ sodium carbonate were from tests conducted with the same concrete after the $0.01 M$ EDTA test. Thus, the data for these two series are somewhat questionable. The results for $1 M$ sodium carbonate were from tests conducted with loaded concrete from series 4 , and the results for $1 \mathrm{M}$ sodium chloride were from tests conducted with loaded concrete from series 6 . Several observations may be made from these results. It is apparent that EDTA is relatively ineffective for dissolution of cesium, at least at the low concentration tested. Cesium loading decreases with increasing sodium concentration. This may be understood as a competition for sorption and/or ion-exchange sites between the singly charged sodium and cesium ions. The cesium loading at high sodium concentration is nearly linear; a Freundlich fit of the combined $1 M$ sodium carbonate and $1 M$ sodium chloride data yields the isotherm

$$
q=2.27 c^{1.04}
$$

Because cesium has significant solubility at high $\mathrm{pH}$ and the cesium loading on concrete can be significantly shifted by introducing sodium (and perhaps other cations), these data indicate that specialized lixiviant solutions should not be necessary for removal of cesium.

\subsubsection{Strontium}

Several series of equilibration tests were conducted with strontium, each involving loading from $0.016 \mathrm{MNaOH}$ with subsequent desorption using $0.01 M \mathrm{EDTA}, 0.016 \mathrm{MNaOH}, 1 \mathrm{MNaCl}$, or $1 \mathrm{MCaCl}_{2}$. The strontium solutions $(0,10,50,100,250$, and $500 \mathrm{ppm})$ used in the tests were generated by diluting a $5000-\mathrm{ppm}$ standard solution prepared from strontium chloride and distilled water with $0.016 \mathrm{M} \mathrm{NaOH}$ solution. As with the cesium tests, a small amount of white precipitate was observed on top of the concrete at the end of the loading period. Although strontium hydroxide is quite soluble, it may be possible that some insoluble strontium carbonate may have been formed from carbon dioxide in the air space of the tubes or 
from carbonate ions in the concrete. The testing procedure we used does not differentiate between metals bound by sorption or ion exchange and metals contained in precipitates.

Results of the strontium equilibration tests are shown in Fig. 3.3. In this figure, results of tests involving the loading from $0.016 \mathrm{MNaOH}$ are shown by solid points, while the results of desorption tests are shown by open points. The loading from $0.016 \mathrm{MNaOH}$ in the first set of tests was well described by a Freundlich isotherm

$$
q=7.77 c^{0.723}
$$

which indicates that the loading of strontium is greater than that of cesium. At a concentration of $0.01 M$, EDTA was not very effective at dissolving the strontium. The EDTA data were fit well by a linear isotherm,

$$
q=29.7 c .
$$

The fact that strontium is not well solubilized by an EDTA solution is not surprising, since $\mathrm{Sr}^{2+}$ forms a weaker complex with EDTA than many other cations, including $\mathrm{Ca}^{2+}$ (Peters et al. 1974).

A second loading test on a different sample of concrete yielded a Freundlich isotherm of

$$
q=2.99 c^{0.423}
$$

The fact that tests with two different batches of concrete resulted in two different isotherms indicates that equilibration data will be specific to particular concrete samples. The concrete from this second loading test was desorbed by contact with one of three solutions: $0.016 \mathrm{MNaOH}, 1 \mathrm{MNaCl}$, or $1 \mathrm{MCaCl}_{2}$. The isotherm for desorption with $0.016 \mathrm{MNaOH}$ was

$$
q=5.15 c^{0.339} \text {. }
$$



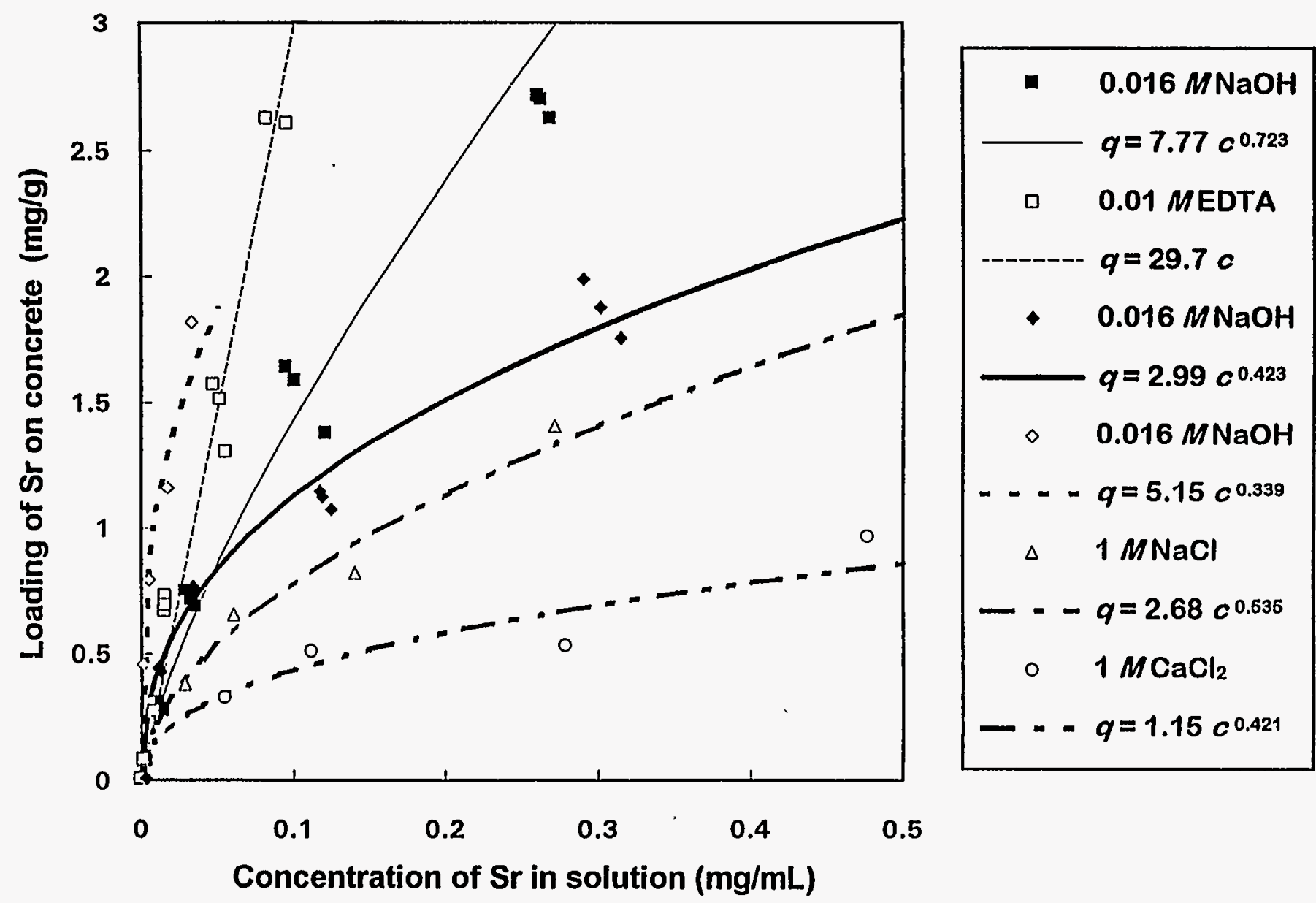

Fig. 3.3. Results of strontium equilibration tests. 
As seen in Fig. 3.3, the equilibrium loading described by this isotherm is greater than that for the initial loading from $0.016 \mathrm{MNaOH}$. This increase may be due to competitive sorption/ion exchange with calcium since there would be a greater number of calcium ions present to compete for sites with the strontium ions during loading than during desorption. The competitive sorption effect is further illustrated by data from desorption with the concentrated solutions. The isotherm for $1 \mathrm{MNaCl}$ was

$$
q=2.68 c^{0.535} \text {, }
$$

resulting in lesser loading of strontium than for the other solutions, and that for $1 \mathrm{MCaCl}_{2}$ was

$$
q=1.15 c^{0.421}
$$

resulting in even less loading of strontium on the concrete.

The greater loading of strontium than cesium in $0.016 \mathrm{MNaOH}$ indicates that it will be more difficult to remove from concrete; however, because relatively high concentrations of strontium are attainable in solution in contact with concrete, it appears that strontium should be removable without special lixiviants. Because of competitive sorption/ion exchange between cations, the loading of strontium could probably be decreased by contact with strong electrolyte solutions. Calcium was found to have greater strength than sodium in freeing strontium from the concrete.

\subsubsection{Cobalt}

Three equilibration tests were conducted with cobalt. The cobalt solutions $(0,10,50,100$, and 250 ppm) used in the tests were generated by diluting a 5000-ppm standard solution prepared by dissolving cobalt chloride with distilled water. A precipitate was formed immediately upon contact of the solutions with the concrete. It was initially a blue-green color and then changed gradually to brown. For higher concentrations of cobalt, this precipitate was of greater volume than the white precipitate from the strontium and cesium 
tests. The production of precipitate is to be expected since cobalt is highly insoluble at high $\mathrm{pH}$ [the solubility products of $\mathrm{Co}(\mathrm{OH})_{2}$ and $\mathrm{Co}(\mathrm{OH})_{3}$ are $2 \times 10^{-16}$ and $1 \times 10^{-43}$, respectively (Peters et al. 1974)].

No cobalt was measured in any sample from the loading tests. Likewise, no cobalt was measured in solution after contact with $0.01 M$ EDTA. These results would correspond to data points along the $y$-axis of a plot such as Fig. 3.3 or to a linear isotherm with an infinite coefficient.

\subsubsection{Uranium}

Five series of equilibration tests were conducted with uranium. The uranium solutions $(0,10,50,100$, 250 , and $500 \mathrm{ppm}$ ) used in the tests were generated by diluting a $500-\mathrm{ppm}$ standard solution prepared from uranyl nitrate with distilled water. Yellow precipitate was formed immediately on contact of the solutions with the concrete. The volume of precipitate formed was similar to that for cobalt.

The results of the loading and desorption tests are shown in Fig. 3.4. The data showed considerable scatter, possibly due to the suspension of precipitate when taking samples. The $0.2-\mu \mathrm{m}$ filters used to remove suspended solids from liquid samples prior to acidification and analysis were slightly yellow after being used for a series of the samples; thus, the material balance may have been upset. In addition, any uranium present in particles smaller than $0.2 \mu \mathrm{m}$ may have been measured as dissolved. The loading data for distilled water showed that almost none of the uranium stayed in solution. The constant for a linear isotherm (distribution coefficient) of these data is $9410 \mathrm{~mL} / \mathrm{g}$. The solids from the first loading were subsequently contacted, first with $0.2 \mathrm{M}$ sodium carbonate solution and, then, $1 \mathrm{M}$ sodium carbonate solution. Uranium was only slightly soluble in the $0.2 \mathrm{M}$ carbonate, resulting in a linear isotherm fit with a constant of $26.4 \mathrm{~mL} / \mathrm{g}$. By increasing the sodium carbonate concentration to $1 M$, a significant increase in uranium solubility was achieved. An increased amount of precipitate was formed in the higher-concentration solution. A $0.01 M$ EDTA lixiviant was tested on a batch of concrete that was loaded separately. The results of this series of tests indicate that $0.01 M$ EDTA is as effective as the $1 M$ sodium carbonate solution in 


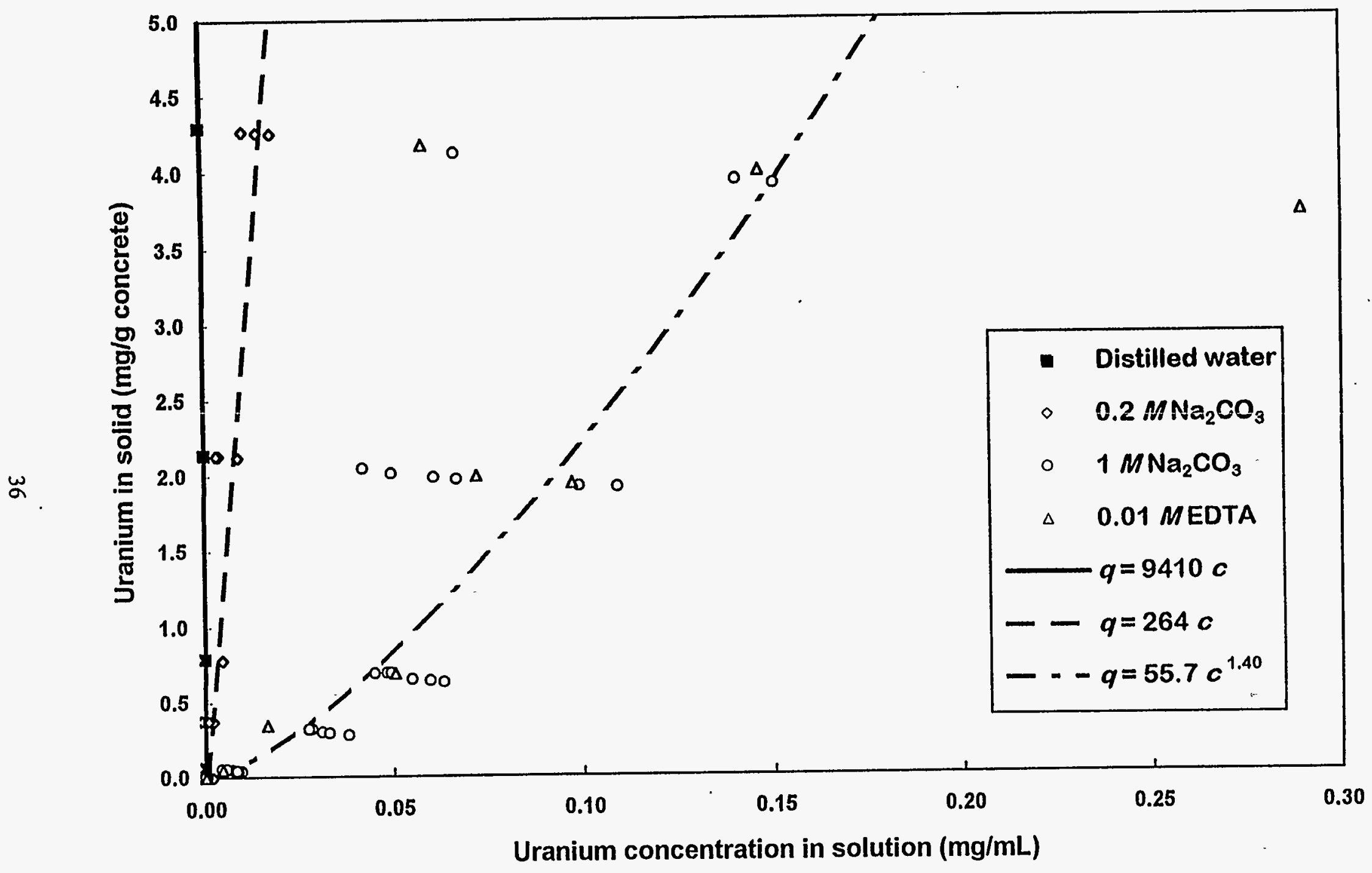

Fig. 3.4. Results of uranium equilibration tests. 
solubilizing uranium. A Freundlich fit of the $1 M$ sodium carbonate and the $0.01 M$ EDTA data together resulted in

$$
q=55.7 c^{1.40}
$$

These equilibration tests indicate that uranium is highly insoluble in contact with concrete. The use of complexing agents such as carbonate or EDTA is shown to increase the solubility by two orders of magnitude. However, the low solution concentrations achievable indicates that removal of uranium from contaminated concrete is likely to be a slow process, particularly by chemical extraction alone. An example of this may be made by considering the amount of solution necessary for removal by differential contact with clean solution. Using a linear isotherm (i.e., $q=K_{d} \mathcal{c}$ ), the mass of contaminant removed, $\Delta(m q)$, by a volume of liquid $\Delta v$ is $c \Delta v$, where $m$ is the mass of homogeneously contaminated concrete. By assuming no dissolution of concrete and differential volumes, a balance may be written as follows:

$$
m d q=-c d v
$$

which may be re-formed to give

$$
\frac{d q}{q}=-\left(\frac{1}{K_{d} m}\right) d v
$$

Integrating this equation results in

$$
K_{d} \ln \left(\frac{q_{0}}{q}\right)=\frac{V}{m},
$$

where $q_{0}$ is the initial loading and $q$ is the loading after differential equilibrium contact with a total volume, $V$, of clean solution. The amount of solution per gram of contaminated concrete, $V / m$, required for a given 
fractional removal may, thus, be estimated from the coefficient of the linear isotherm. For example, for $90 \%$ removal of uranium using $0.01 M$ EDTA (assuming a linear fit with $K_{d} \approx 20 \mathrm{~mL} / \mathrm{g}$ ), $V / m$ is approximately $46 \mathrm{~mL} / \mathrm{g}$. Thus, treatment to $90 \%$ removal of a contaminated area of concrete measuring $1 \mathrm{~m} \times 1 \mathrm{~m} \mathrm{x} 1 \mathrm{~cm}$ (approximately $31,500 \mathrm{~g}$ ) would require the contacting of $1450 \mathrm{~L}$ of clean solution with the concrete. This represents $145 \mathrm{~m}^{3}$ of wash solution per cubic meter of concrete. Subsequent treatment to a level of $99 \%$ removal would require an additional $1450 \mathrm{~L}$. This suggests that large volumes of solution would be required for chemical extraction of contaminants. Although this example may be directly compared with chemical extraction, it is difficult to predict the time necessary for cleanup by EK using such a simple model since EK does not depend on convective transport due to bulk solution movement; instead, electromigration will govern transport rates. However, the magnitude of the isotherm constant does indicate that the concentration of uranium in solution subject to electromigration will be low.

\subsubsection{Summary of Equilibration Tests}

Figure 3.5 shows the isotherms fit to the data from the equilibration tests. This plot summarizes the relative solubility of $\mathrm{Cs}, \mathrm{Sr}$, and $\mathrm{U}$ in contact with concrete and the relative potential of various solutions as lixiviants for concrete decontamination. Isotherms that are closer to the $x$-axis are preferred for removal of the contaminant from concrete. Of the species tested, cesium is the least tightly bound by concrete. It is relatively soluble and can be preferentially desorbed by other cations. Strontium is more tightly bound by concrete than cesium, but it still can exist in relatively high concentration in solution. Uranium and cobalt are much less soluble. Carbonate and EDTA complexants increase the amount of uranium in solution; however, the isotherms for uranium with these complexants are still very steep. Thus, the relative capability

for removal of these species by chemical means (either by chemical extraction or by EK) appears to be $\mathrm{Cs}>\mathrm{Sr} \gg \mathrm{U}, \mathrm{Co}$. 


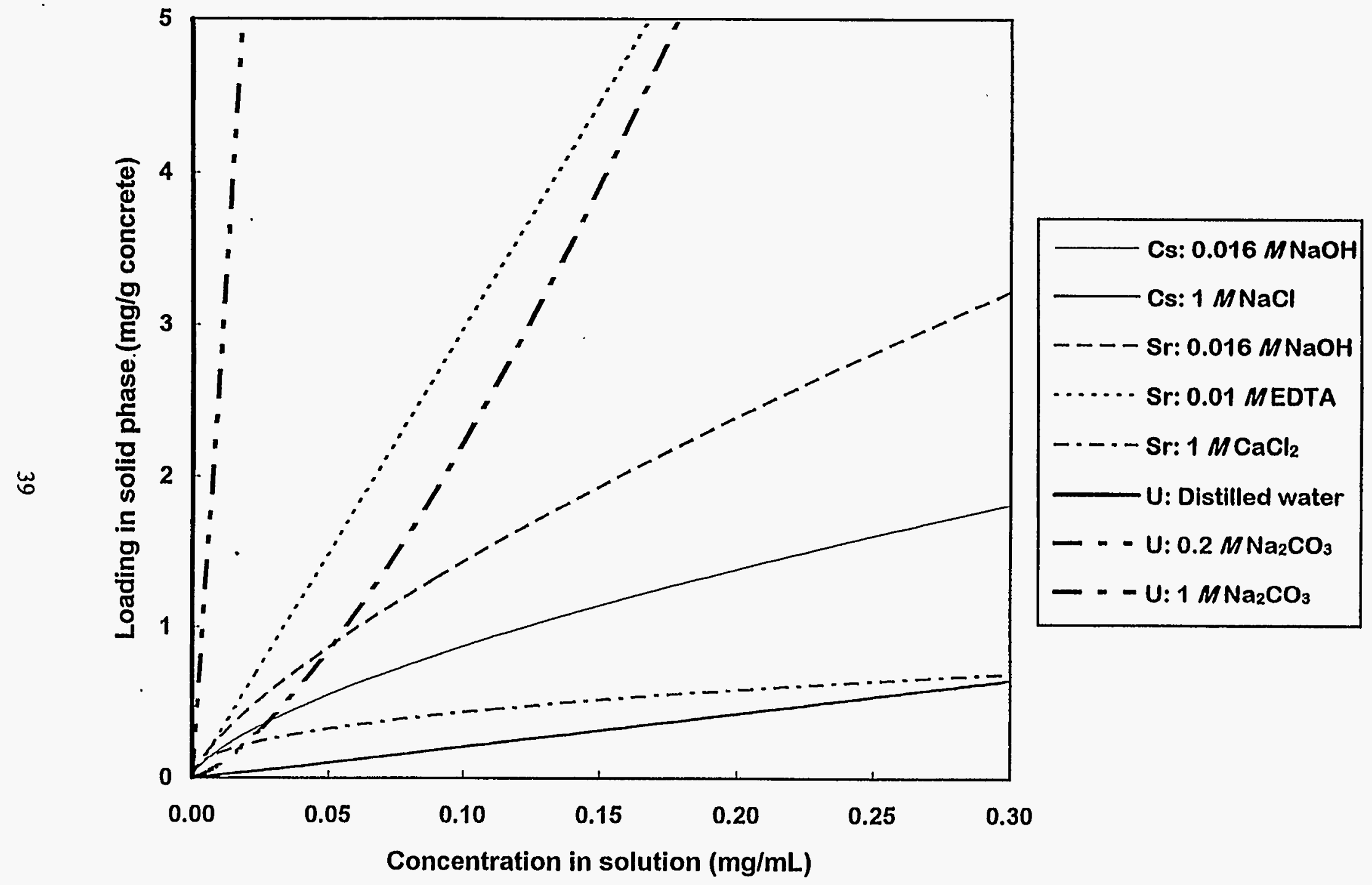

Fig. 3.5. Summary of equilibration tests. 


\subsubsection{Dynamic Loading/Desorption Experiments}

Dynamic experiments have been designed to determine the mobility of contaminants in concrete during EK. As shown schematically in Fig. 3.6, these experiments are conducted in a manner similar to those of the electroosmosis experiments described previously in that a concrete disk is held between solutions containing energized electrodes. A known amount of contaminant is added to one of the solutions. The voltage is applied in such a manner that the contaminant ions are transported into the concrete toward the solution containing the opposite electrode. The solution concentrations are measured as a function of time in order to determine the rate at which the contaminants are loaded onto the concrete and transported into the opposite solution.

The apparatus used in these experiments was fabricated from glass. Two identical 11.5 -cm-tall cells were constructed from 57-mm-diam tubing. The tops of the cells were open, while the bottoms were sealed and rounded. Near the bottom of each cell, one short piece of 48 -mm-diam tubing was fused at a $90^{\circ}$ angle. The end of this tubing was flared to accommodate a concrete disk cut from $46-\mathrm{mm}$-diam cores. Prior to a dynamic test, a 46-mm-diam concrete disk was sealed into one of the pieces of glassware using silicone caulk; then the two pieces of glassware were joined using a bead of silicone caulk and electrical tape. After the assembly had been allowed to sit overnight to allow the caulk to cure, it was secured above two magnetic stirring plates. Platinum-wire electrodes were placed in each cell. The ends of these electrodes were shaped into approximately 1 -in.-diam loops of 20-gauge wire held parallel and in close proximity to the faces of the concrete disk. Teflon-coated magnetic stir bars were placed in each reservoir, the assembly was checked for leaks, and depth scales on each reservoir were calibrated by adding known volumes of water in each side. Prior to conducting several of the dynamic tests, distilled water was placed in each reservoir, and a large potential difference was applied across the concrete. No large electroosmotic flow was noted, with an estimated detection level in these short tests of $5 \mathrm{~mL} / \mathrm{h}$. Known volumes of solutions of known concentration were added to each reservoir, and electrical power was applied by using a Sigma Aldrich PS 4010-1 electro- 


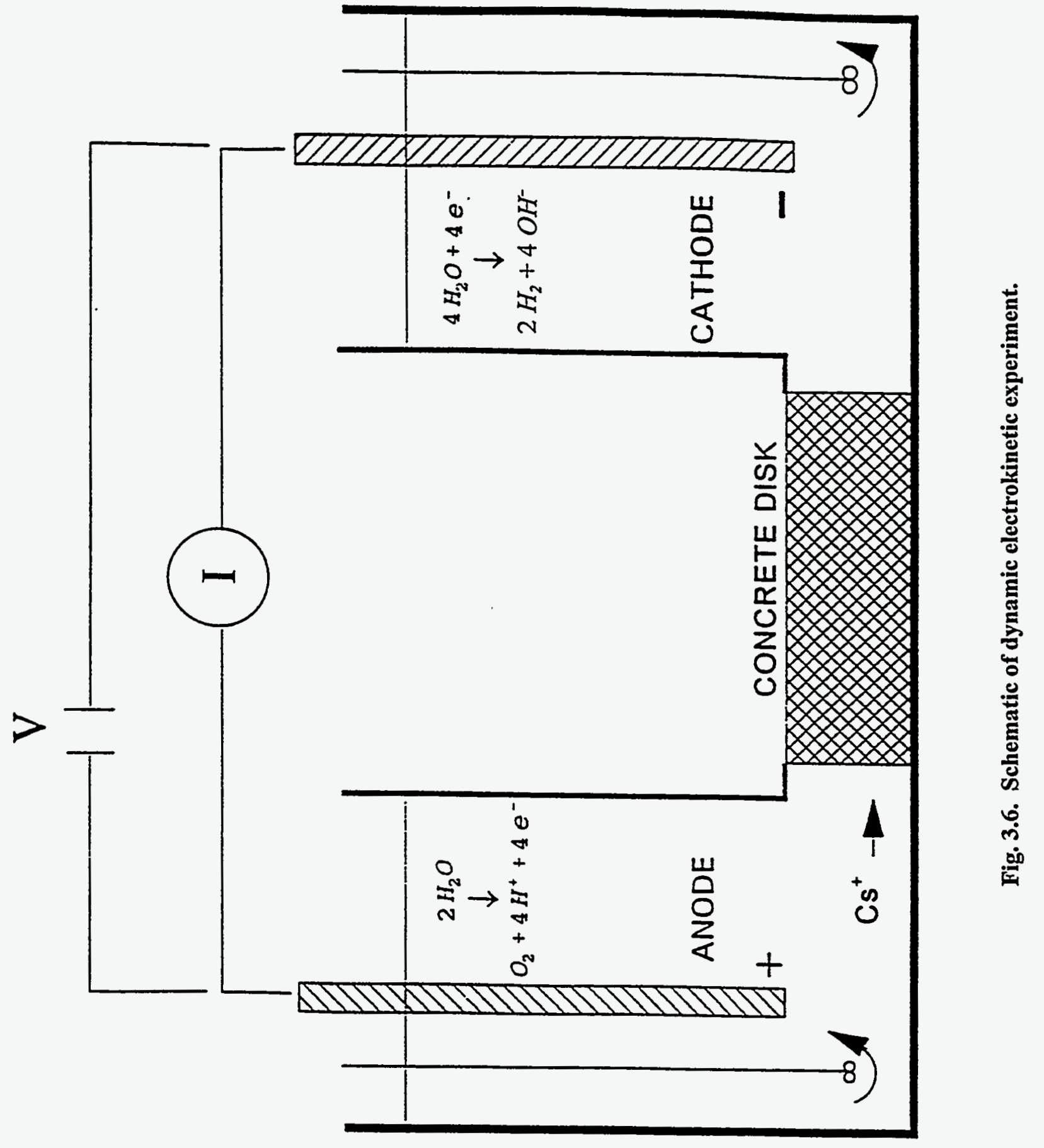


phoresis power supply. Typical limit settings for an experiment were $500 \mathrm{~V}, 100 \mathrm{~mA}$, and $100 \mathrm{~W}$. The applied voltage, current, and $\mathrm{pH}$ and level of each solution were recorded periodically. In addition, samples of each solution were taken for analysis as each experiment progressed.

\subsubsection{Cesium}

Two dynamic experiments were conducted with cesium using a $0.95-\mathrm{cm}$-thick concrete disk (mass, $34 \mathrm{~g}$ ). The initial anolyte in each test was $200 \mathrm{~mL}$ of solution containing $1000 \mathrm{ppm}$ of cesium in $0.016 \mathrm{M}$ $\mathrm{NaOH}$, while $218 \mathrm{~mL}$ of $0.016 \mathrm{MNaOH}$ was the initial catholyte. The solutions were stirred vigorously throughout the tests. In the first test, the current was held constant at $100 \mathrm{~mA}$ for $7 \mathrm{~h}$, reduced to $50 \mathrm{~mA}$ for $16.8 \mathrm{~h}$, and then held at $100 \mathrm{~mA}$ for an additional $6.2 \mathrm{~h}$.

The results of the first dynamic experiment are shown in Table 3.2. The voltage required for $100 \mathrm{~mA}$ was initially $91 \mathrm{~V}$, dropping to approximately $55 \mathrm{~V}$ after $1 \mathrm{~h}$. The conductivity was then steady through $6 \mathrm{~h}$ of operation. Upon resuming operation at $100 \mathrm{~mA}$, the required voltage had risen to a nearly constant 107 V. The anolyte volume change was consistent with the removal of 1-mL samples, while the catholyte volume change amounted to nearly $2 \mathrm{~mL} / \mathrm{h}$ after adjustment for samples. Electrolysis during the course of the experiment would account for the loss of approximately $1.5 \mathrm{~mL}$ of water from the catholyte and $0.75 \mathrm{~mL}$ from the anolyte. It is probable that evaporation was responsible for a significant portion of the water loss; this is supported by an increase in water loss in the later stages of the test, when the input power (and, thus, the solution temperature) was increased. Accounting for the losses due to electrolysis and sampling and assuming equal evaporation in each cell, electroosmotic flow may have been as large as $0.8 \mathrm{~mL} / \mathrm{h}$. This electroosmotic flow would have been toward the positive electrode, in the opposite direction of the electromigration of cesium ions.

The concentration of cesium in the anolyte decreased rapidly, while the concentration in the catholyte increased with time, signaling a transport of cesium through the concrete. By the end of the test, the cesium 
Table 3.2. Results of first dynamic loading/desorption test with cesium ${ }^{a}$

\begin{tabular}{|c|c|c|c|c|c|c|}
\hline $\begin{array}{l}\text { Time } \\
\text { (h) }\end{array}$ & $\begin{array}{c}\text { Voltage } \\
\text { (V) }\end{array}$ & $\begin{array}{c}\text { Current } \\
(\mathrm{mA})\end{array}$ & $\begin{array}{c}\text { Anolyte } \\
\text { volume } \\
(\mathrm{mL})\end{array}$ & $\begin{array}{c}{\left[\mathrm{Cs}^{+}\right] \text {in }} \\
\text { anolyte } \\
\text { (ppm) }\end{array}$ & $\begin{array}{c}\text { Catholyte } \\
\text { volume } \\
\text { (mL) }\end{array}$ & $\begin{array}{c}{\left[\mathrm{Cs}^{+}\right] \text {in }} \\
\text { catholyte } \\
(\mathrm{ppm})\end{array}$ \\
\hline 0 & 91 & 100 & 200 & 922 & 218 & 3.0 \\
\hline 0.17 & 73 & 100 & & & & \\
\hline 0.5 & 61 & 100 & & & & \\
\hline 1.0 & 55 & 100 & & 702 & & 77 \\
\hline 2.0 & 52 & 100 & & 557 & & 197 \\
\hline 3.0 & 52 & 100 & & 384 & & 720 \\
\hline 5.0 & 52 & 100 & & 134 & & 582 \\
\hline 7.0 & 58 & 100 & 194 & 27 & 206 & 799 \\
\hline 7.0 & & 50 & & & & \\
\hline 22.7 & 63 & 50 & & & & \\
\hline 23 & 107 & 100 & 194 & 0.3 & 184 & 950 \\
\hline 25 & 104 & 100 & & 1.0 & & 992 \\
\hline 27 & 107 & 100 & & 1.0 & & 1020 \\
\hline 29 & 110 & 100 & 193 & 0.3 & 161 & 1090 \\
\hline
\end{tabular}

${ }^{a}$ Initial anolyte, $1000 \mathrm{ppm}$ cesium in $0.016 \mathrm{MNaOH}$; initial catholyte, $0.016 \mathrm{MNaOH}$.

had essentially been quantitatively transferred from the anolyte to the catholyte. The concentrations in the catholyte exceeded the initial $1000 \mathrm{ppm}$ because of the volume loss during the test. Taking into account the cesium removed in the $1-\mathrm{mL}$ samples, the material balance for cesium at the end of the test is within $1 \%$.

The data from the test are presented in graphical form in Fig. 3.7( $a, b)$, which shows the amounts of cesium present in the anolyte and catholyte as a fraction of the total amount of cesium present in the system. As shown in Fig. 3.7a, the concentration of cesium in the anolyte decreased quickly and that in the catholyte increased until eventually all of the cesium was present in the catholyte. The difference between the total 

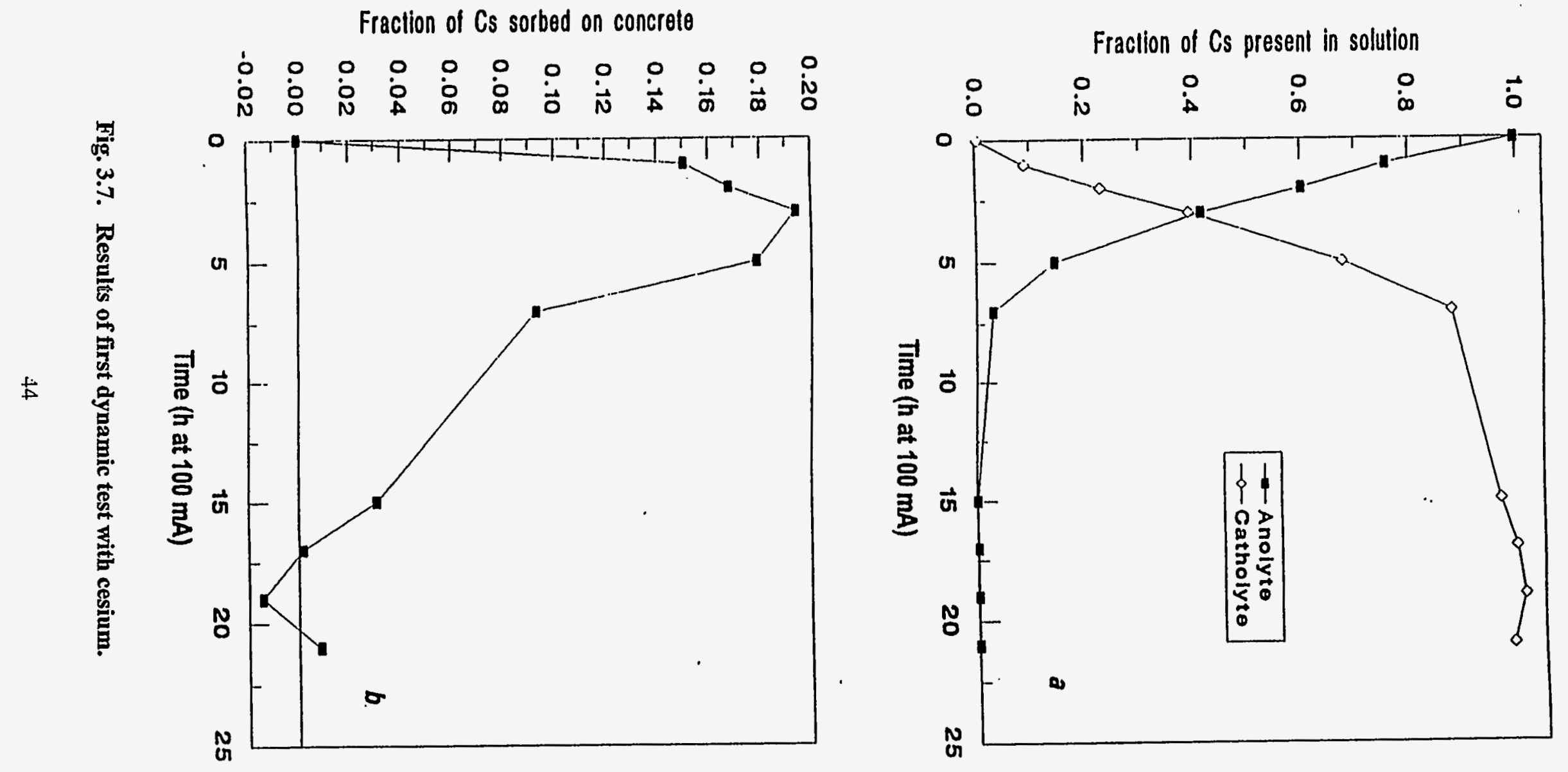
amount of cesium present and that in the two solutions was assumed to be held in the concrete disk. As shown in Fig. 3.7b, the amount of cesium loaded on the concrete varied with time, reaching a maximum of $19.4 \%$ of the total cesium present. The test could have been terminated at that point, resulting in a concrete disk loaded with a known quantity of cesium. In addition, because the cesium was driven off the concrete with further operation, it is shown that EK may be effectively used for removal of cesium contamination.

The second dynamic test with cesium was conducted with the same disk. Prior to operation, the solutions from the previous test were removed and the walls of the catholyte cell were rinsed with a small volume of $8 \mathrm{M}$ hydrochloric acid to dissolve a coating of white precipitate. The release of gas was audible upon contact with the acid. No analysis of the precipitate was performed. An attempt to drive any remaining cesium off the concrete was made by operating the system for $30 \mathrm{~min}$ with $1 \mathrm{MNaCl}$ solution as the anolyte and distilled water as the catholyte. The solutions were removed; then the cells were rinsed with distilled water, and new solutions $(200 \mathrm{~mL}$ of $1000 \mathrm{ppm}$ cesium in $0.016 \mathrm{MNaOH}$ as the anolyte and $218 \mathrm{~mL}$ of $0.016 \mathrm{MNaOH}$ as the catholyte) were placed in the reservoirs.

The results of the second dynamic experiment with cesium are shown in Table 3.3. This experiment was conducted similarly to the first; the major difference was that the current was maintained at $100 \mathrm{~mA}$ for $10 \mathrm{~h}$. The volume of the anolyte was again consistent with sampling, while the catholyte level, corrected for sampling, decreased by $0.7 \mathrm{~mL} / \mathrm{h}$. Using the same assumptions as for the first dynamic test, this could correspond to an electroosmotic flow of up to $0.2 \mathrm{~mL} / \mathrm{h}$ in the direction opposing cesium electromigration. As with the first test, the cesium was transferred from the anolyte relatively quickly, and, with a lag due to uptake on the concrete, the cesium was transferred readily to the catholyte. The results of the two dynamic runs conducted with cesium are compared in Fig. 3.8. The results show that the experiment is qualitatively repeatable. A slightly faster uptake and a greater peak loading of cesium on the concrete $(25.8 \%)$ occurred during the second test. However, the peak in the second test occurred at approximately the same time as was observed for the first test. The differences are likely due to changes in chemistry on the surfaces of 
Table 3.3. Results of second dynamic loading/desorption test with cesium ${ }^{a}$

\begin{tabular}{ccccccccc}
\hline $\begin{array}{c}\text { Time } \\
(\mathrm{h})\end{array}$ & $\begin{array}{c}\text { Voltage } \\
(\mathrm{V})\end{array}$ & $\begin{array}{c}\text { Current } \\
(\mathrm{mA})\end{array}$ & $\begin{array}{c}\text { Anolyte } \\
\text { volume } \\
(\mathrm{mL})\end{array}$ & $\begin{array}{c}{\left[\mathrm{Cs}^{+}\right] \text {in }} \\
\text { anolyte } \\
(\mathrm{ppm})\end{array}$ & $\begin{array}{c}\text { Anolyte } \\
\mathrm{pH}\end{array}$ & $\begin{array}{c}\text { Catholyte } \\
\text { volume } \\
(\mathrm{mL})\end{array}$ & $\begin{array}{c}{\left[\mathrm{Cs}^{+}\right] \text {in }} \\
\text { catholyte } \\
(\mathrm{ppm})\end{array}$ & $\begin{array}{c}\text { Catholyte } \\
\mathrm{pH}\end{array}$ \\
\hline 0 & 80 & 100 & 200 & 945 & 12.3 & 218 & 0.7 & 12.2 \\
0.5 & 74 & 100 & 202 & 790 & 12.0 & 216 & 15.3 & 12.0 \\
1.0 & 68 & 100 & 200 & 682 & 11.8 & 214 & 70.7 & 12.1 \\
1.5 & 65 & 100 & 200 & 625 & 11.7 & 214 & 135 & 12.1 \\
2.0 & 64 & 100 & 198 & 495 & 11.5 & 212 & 212 & 12.1 \\
3.0 & 59 & 100 & 196 & 327 & 9.9 & 210 & 350 & 12.3 \\
4.0 & 56 & 100 & 194 & 189 & 3.4 & 208 & 497 & 12.3 \\
5.0 & 54 & 100 & 192 & 79 & 2.7 & 208 & 631 & 12.3 \\
6.0 & 59 & 100 & 192 & 34 & 2.6 & 208 & 715 & 12.4 \\
7.0 & 81 & 100 & 190 & 15 & 2.6 & 204 & 812 & 12.4 \\
8.0 & 103 & 100 & 190 & 7.0 & 2.6 & 203 & 792 & 12.4 \\
9.0 & 114 & 100 & 190 & 4.0 & 2.5 & 202 & 862 & 12.2 \\
10.0 & 119 & 100 & 188 & 3.0 & 2.5 & 199 & 894 & 12.2 \\
\hline Initial anolyte, $1000 \mathrm{ppm}$ cesium in $0.016 \mathrm{MNaOH}$; initial catholyte, $0.016 \mathrm{MNaOH}$. &
\end{tabular}




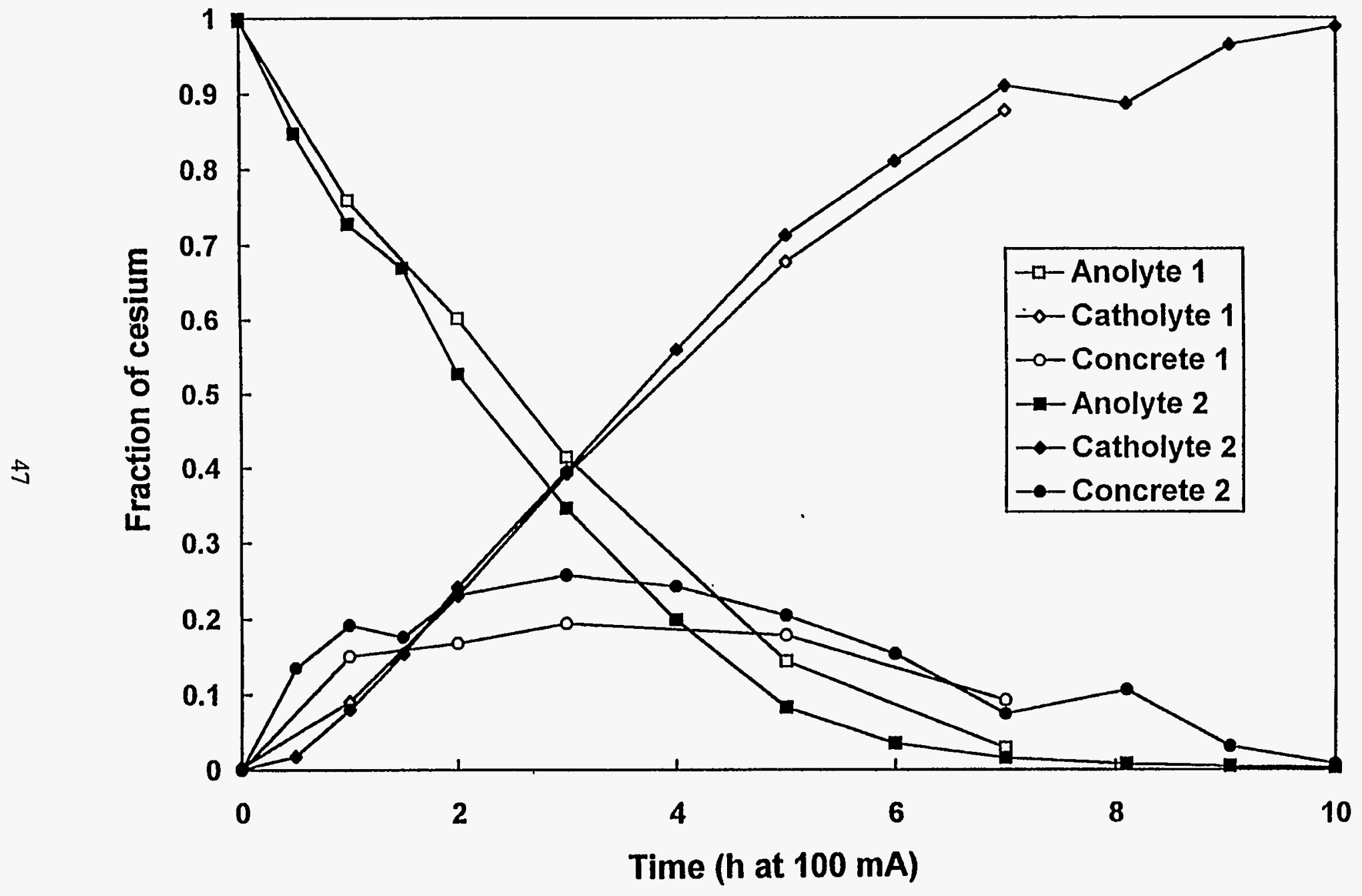

Fig. 3.8. Comparison of cesium dynamic tests. 
the concrete pores as the ions were driven through the concrete over the course of the first test and the $0.5-\mathrm{h}$ run with $1 \mathrm{MNaCl}$.

The results have shown that it is possible to transport cesium quantitatively through concrete at a relatively fast rate. Cesium was fully transferred across a 46-mm-diam, 9.5-mm-thick concrete disk in less than $24 \mathrm{~h}$ at a current of $100 \mathrm{~mA}$, with electromigration as the dominant transport mechanism. As much as approximately $25 \%$ of the cesium was loaded on the concrete during the transfer, indicating that this process could be used to load concrete, in a controllable manner, with a contaminant for testing. In addition, the tests show that EK may be applied to remove cesium contamination from bulk concrete.

\subsubsection{Strontium}

One dynamic loading/desorption test was conducted with strontium. In this test, strontium at 1000 ppm in $0.016 M \mathrm{NaOH}$ was used as the anolyte, while $0.016 \mathrm{MNaOH}$ was used as the catholyte. A new concrete disk, $8 \mathrm{~mm}$ thick, was used for this test. During this test, the current was held constant successively at $100 \mathrm{~mA}$ for $8 \mathrm{~h}$, at $50 \mathrm{~mA}$ for $15.2 \mathrm{~h}$, and at $100 \mathrm{~mA}$ for an additional $3.8 \mathrm{~h}$. A small amount of white precipitate was noted in the anolyte prior to operation, and additional precipitate formation was noted during the experiment. It is possible that this precipitate was strontium carbonate [solubility constant $=1.1 \times 10^{-10}$ (Peters et al. 1974)]. The change in solution levels was similar to that observed in the cesium tests, with a possible electroosmotic flow of 0 to $0.5 \mathrm{~mL} / \mathrm{h}$ toward the anolyte (opposite the electromigration of strontium).

The results of the strontium dynamic test are shown in Table 3.4 and Fig. 3.9. These results show that loss of strontium from the anolyte was approximately half as fast as that for cesium. Because the samples were taken from a well-agitated solution and acidified without filtration, it is unlikely that a significant portion of the strontium loss from the anolyte is due to precipitate formation. The transfer of strontium through the concrete to the catholyte was significantly slower than that for cesium, and strontium in the 
Table 3.4. Results of dynamic loading/desorption test with strontium ${ }^{a}$

\begin{tabular}{ccccccccc}
\hline $\begin{array}{c}\text { Time } \\
(\mathrm{h})\end{array}$ & $\begin{array}{c}\text { Voltage } \\
(\mathrm{V})\end{array}$ & $\begin{array}{c}\text { Current } \\
(\mathrm{mA})\end{array}$ & $\begin{array}{c}\text { Anolyte } \\
\text { volume } \\
(\mathrm{mL})\end{array}$ & $\begin{array}{c}\left.\mathrm{Sr}^{2+}\right] \text { in } \\
\text { anolyte } \\
(\mathrm{ppm})\end{array}$ & $\begin{array}{c}\text { Anolyte } \\
\mathrm{pH}\end{array}$ & $\begin{array}{c}\text { Catholyte } \\
\text { volume } \\
(\mathrm{mL})\end{array}$ & $\begin{array}{c}\mathrm{S}^{2+} \mathrm{in}^{2} \\
\text { catholyte } \\
(\mathrm{ppm})\end{array}$ & $\begin{array}{c}\text { Catholyte } \\
\mathrm{pH}\end{array}$ \\
\hline 0 & 121 & 100 & 200 & 968 & 12.0 & 218 & 0 & 12.0 \\
0.5 & 88 & 100 & 202 & 848 & 11.5 & 214 & 0 & 11.8 \\
1.0 & 76 & 100 & 198 & 795 & 11.2 & 211 & 0.7 & 11.8 \\
1.5 & 77 & 100 & 196 & 719 & 10.9 & 210 & 1.3 & 11.9 \\
2.0 & 76 & 100 & 195 & 683 & 9.7 & 209 & 0.7 & 11.9 \\
3.0 & 79 & 100 & 194 & 605 & 6.5 & 205 & 1.7 & 11.8 \\
4.3 & 85 & 100 & 193 & 514 & 4.2 & 202 & 5.7 & 11.9 \\
5.0 & 87 & 100 & 192 & 463 & 3.9 & 203 & 10.3 & 11.9 \\
6.0 & 89 & 100 & 191 & 414 & 3.0 & 201 & 17 & 11.9 \\
7.0 & 92 & 100 & 189 & 381 & 2.8 & 199 & 29 & 11.9 \\
8.0 & 96 & 100 & 187 & 329 & 2.8 & 195 & 42 & 11.9 \\
23.2 & 88 & 50 & 180 & 96 & 2.4 & 182 & 151 & 12.3 \\
25 & 145 & 100 & 180 & 62 & 2.3 & 177 & 168 & 12.0 \\
27 & 168 & 100 & 176 & 39 & 2.4 & 173 & 183 & 11.9 \\
\hline
\end{tabular}

${ }^{a}$ Initial anolyte, $1000 \mathrm{ppm}$ strontium in $0.016 \mathrm{MNaOH}$; initial catholyte, $0.016 \mathrm{MNaOH}$. 


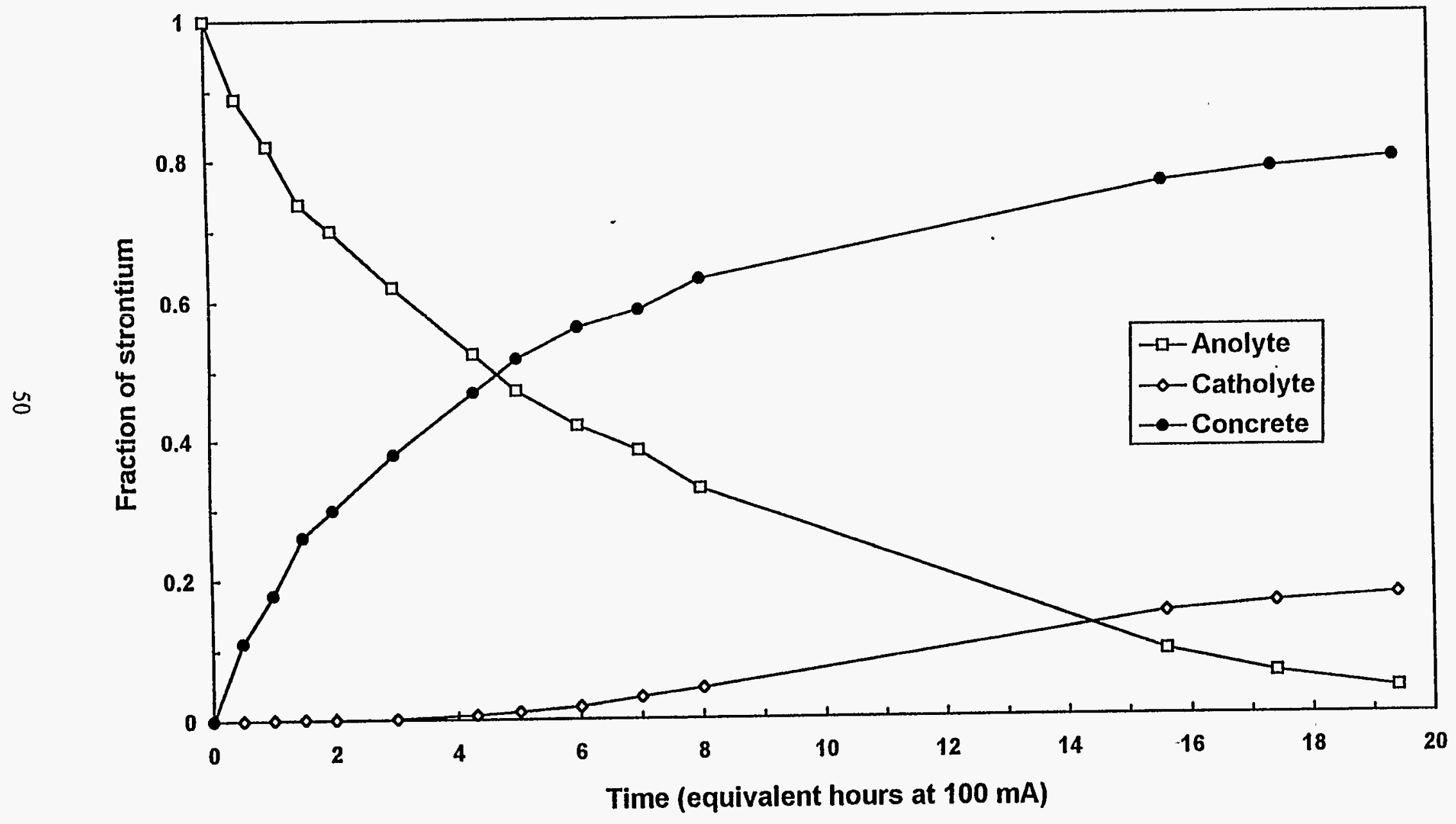

Fig. 3.9. Results of dynamic test with strontium. 
catholyte amounted to only $17 \%$ of the total strontium present at the end of the test. Factors contributing to the slower transport of strontium are: (1) the formation of larger, monovalent $\operatorname{Sr}(\mathrm{OH})^{+}$ions; and (2) the formation of insoluble carbonate. Most of the strontium appears to have been loaded onto the concrete. At the end of the test, $79 \%$ of the strontium was not present in either solution and,therefore, was assumed to be on the concrete. This value appears to be near the peak of the loading curve. The greater uptake of strontium than cesium illustrates the effect of the difference in the loading isotherms.

It is of interest to conduct additional dynamic experiments with strontium. An experiment that would be informative would be one similar to this run, but for an extended period, to determine whether strontium can be fully transferred across the concrete and how long the transfer would require. Another recommended experiment would start with a run similar to this one for loading of the concrete, followed by a change to an anolyte of high ionic strength, such as $1 \mathrm{MNaCl}$ or $1 \mathrm{MCaCl}_{2}$ to determine whether competitive sorption/ion exchange could be exploited to force the strontium off the concrete more completely and at a faster rate.

\subsubsection{Cobalt}

Two series of dynamic tests were conducted with cobalt to evaluate several techniques for their effectiveness in mobilizing species that precipitate at high $\mathrm{pH}$ levels.

The first series of tests was run with the same disk that had been used for the two cesium dynamic tests. In the first test of the series, the electrical current was maintained at $100 \mathrm{~mA}$ for $9 \mathrm{~h}$ using an initial anolyte consisting of $1000 \mathrm{ppm}$ cobalt in distilled water and a distilled-water catholyte. The anolyte was initially a pink color. Because of this coloration, spectrophotometric methods were used for the estimation of cobalt concentration in each solution. A Turner model 340 spectrophotometer was used at $512 \mathrm{~nm}$ for approximate determination of cobalt concentration. A linear calibration curve was determined for the concentration range of 0 to $1000 \mathrm{ppm}$.

The results of the first dynamic test with cobalt are shown in Table 3.5. The voltage required to 
maintain a current of $100 \mathrm{~mA}$ was somewhat greater than in the previous tests with cesium and strontium because of the lower conductivity of distilled water, starting at $160 \mathrm{~V}$ and steadily decreasing to $120 \mathrm{~V}$ during the test. The change in solution volumes followed the same trend as observed in the other tests. As measured by the spectrophotometer, the cobalt concentration in the anolyte decreased steadily and then essentially leveled out after 50 to $60 \%$ of the cobalt had been transferred from the solution. No cobalt was measured in the catholyte. During the test, a dark-brown precipitate formed on the surface of the concrete exposed to the anolyte. This precipitate persisted throughout the test, even though the $\mathrm{pH}$ of the anolyte was as low as 2.3. It may be that the near-steady cobalt concentration resulted from a balance of dissolution from the concrete face and electromigration into the concrete. Samples of the final solutions were analyzed for

Table 3.5. Results of first dynamic test with cobalt ${ }^{a}$

\begin{tabular}{cccccccc}
\hline $\begin{array}{c}\text { Time } \\
(\mathrm{h})\end{array}$ & $\begin{array}{c}\text { Voltage } \\
(\mathrm{V})\end{array}$ & $\begin{array}{c}\text { Current } \\
(\mathrm{mA})\end{array}$ & $\begin{array}{c}\text { Anolyte } \\
\text { volume } \\
(\mathrm{mL})\end{array}$ & $\begin{array}{c}\text { Approximate }\left[\mathrm{Co}^{2+}\right] \\
\text { in anolyte } \\
(\mathrm{ppm})\end{array}$ & $\begin{array}{c}\text { Anolyte } \\
\mathrm{pH}\end{array}$ & $\begin{array}{c}\text { Catholyte } \\
\text { volume } \\
(\mathrm{mL})\end{array}$ & $\begin{array}{c}\text { Catholyte } \\
\mathrm{pH}\end{array}$ \\
\hline 0 & 160 & 100 & 218 & 1100 & 7.1 & 200 & 6.2 \\
0.5 & 145 & 100 & 217 & 1000 & 2.8 & 200 & 10.7 \\
1 & 138 & 100 & 216 & 870 & 2.7 & 200 & 11.0 \\
1.5 & 133 & 100 & 216 & 788 & 2.5 & 197 & 11.0 \\
2 & 135 & 100 & 210 & 700 & 2.4 & 192 & 11.0 \\
3 & 144 & 100 & 206 & 590 & 2.4 & 187 & 11.2 \\
4 & 144 & 100 & 204 & 540 & 2.4 & 181 & 11.4 \\
5 & 140 & 100 & 202 & 570 & 2.4 & 176 & 11.3 \\
6 & 140 & 100 & 201 & 570 & 2.4 & 171 & 11.4 \\
7 & 133 & 100 & 195 & 440 & 2.3 & 162 & 11.5 \\
8 & 120 & 100 & 195 & 460 & 2.4 & 162 & 11.5 \\
9 & 120 & 100 & 190 & 480 & 2.4 & 150 & 11.7 \\
\hline$a$ & Initial anolyte, $1000 \mathrm{ppm}$ cobalt in distilled water; initial catholyte, distilled water. &
\end{tabular}


cobalt by ICP, yielding a value of $215 \mathrm{ppm}$ for the anolyte and $0 \mathrm{ppm}$ for the catholyte. This test determined that the precipitating cobalt species would not be readily transferred across concrete.

To determine whether the precipitate could be removed by chemical means without application of electrical power, the anolyte was removed and replaced with $0.025 M$ EDTA solution (pH adjusted to 5.6 for complete EDTA dissolution). This solution, which was stirred overnight, did not become colored immediately; however, as stirring commenced, it turned pink, and, by the next morning ( $13.5 \mathrm{~h}$ later), had a $\mathrm{pH}$ of 6.4 and was a dark purple color, indicative of a cobalt-EDTA complex. Therefore, a significant amount of cobalt precipitate had been removed from the concrete surface; however, since a large amount of the brown precipitate was still present on the concrete, the test was not conclusive as to whether chemical extraction is capable of removing all of the contaminant.

Another dynamic test was conducted with this loaded disk to determine whether EDTA could be transported through the concrete to dissolve the cobalt. The solutions were removed from each reservoir and replaced with distilled water on the side with the cobalt precipitate and $0.025 M$ EDTA on the other side. After $200 \mathrm{~min}$ of operation with the wrong polarity, the test was operated for $3.5 \mathrm{~h}$ at $100 \mathrm{~mA}$ and then for $16 \mathrm{~h}$ at $25 \mathrm{~mA}$ with the EDTA solution as the catholyte. Under this configuration, electromigration of the unprotonated EDTA ions, carrying a -4 charge, toward the anolyte is expected. After $3.5 \mathrm{~h}$, the concentration of cobalt in the anolyte had increased to $42 \mathrm{ppm}$. At the end of the test, the anolyte had turned a dark purple color. These results indicate that EDTA may be transported through concrete by electromigration to complex and dissolve cobalt. .

A second series of dynamic tests was conducted with the disk that had been used for the strontium dynamic test. The disk was first loaded for $7 \mathrm{~h}$ at $100 \mathrm{~mA}$ using $218 \mathrm{~mL}$ of anolyte containing $1080 \mathrm{ppm}$ cobalt in distilled water. Analysis of the solutions by ICP at the end of the loading stage indicated that no cobalt reached the catholyte, while the anolyte had decreased in volume to $186 \mathrm{~mL}$ and in cobalt concentration to $474 \mathrm{ppm}$. This indicates that $63 \%$ of the cobalt had precipitated on the concrete. The 
solutions were removed, replaced with a distilled-water anolyte and a $0.025 M$ EDTA catholyte, and electrical power was applied for $7 \mathrm{~h}$ at $100 \mathrm{~mA}$. After $90 \mathrm{~min}$, the anolyte was a noticeable pink color, indicating that some EDTA had been transferred across the concrete and had formed a soluble complex with cobalt from the precipitate. By the end of the test, the anolyte was dark purple, while a small amount of $\tan$ precipitate, perhaps a product from strontium left over from the previous tests, was present in the catholyte. Analyses of anolyte samples by ICP showed an increase in cobalt concentration corresponding to the color change; at run times of 2,4 , and $7 \mathrm{~h}$, the cobalt concentrations were 15,130 , and $320 \mathrm{ppm}$, respectively. The final anolyte volume was $173 \mathrm{~mL}$. Thus, $38 \%$ of the cobalt that had been precipitated in the loading phase was dissolved by the electrokinetic transport of EDTA through the concrete. Since the cobalt concentration had not leveled off, it is likely that significantly more cobalt could have been dissolved with further operation.

An additional dynamic test was conducted with this disk. The purple solution containing the EDTA and cobalt was retained, while $0.016 \mathrm{M} \mathrm{NaOH}$ was added to the opposite reservoir. The polarity was changed such that the cobalt-EDTA solution was the catholyte and the $\mathrm{NaOH}$ solution was the anolyte. Because the cobalt-EDTA complex is negatively charged, there was a driving force for electromigration of the cobalt complex to the anolyte. After $5 \mathrm{~h}$ of operation, the initially purple catholyte had changed to a suspension of muddy-brown precipitate, while the anolyte had a slight pink tint. The pink tint became darker with time, while the precipitate persisted in the catholyte. The progress of this test was followed qualitatively using the spectrophotometer at $537 \mathrm{~nm}$; in addition, samples were taken for analysis by ICP. The spectrophotometric data are not expected to be accurate measures of concentration due to the varying levels of EDTA in the matrix. The results of this test, shown in Table 3.6, show that the cobalt-EDTA complex was nearly fully removed from the catholyte. The spectrophotometric results, along with visual observation of the pink tint, indicate that a small amount of the complex was transferred to the anolyte. The formation of precipitate in the high-pH catholyte suggests that a portion of the cobalt present was not 
Table 3.6. Results of second dynamic test to study electromigration of cobalt-EDTA complex across concrete

\begin{tabular}{|c|c|c|c|c|c|c|c|c|c|c|}
\hline $\begin{array}{c}\text { Time } \\
\text { (h) }\end{array}$ & $\begin{array}{c}\text { Voltage } \\
\text { (V) }\end{array}$ & $\begin{array}{c}\text { Current } \\
\text { (mA) }\end{array}$ & $\begin{array}{c}\text { Anolyte } \\
\text { volume } \\
\text { (mL) }\end{array}$ & $\begin{array}{c}\text { Anolyte } \\
\text { absorbance } \\
\text { reading }\end{array}$ & $\begin{array}{l}{[\mathrm{Co}] \text { in }} \\
\text { anolyte } \\
\text { by ICP } \\
(\mathrm{ppm}) \\
\end{array}$ & $\begin{array}{c}\text { Anolyte } \\
\mathrm{pH}\end{array}$ & $\begin{array}{c}\text { Catholyte } \\
\text { volume } \\
\text { (mL) }\end{array}$ & $\begin{array}{c}\text { Catholyte } \\
\text { absorbance } \\
\text { reading }\end{array}$ & $\begin{array}{c}\text { [Co] in } \\
\text { catholyte } \\
\text { by ICP } \\
\text { (ppm) }\end{array}$ & $\begin{array}{c}\text { Catholyte } \\
\mathrm{pH}\end{array}$ \\
\hline 0 & 164 & 100 & 214 & 0.001 & 0 & 12.2 & 200 & 1.32 & 333 & 2.6 \\
\hline 0.5 & 137 & 100 & 214 & 0.000 & 0 & .11 .7 & 198 & 1.19 & 295 & 8.5 \\
\hline 1 & 119 & 100 & 214 & 0.000 & 0 & 11.3 & 199 & 1.07 & 260 & 10.9 \\
\hline 1.5 & 118 & 100 & 214 & 0.001 & 0 & 10.3 & 198 & 0.788 & 236 & 11.3 \\
\hline 2 & 129 & 100 & 210 & 0.004 & 0 & 7.0 & 198 & 0.619 & 207 & 11.5 \\
\hline 2.5 & 169 & 100 & 205 & 0.005 & 0 & 5.8 & 198 & 0.187 & 202 & 11.5 \\
\hline 3 & 175 & 100 & 199 & 0.008 & 0 & 4.4 & 194 & 0.103 & 197 & 11.5 \\
\hline 5 & 187 & 100 & 196 & 0.033 & 0 & 3.0 & 191 & 0.025 & 174 & 11.5 \\
\hline 6 & & 100 & 192 & 0.043 & 0 & 3.2 & 187 & 0.015 & 19.4 & 11.6 \\
\hline 7 & & 100 & 188 & & 0 & 3.3 & 183 & & 19.8 & 11.6 \\
\hline
\end{tabular}


transferred by the EDTA.

These results confirm that it is possible to move the cobalt-EDTA complex through concrete by electromigration. This finding is significant since it shows that a charged complexant, such as EDTA, can be moved through concrete to the contaminant and, more importantly, that the resulting contaminantcontaining complex can also be moved through concrete. Thus, the removal of precipitating species from concrete is possible if suitable complexants are found. Of course, it should be noted that these results are qualitative at this point. They do not provide information as to the length of time required to remove all of the precipitating species; nor do they confirm whether EK is necessary in conjunction with complexation to remove contaminants.

\subsubsection{Uranium}

Three dynamic experiments were conducted with uranium. As with cobalt, these experiments were conducted to determine whether this precipitating contaminant could be mobilized through concrete by electrokinetic means.

The first dynamic test with uranium was conducted using a new, 7.5-mm-thick concrete disk. The solutions used were a distilled-water anolyte and a catholyte consisting of $218 \mathrm{~mL}$ of a solution of uranyl nitrate (250 ppm uranium) in $0.5 \mathrm{M}$ sodium carbonate/bicarbonate with $\mathrm{pH}$ adjusted to 9.8 . This configuration was used so that there would be a driving force for electromigration of the uranyl tricarbonate ion, $\mathrm{UO}_{2}\left(\mathrm{CO}_{3}\right)_{3}^{4-}$, formed by complexation of the uranyl cation with carbonate anions, through the concrete toward the anolyte. The test was run for $7 \mathrm{~h}$ with voltage and current limits of $500 \mathrm{~V}$ and $100 \mathrm{~mA}$, respectively; then the power was shut off for $16 \mathrm{~h}$. The solutions were returned to their initial levels by the addition of distilled water, and the power was then resumed.

The results of the first test are shown in Table 3.7. The initial yellow coloration of the catholyte continued throughout the test; no color change was noted in the anolyte. The volume change for each 
reservoir was nearly equal, indicating that there was no electroosmotic flow. The concentration of uranium in the catholyte remained nearly constant, and no transport of uranium into the anolyte was measured. The most striking feature of this test was the low conductivity. Initially, $367 \mathrm{~V}$ was required for a current of $100 \mathrm{~mA}$, and the conductivity continued to decrease throughout the test, with the exception of a "spike" of increased conductivity at the restart of the system.

Table 3.7. Results of first dynamic test with uranium ${ }^{a}$

\begin{tabular}{|c|c|c|c|c|c|c|c|c|}
\hline $\begin{array}{l}\text { Time } \\
\text { (h) }\end{array}$ & $\begin{array}{c}\text { Voltage } \\
\text { (V) }\end{array}$ & $\begin{array}{l}\text { Current } \\
(\mathrm{mA})\end{array}$ & $\begin{array}{c}\text { Anolyte } \\
\text { volume } \\
\text { (mL) }\end{array}$ & $\begin{array}{c}\text { Anolyte } \\
\mathrm{pH}\end{array}$ & $\begin{array}{c}\text { Total }[\mathrm{U}] \\
\text { in anolyte } \\
(\mathrm{ppm})\end{array}$ & $\begin{array}{c}\text { Catholyte } \\
\text { volume } \\
\text { (mL) }\end{array}$ & $\begin{array}{c}\text { Catholyte } \\
\text { pH }\end{array}$ & $\begin{array}{c}\text { Total [U] in } \\
\text { catholyte } \\
(\mathrm{ppm})\end{array}$ \\
\hline 0 & 367 & 100 & 218 & 6.2 & 0 & 200 & 9.8 & 173 \\
\hline 0.5 & 500 & 97 & 218 & 3.2 & 0 & 203 & 9.6 & 173 \\
\hline 1 & 500 & 51 & 216 & 3.0 & 0 & 200 & 9.6 & 178 \\
\hline 1.5 & 500 & 34 & 214 & 3.0 & 0 & 195 & 9.6 & 179 \\
\hline 2 & 500 & 28 & 211 & 3.0 & 0 & 191 & 9.7 & 177 \\
\hline 3 & 500 & 23 & 209 & 3.0 & 0 & 186 & 9.7 & 181 \\
\hline 4.4 & 500 & 19 & 206 & 3.0 & 0 & 183 & 9.8 & 172 \\
\hline 5 & 500 & 17 & 204 & 3.0 & 0 & 180 & 9.8 & 172 \\
\hline 6 & 500 & 18 & 203 & 3.0 & 0 & 179 & 9.8 & 171 \\
\hline 7 & 500 & 15 & 202 & 3.0 & 0 & 177 & 9.8 & 183 \\
\hline $7^{b}$ & 500 & 43 & 218 & 6.9 & & 200 & 9.9 & \\
\hline 8 & 500 & 25 & 217 & 4.3 & 0 & 201 & 9.9 & 161 \\
\hline 10 & 500 & 14 & 215 & 3.2 & 0 & 197 & 9.9 & 170 \\
\hline 12 & 500 & 11 & 213 & 3.1 & 0 & 194 & 9.9 & 160 \\
\hline 14 & 500 & 11 & 210 & 3.1 & 0 & 191 & 10.0 & 165 \\
\hline
\end{tabular}


The low conductivity, even with a $1 M$ carbonate solution in one reservoir, is probably due to the use of carbonate as the complexing ion for uranium. Carbonate forms insoluble compounds with several cations, including calcium and magnesium [solubility products of $-9 \times 10^{-9}$ and $1 \times 10^{-5}$, respectively (Peters et al., 1974)], that are prevalent in concrete; in addition, any carbonate transferred to the anolyte would form weakly dissociated carbonic acid. These factors will limit the amount of free ions in solution and, thus, will lower the conductivity. The formation of carbonate-containing precipitates within the concrete would lead to the possibility of precipitation of noncomplexed uranium; in addition, it may be possible that some pores may be blocked by precipitate.

To further investigate the use of carbonate lixiviant, a second dynamic test was conducted with the same disk used in the first test. Both the anolyte and catholyte solutions used in this test were $1 M$ carbonate/bicarbonate solution with the $\mathrm{pH}$ adjusted to 9.64 . The catholyte also contained $500 \mathrm{ppm}$ uranium. The catholyte was initially yellow, while the anolyte was clear. Some precipitate from the first experiment remained in the catholyte reservoir.

The results of the second test are shown in Table 3.8. The conductivity was initially relatively low but increased throughout the first $7 \mathrm{~h}$ of the test. The precipitate initially in the catholyte appeared to dissolve after approximately $90 \mathrm{~min}$, near the time when a sharp rise in conductivity was noted. Throughout the test, no color change was observed, and the $\mathrm{pH}$ values remained close to the initial value of 9.6 , presumably due to the combined buffering of the concrete and the carbonate/bicarbonate solutions. Results of this test indicated that the conductivity may be adequate when using carbonate solution lixiviants if high-conductivity solution is applied at both electrodes. In addition, the test was successful in transporting uranium slowly through the concrete disk. Because of these favorable results, further study of the system is recommended.

A third dynamic test was conducted using EDTA, rather than carbonate, as the complexant. For this test, the solutions used previously were removed, but the concrete disk was retained. The initial anolyte was tap water, while $400 \mathrm{ppm}$ uranium in $0.025 \mathrm{MEDTA}$ solution was used as the catholyte. Yellow precipitate 
Table 3.8. Results of second dynamic test with uranium ${ }^{a}$

\begin{tabular}{ccccccccc}
\hline $\begin{array}{c}\text { Time } \\
(\mathrm{h})\end{array}$ & $\begin{array}{c}\text { Voltage } \\
(\mathrm{V})\end{array}$ & $\begin{array}{c}\text { Current } \\
(\mathrm{mA})\end{array}$ & $\begin{array}{c}\text { Anolyte } \\
\text { volume } \\
(\mathrm{mL})\end{array}$ & $\begin{array}{c}\text { Anolyte } \\
\mathrm{pH}\end{array}$ & $\begin{array}{c}\text { Total [U] } \\
\text { in anolyte } \\
(\mathrm{ppm})\end{array}$ & $\begin{array}{c}\text { Catholyte } \\
\text { volume } \\
(\mathrm{mL})\end{array}$ & $\begin{array}{c}\text { Catholyte } \\
\mathrm{pH}\end{array}$ & $\begin{array}{c}\text { Total [U] in } \\
\text { catholyte } \\
\text { (ppm) }\end{array}$ \\
\hline 0 & 500 & 52 & 218 & 9.6 & 0 & 200 & 9.6 & 262 \\
0.5 & 500 & 35 & 221 & 9.5 & 0 & 202 & 9.5 & 264 \\
1 & 500 & 64 & 221 & 9.5 & 0 & 202 & 9.4 & 263 \\
1.5 & 500 & 74 & 219 & 9.4 & 0 & 200 & 9.4 & 261 \\
2 & 83 & 100 & 217 & 9.5 & 0 & 196 & 9.5 & 267 \\
3 & 50 & 100 & 217 & 9.5 & 0 & 196 & 9.5 & 265 \\
5 & 74 & 100 & 209 & 9.4 & 1.2 & 187 & 9.8 & 268 \\
6 & 74 & 100 & 206 & 9.4 & 1.5 & 186 & 9.8 & \\
7 & 72 & 100 & 202 & 9.3 & 2.3 & 184 & 9.9 & 347 \\
$7^{b}$ & 52 & 100 & & & & & & \\
12 & 62 & 100 & 193 & & 7.8 & 177 & & 338 \\
$12^{c}$ & 47 & 100 & 208 & & & 186 & & \\
19 & 56 & 100 & 204 & 8.9 & 19 & 184 & 12.3 & 314 \\
$19^{d}$ & 39 & 100 & 200 & & & 176 & & \\
26 & 53 & 100 & 195 & 8.6 & 27 & 175 & 12.7 & 315 \\
\hline
\end{tabular}

${ }^{a}$ Initial anolyte, $1 \mathrm{MNa}_{2} \mathrm{CO}_{3}$ solution; initial catholyte, $1 \mathrm{MNa}_{2} \mathrm{CO}_{3}$ solution containing $500 \mathrm{ppm}$ uranium.

${ }^{b}$ System was shut down for $19 \mathrm{~h}$ and then restarted.

'System was shut down for $17 \mathrm{~h}$; then $20 \mathrm{~mL}$ of distilled water was added to each reservoir, and the test was restarted.

${ }^{d}$ System was shut down for $17 \mathrm{~h}$ and then restarted. 
was noted in the catholyte. Electrical power was maintained for $54 \mathrm{~h}$. With the exception of a large volume of evaporation (total, approximately $445 \mathrm{~mL}$ ), no noticeable difference was noted in either solution. The results are summarized in Table 3.9, which shows that the conductivity of the system decreased throughout the test. Although the analytical data for the catholyte were very irregular (presumably due to the presence of suspended solids), no measurable transfer of uranium into the anolyte was noted. This indicates that uranium transport through concrete via EDTA complexation may not be effective.

\subsubsection{Discussion of Dynamic Tests}

These dynamic tests have allowed us to collect valuable information regarding the mobility of contaminants through concrete using EK. This information indicates that contaminants may be divided into two general types of species: those that do not precipitate at high $\mathrm{pH}$, and those that do. The nonprecipitating species may be transported through concrete by EK using electrolyte solutions. It appears that the rate at which these species are transported may be qualitatively compared from the sorption isotherms; for instance, strontium exhibited greater loading and slower electromigration through concrete. Precipitating species are not easy to move through concrete using noncomplexing electrolyte solutions. It is possible, in principle, to operate analogously to soil remediation by flushing or neutralizing the catholyte to permit the formation of an acid front in the concrete that would dissolve the contaminants; however, a large volume of acid would be necessary to neutralize the concrete, and the concrete structure would likely be damaged.

An apparently more feasible approach involves the use of complexants. Tests that displayed the movement of EDTA and the cobalt-EDTA complex through concrete indicate that decontamination of concrete-containing precipitating species may be possible through the use of a proper complexant. In addition, some success was achieved in transport of uranium using a carbonate lixiviant. However, at this point, the decontamination of concrete containing precipitating species using EK appears to be slow and 
Table 3.9. Results of third dynamic test with uranium ${ }^{a}$

\begin{tabular}{ccccccccc}
\hline $\begin{array}{c}\text { Time } \\
(\mathrm{h})\end{array}$ & $\begin{array}{c}\text { Voltage } \\
(\mathrm{V})\end{array}$ & $\begin{array}{c}\text { Current } \\
(\mathrm{mA})\end{array}$ & $\begin{array}{c}\text { Anolyte } \\
\text { volume } \\
(\mathrm{mL})\end{array}$ & $\begin{array}{c}\text { Anolyte } \\
\mathrm{pH}\end{array}$ & $\begin{array}{c}\text { Total [U] } \\
\text { in anolyte } \\
(\mathrm{ppm})\end{array}$ & $\begin{array}{c}\text { Catholyte } \\
\text { volume } \\
(\mathrm{mL})\end{array}$ & $\begin{array}{c}\text { Catholyte } \\
\mathrm{pH}\end{array}$ & $\begin{array}{c}\text { Total [U] in } \\
\text { catholyte } \\
(\mathrm{ppm})\end{array}$ \\
\hline 0 & 221 & 100 & 218 & 9.9 & 0 & 200 & 11.8 & 160 \\
1 & 500 & 55 & & & & & & \\
4 & 500 & 45 & 202 & 2.6 & 0 & 176 & 11.4 & 175 \\
7 & 500 & 48 & 191 & 2.6 & 0 & 200 & 11.4 & 1215 \\
$24^{b}$ & 500 & 42 & 218 & 2.9 & 0 & 185 & 11.6 & 162 \\
28 & 500 & 47 & 205 & & 0 & 169 & & 3040 \\
30.8 & 500 & 50 & 192 & & 0 & 200 & & $3300^{e} / 16^{f}$ \\
$47^{c}$ & 500 & 37 & 177 & 3.1 & 0 & 155 & 11.6 & 2630 \\
$49.8^{d}$ & 500 & 36 & 218 & & 0 & 200 & & \\
54 & 500 & 33 & 203 & 3.1 & 0 & 178 & 11.7 & 2020 \\
\hline
\end{tabular}

${ }^{a}$ Initial anolyte, tap water; initial catholyte, $400 \mathrm{ppm}$ uranium in $0.025 \mathrm{MEDTA}$ solution.

${ }^{b} \mathrm{~A} 138-\mathrm{mL}$ volume of distilled water was added to the catholyte; $100 \mathrm{~mL}$ of tap water was added to the anolyte between measurements.

${ }^{c} \mathrm{~A} 58-\mathrm{mL}$ volume of distilled water was added to the catholyte; $29 \mathrm{~mL}$ of tap water was added to the anolyte between measurements.

${ }^{d} \mathrm{~A} 47-\mathrm{mL}$ volume of distilled water was added to the catholyte; $35 \mathrm{~mL}$ of tap water was added to the anolyte between measurements.

${ }^{e}$ Sample was acidified and then filtered.

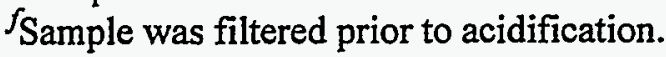


troublesome. Further testing is needed to devise lixiviant solutions that are successful at solubilizing these species and do not interact significantly with concrete.

\subsubsection{Magnetic Resonance Imaging}

The penetration of the liquid/lixiviant into a "dry" pore of concrete can be observed in situ and nondestructively by magnetic resonance imaging (MRI). Currently, there is only one reported study on the use of MRI to image water in concrete (Kaufman et al. 1992). This technique allows the measurement of the concentration of protons in the concrete, providing a three-dimensional image. Using MRI, the concrete can be sliced into various sections and in numerous orientations to obtain the best possible analysis of the data. MRI can also be used to determine the rate of penetration of lixiviant and the average diffusion of water in the pores of the concrete. Furthermore, if the lixiviant contains a compound that is susceptible to proton nuclear magnetic resonance (NMR), then the pore diffusion of that compound and the extent of migration of that molecule into the pore can be determined. Such data would be extremely valuable in determining the removal of contaminants by chemical extraction, which relies on the shallow penetration of their lixiviant solution into the pores of the concrete.

Several tests have been performed to determine whether MRI could be used to obtain threedimensional images of water trapped in the pores of concrete. Figure 3.10 shows the proton NMR and MRI of water in a concrete core that is $1.91 \mathrm{~cm}$ in diameter and $5 \mathrm{~cm}$ high. The NMR spectrum shows a splitting of the proton peaks when water is in the pores of the concrete. Ordinarily, there is one central peak at $0 \mathrm{ppm}$ for the protons in water. These results show that MRI can be used as a nondestructive technique for determining the penetration of lixiviants into concrete. Additional tests are under way to improve the resolution and acquisition time of the MRI of concrete. Earlier experiments required hours to acquire a good image; however, the acquisition time has now been reduced to less than $15 \mathrm{~min}$. 

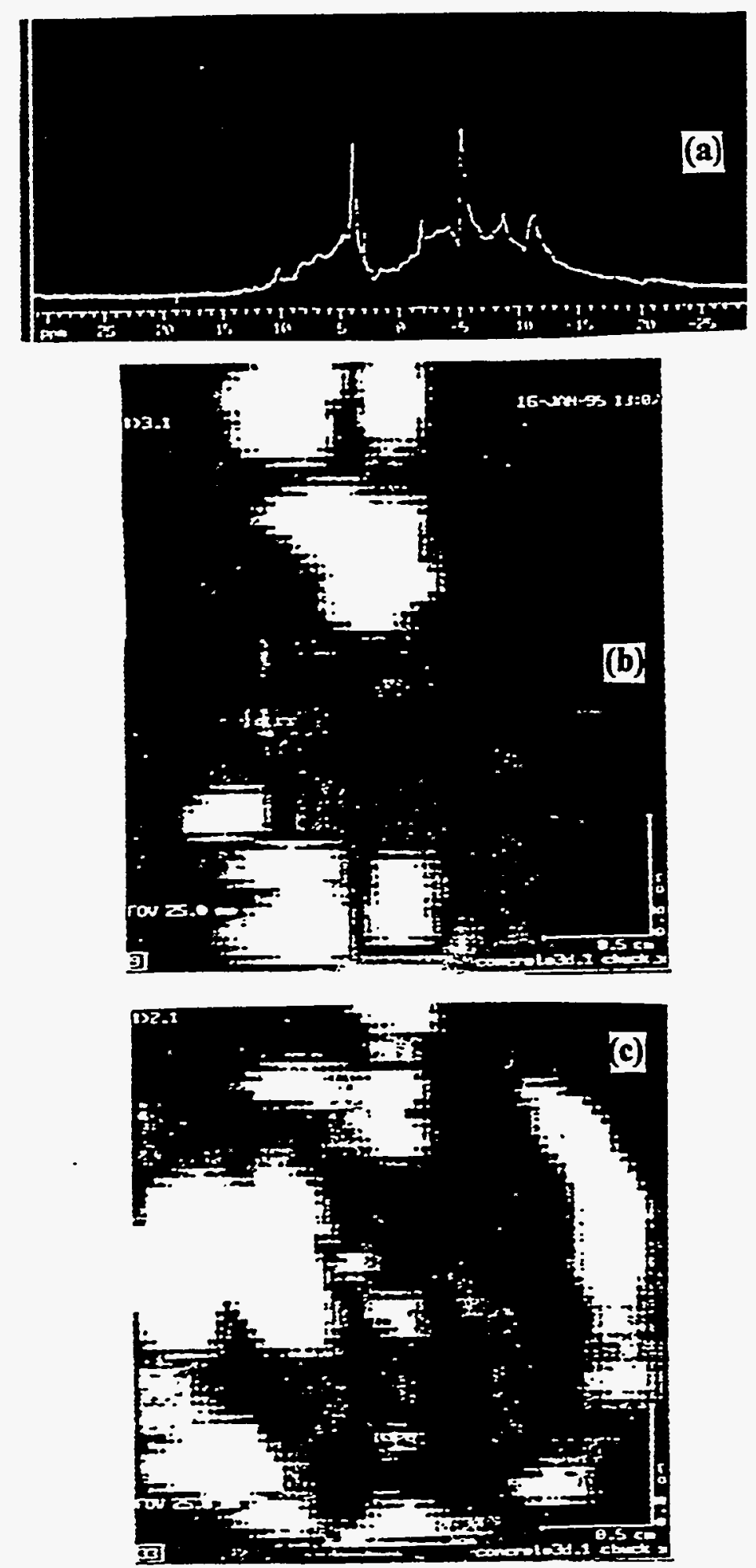

Fig. 3.10. Results of tests to obtain three-dimensional images of water trapped in a 1.91-cmdiam, 5-cm-high concrete core: (a) proton NMR spectrum of water in pores, $(b)$ MRI of axial slice of concrete core, and (c) MRI of radial slice of concrete core. 


\subsubsection{Zeta Potential Measurements}

Zeta potential is very important in computing the convective transport of liquid in a pore by electroosmosis (Evans and Wennerstrom 1994). The zeta potential of crushed concrete was determined and compared with literature values for portland cement (Nagele and Schneider 1987, 1988, 1989a, 1989b; Nagele 1985, 1987, 1991) and hardened cement (Nagele 1991).

\subsubsection{Experimental Procedure}

In the electrophoretic technique for measuring zeta potential, a suspension of colloidal particles is prepared and placed in a transparent cell. A dc voltage is applied to the cell that causes the particles to flow toward either the cathode or the anode, depending on their charge. A microscope is used to track the time required for particles to travel a given distance.

For the experiments dealing with concrete concentration, the samples were prepared by crushing the concrete and sieving the powder to obtain particles that were $<50 \mu \mathrm{m}$. Various quantities of crushed concrete were added to distilled water or to an aqueous solution that contained between 0.0001 and $0.01 \mathrm{MNaOH}$ or between 0.001 and $0.1 \mathrm{MNaCl}$. Immediately after preparation, each sample was placed in a sonicator for $120 \mathrm{~s}$. The $\mathrm{pH}$ was measured, and then the sample was placed in a centrifuge for approximately $1 \mathrm{~min}$ to separate the concrete particles from the supernatant. The supernatant was used to prepare suspensions that contained not more than $200 \mathrm{mg}$ of concrete particles per liter. This sample was placed in a Riddick electrophoresis cell (G-T297) that was put in a Zeiss zeta meter to determine the electrophoretic mobility. An HP6653A power supply set at $0.1 \mathrm{~A}$ and $35 \mathrm{~V}$ was used as the primary power supply. The positive terminal of the power supply was connected to the molybdenum anode, which was placed in the sealed end of the electrophoresis cell. The negative terminal was attached to a platinum strip that was placed in the open end of the cell. A thermometer was placed in the open end of the cell to determine the temperature of the sample, which was necessary for temperature correction of the measurements. The times required for 
ten particles to travel a distance of $160 \mu \mathrm{m}$, set by an ocular micrometer provided by the microscope manufacturer, were averaged to obtain one tracking value at a particular voltage. The particle velocity was computed by dividing the distance traveled by the average tracking time, and the electrophoretic mobility was computed from the particle velocity and the applied electric field strength. The HelmholtzSmoluchowski equation (Evans and Wennerstromm 1994) was used to calculate the zeta potential, $\zeta$.

\subsubsection{Results}

Nagele (1985, 1986, 1987, and 1991) and Nagele and Schneider (1987 and 1989) previously observed a variation of the zeta potential with time. They attributed the transient behavior of the zeta potential to changes in surface area and composition due to reactions between cement and water and to the fact that ions released from the cement result in a variation in the composition of the electrical double layer on the concrete. The crushed concrete that was used in our studies shows a similar behavior to the results of Nagele (1987). Figure 3.11 shows that, for cases of $0.0001 M$ and $0.01 M \mathrm{NaOH}, \zeta$ increases and reaches a constant value within $40 \mathrm{~min}$. The zeta potential values are negative and range from $-3 \dot{5}$ to $-17 \mathrm{mV}$ as $[\mathrm{NaOH}]$ varies from 0.1 to $0.001 M$.

Figure 3.12 shows that the $\mathrm{NaCl}$ concentration has little effect, in comparison to the effect of $[\mathrm{NaOH}]$, on $\zeta$ at $\mathrm{pH}=12$. There is not a clear trend in the time variation of the zeta potential for this system. The zeta potential increases from -35 to $-28 \mathrm{mV}$ as the concentration of $\mathrm{NaCl}$ increases from 0.001 to $0.1 \mathrm{M}$. The increase in $\zeta$ with increasing $[\mathrm{NaCl}]$ is in accord with findings of Nagele and Schneider (1987), who stated that $\mathrm{Na}^{+}$is a potential-determining ion for cement.

The effect of the $[\mathrm{NaOH}]$ on $\zeta$ is shown in Fig. 3.13. The zeta potential decreases rapidly from $-19 \mathrm{mV}$ to a value of $-34 \mathrm{mV}$ as $[\mathrm{NaOH}]$ varies from 0 to $0.01 M$. The zeta potential remains essentially constant as $[\mathrm{NaOH}]$ is varied from 0.01 to $0.1 M$. Figure 3.14 shows the variation of zeta potential as a function of $\mathrm{pH}$. 


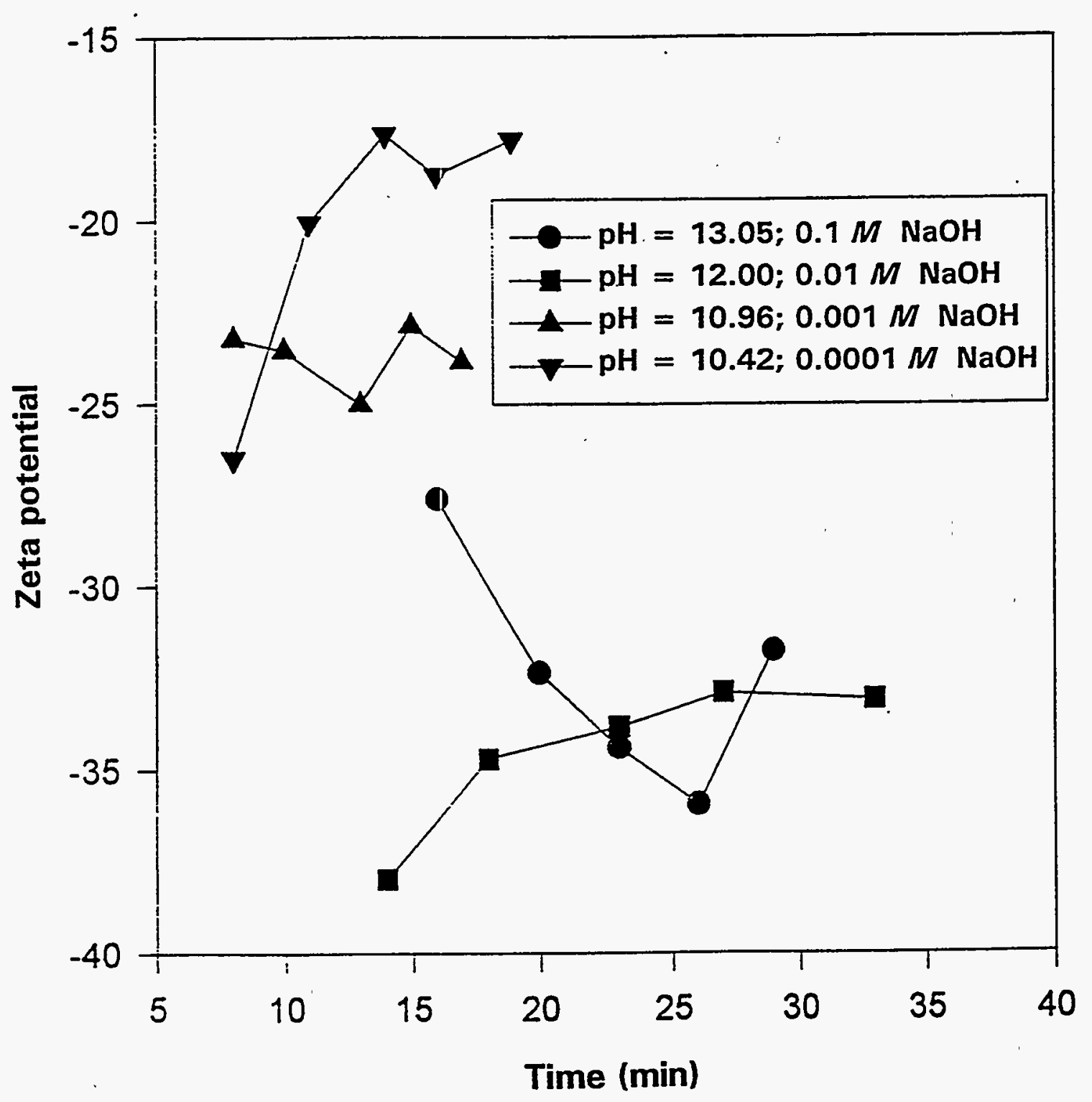

Fig. 3.11. Effects of $\mathrm{pH}$ and $[\mathrm{NaOH}]$ on dynamic change in zeta potential of concrete (0.2 mg concrete/mL solution). 


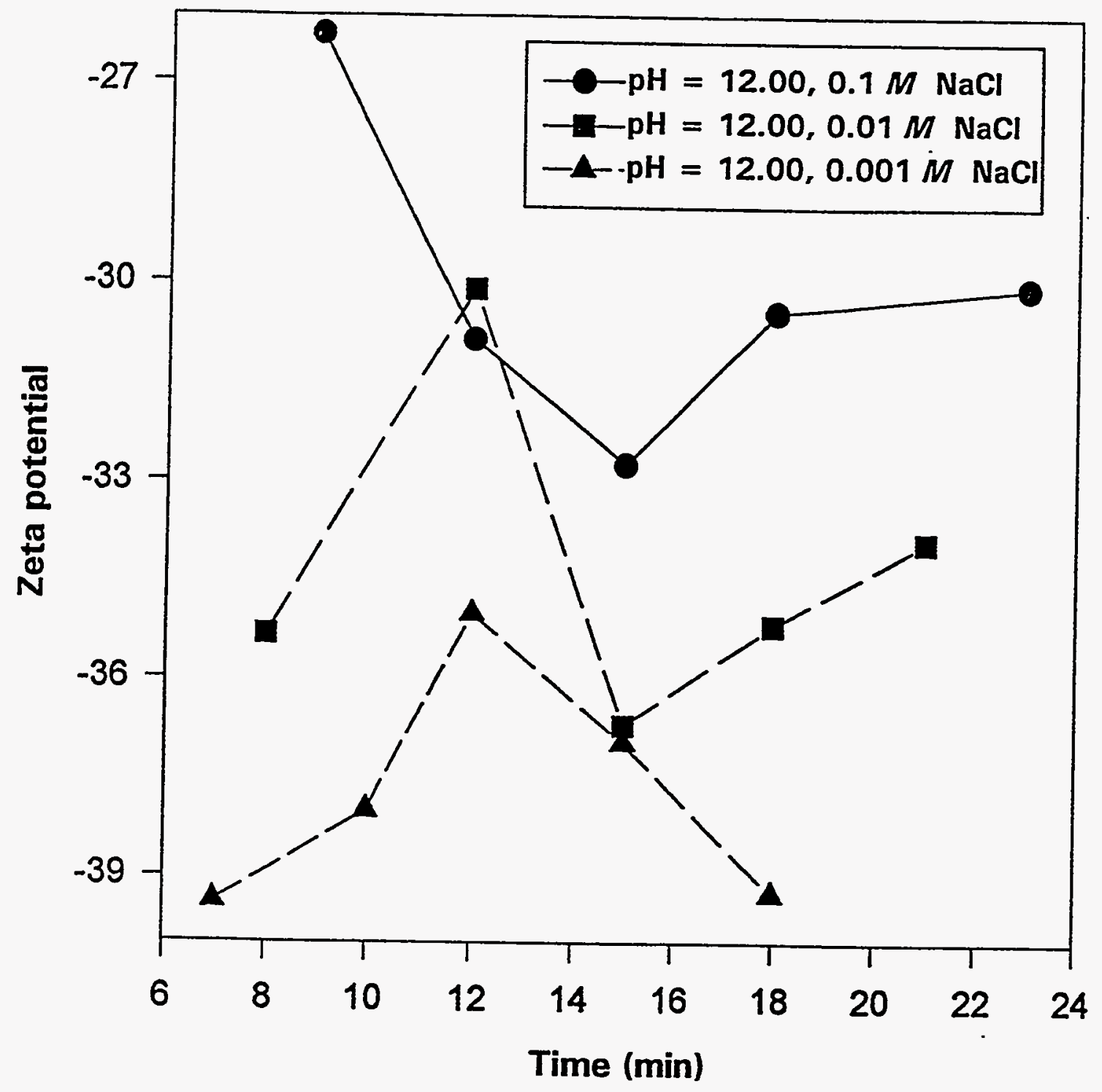

Fig. 3.12. Effects of $\mathrm{pH}$ and $[\mathrm{NaOH}]$ on dynamic change in zeta potential of concrete $(0.2 \mathrm{mg}$ concrete/mL solution). 




Fig. 3.13. Effect of [NaOH] on zeta potential of concrete. 


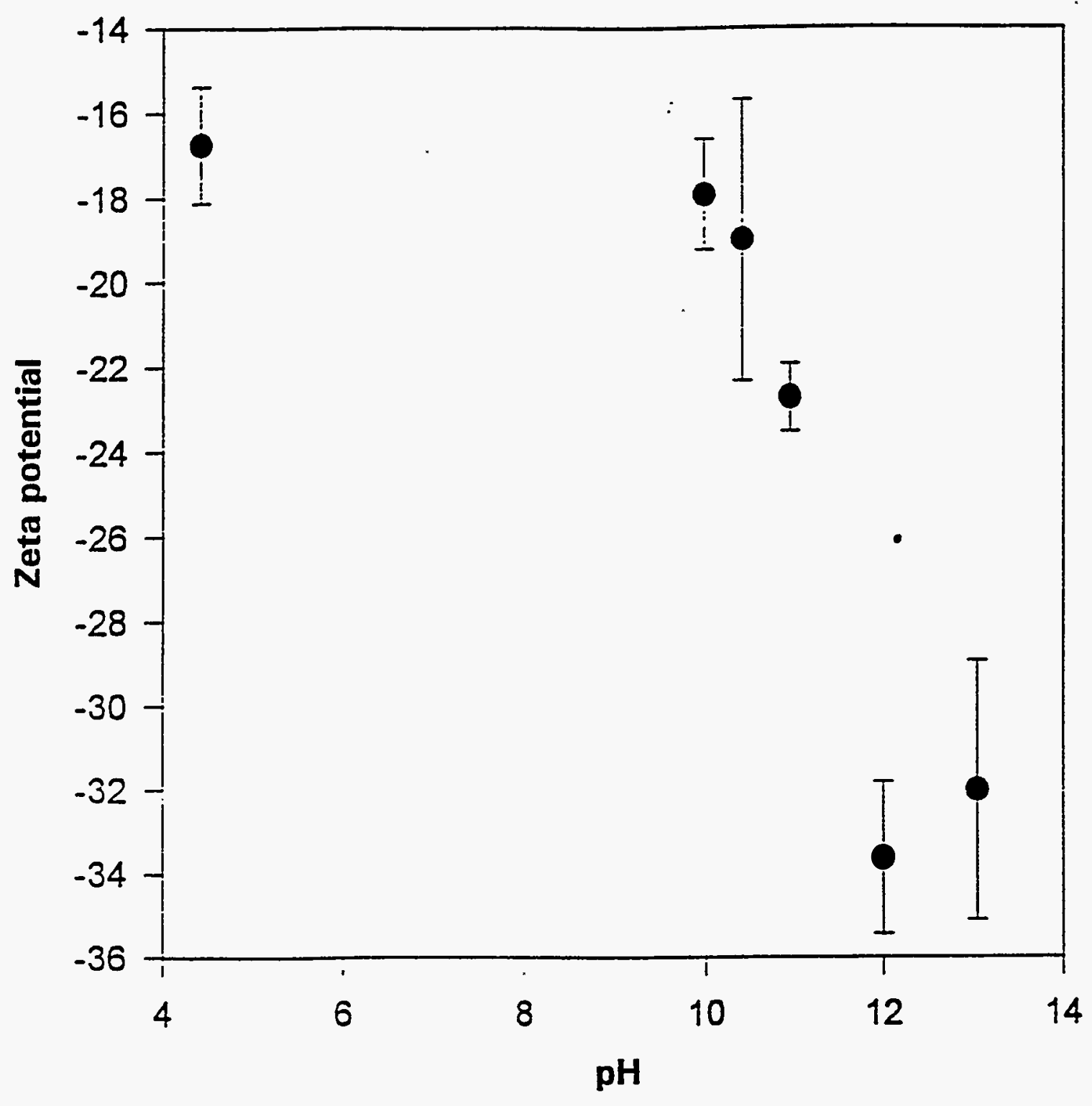

Fig. 3.14. Effect of $\mathrm{pH}$ on zeta potential of concrete ( $0.2 \mathrm{mg}$ concrete/mL solution). 
Figure 3.15 illustrates the effect of the concentration of crushed concrete on the zeta potential. Varying amounts of concrete were added to $0.01 M \mathrm{NaOH}$ solutions. The zeta potential increases asymptotically as the concentration of the concrete powder increases. This increase is attributed to the adsorption of potential-determining ions such as $\mathrm{Ca}^{2+}$ onto the surface of the concrete particles. Nagele and Schneider (1989b) saw a similar behavior with cement particles in the concentration range of 100 to 5000 $\mathrm{mg} / \mathrm{L}$.

Figure 3.16 shows how the electrical conductivity of the supernatant increases asymptotically as the concentration of concrete particles increases. The conductivity is a measure of the concentration of ions in the supernatant. The increases in the electrical conductivity and zeta potential values support the idea that the zeta potential increases with the concentration of concrete because of the presence of potentialdetermining ions.

The fact that concrete particles can have a wide range of zeta potentials has significant implications in the use of electroosmosis to remove contaminants from concrete. Electroosmotic transport is proportional to the zeta potential. Depending on the lixiviant used, the zeta potential of the concrete pore walls/particles can be either positive or negative; the value typically ranges between -40 and $20 \mathrm{mV}$.

The relative importance of electroosmosis in EK applications with concrete may be estimated by comparing the rates of transport of ions by electromigration and by electroosmosis. For ions and small, charged molecules, the ratio between transport by electromigration and electroosmosis is (Shapiro 1990)

$$
\lambda_{e}=0.0546 \frac{z_{i}}{|\zeta|}
$$

where

$\lambda_{\mathrm{e}}=$ ratio between transport by electromigration and electroosmosis,

$z_{i}=$ charge of ion of species $i$,

$\zeta=$ zeta potential, $\mathrm{V}$. 


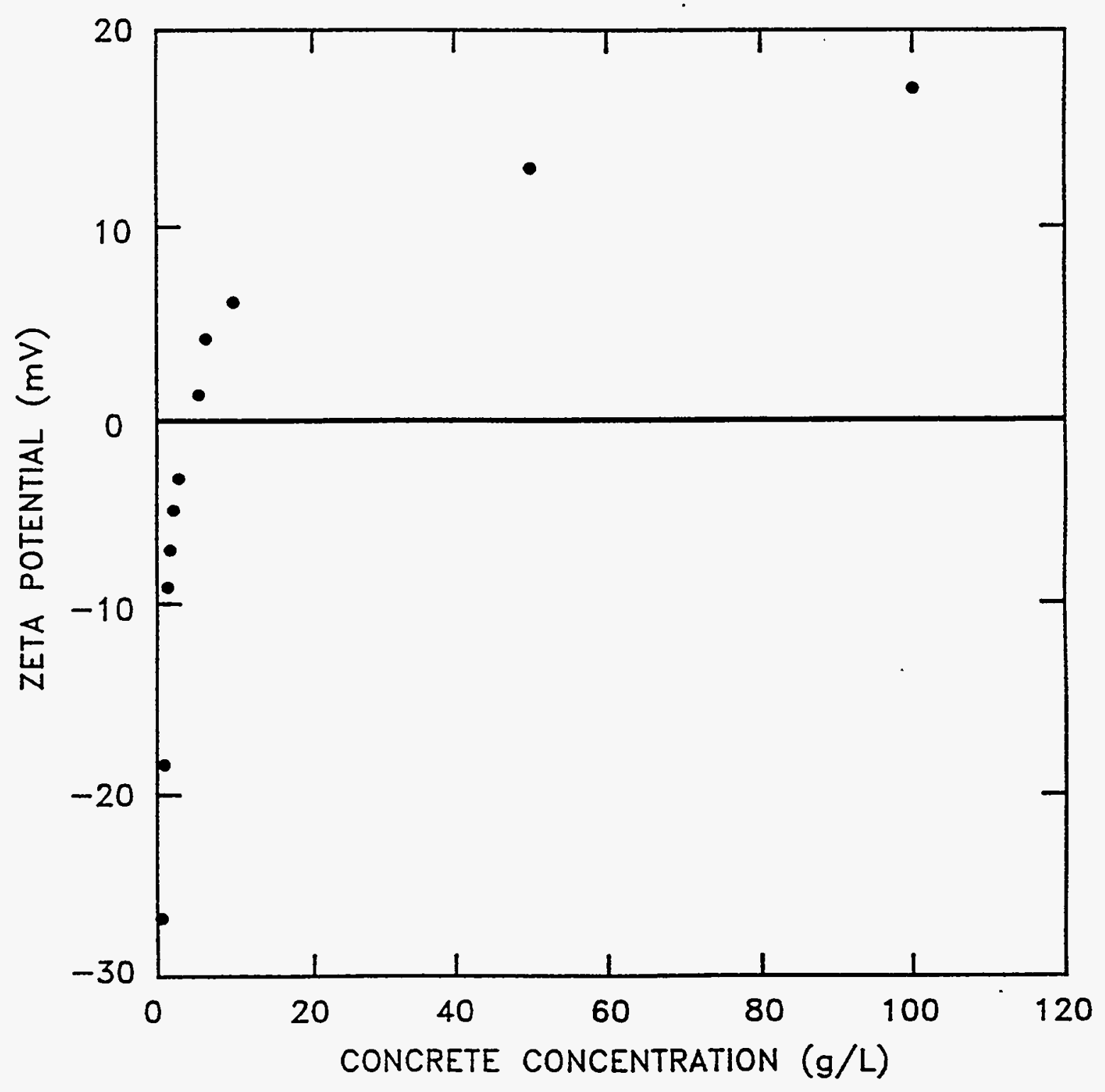

Fig. 3.15. Effect of concentration of concrete particles in suspension on zeta potential. 


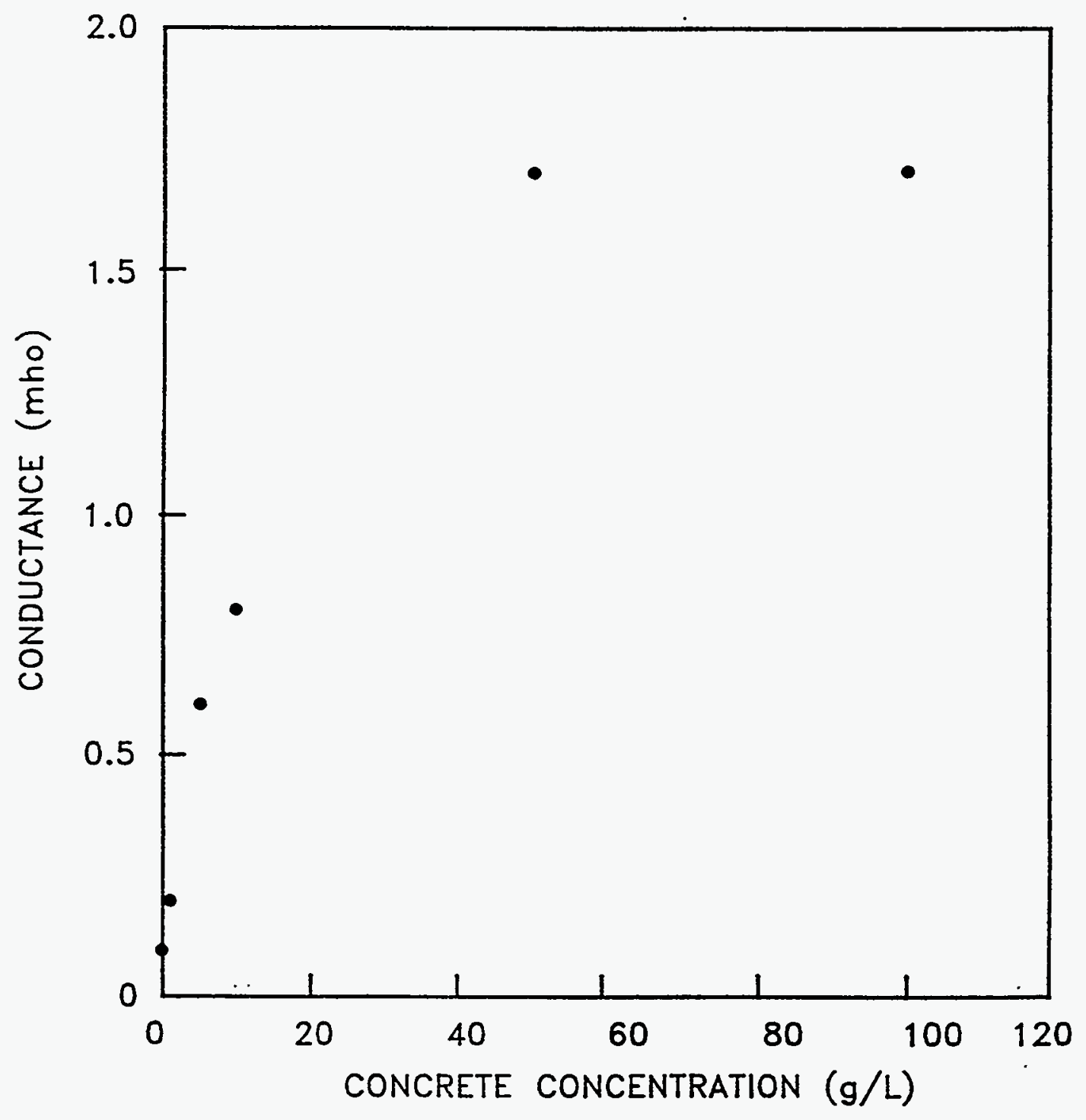

Fig. 3.16. Effect of concentration of concrete particles in suspension on electrical conductivity. 
This equation shows that for monovalent ions such as $\mathrm{Cs}^{+}, \lambda_{e}$ is greater than 1 only when the absolute value of $\zeta$ is less than $54.6 \mathrm{mV}$. Thus, electromigration is most likely the dominant transport mechanism when EK is applied to concrete. It becomes even more dominant as the charge number on the ions increases.

\subsection{COMPUTATIONAL RESULTS}

\subsubsection{Liquid Penetration of Pores}

Before contaminants can be removed from concrete by EK, the "dry" pores in the concrete must be filled with lixiviant. Static computations were made to determine the penetration depth and rate of penetration of lixiviant into the pores of concrete. Additional static computations were also used to determine the effect of an electric field on the stability of the liquid in the pore.

Capillary forces cause liquid to penetrate pores. A schematic of the system used for static computation of the filling of an ideal vertical pore is shown in Fig. 3.17. The pore configuration is closed at one end, representing a worst-case scenario for the penetration of a liquid into an idealized cylindrical pore. In the absence of an electric field, the force balance on the liquid in the pore is

$$
P_{0}+\frac{2 \sigma \cos \theta}{r}+\rho g\left(h_{2}+h_{1}\right)=P_{0}\left(\frac{h_{\text {pore }}}{h_{\text {pore }}-h_{2}}\right) \text {, }
$$

where

$P_{\mathrm{o}}=$ atmospheric pressure,

$\sigma=$ surface tension of liquid,

$r=$ radius of pore,

$\mathrm{g}=$ acceleration due to gravity,

$\rho$ = density of liquid,

$h_{2}=$ liquid penetration depth,

$h_{\text {pore }}=$ total pore depth,

$\theta=$ contact angle between liquid and pore wall. 


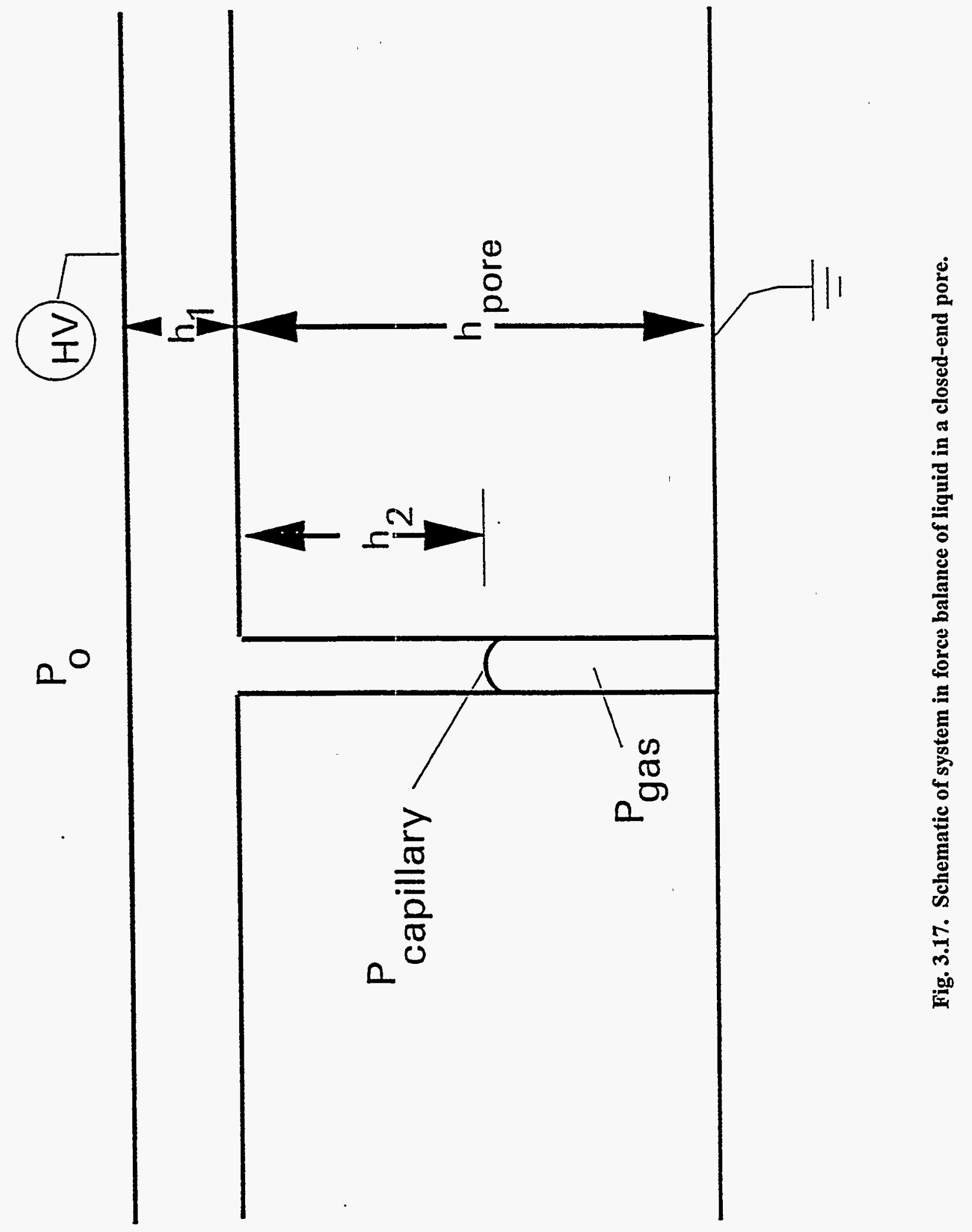


Figure 3.18 shows a comparison between the forces acting on liquid in a pore as a function of pore size when the contact angle is $60^{\circ}$ and the total pore depth is $1.27 \mathrm{~cm}$. Relative to atmospheric pressure, capillary pressures are high for small pores $(r<0.1 \mu \mathrm{m})$; consequently, the liquid fills almost the entire pore in this case. Therefore, the pressure of the compressed gas in the small pores approaches the capillary pressure and becomes several orders of magnitude higher than atmospheric pressure. Figure 3.19 shows that there is negligible penetration of liquid in "closed-end" pores (see Fig. 3.17) with radii larger than $10 \mu \mathrm{m}$. Thus, the lixiviant solution is expected to penetrate the concrete pores to a greater depth as the pore diameter is decreased.

Electrohydrostatic computations were performed to determine the voltage needed to cause the liquid interface in a pore to become unstable. As the interface becomes unstable, the capability of surface tension to hold the liquid meniscus in the pore is disturbed and small water droplets may be formed, falling to the bottom of the pore. Thus, an electric field could be used to fully wet pores with lixiviant solution. In the simulations, it was assumed that the contact lines (i.e., the boundaries of the liquid, air, and solid phases) are fixed. This assumption leads to a prediction of a higher critical voltage requirement than if the contact lines were allowed to move with a fixed contact angle. The governing equations for the electrohydrostatic computations are the augmented Young-Laplace equation for the meniscus force balance and the Laplace equation for the electrical potential. The augmented Young-Laplace equation, including electrical field effects, may be written in dimensionless form as

$$
-2 \mathcal{H}=K+G z-P_{\text {gas }}+N_{e} E_{n}^{2}
$$

where $\mathcal{H}$ is the local mean curvature of the gas-liquid interface, $K$ is the reference pressure, $G$ is the gravitational Bond number (signifying the relative magnitude of gravitational to surface forces), $z$ is the 


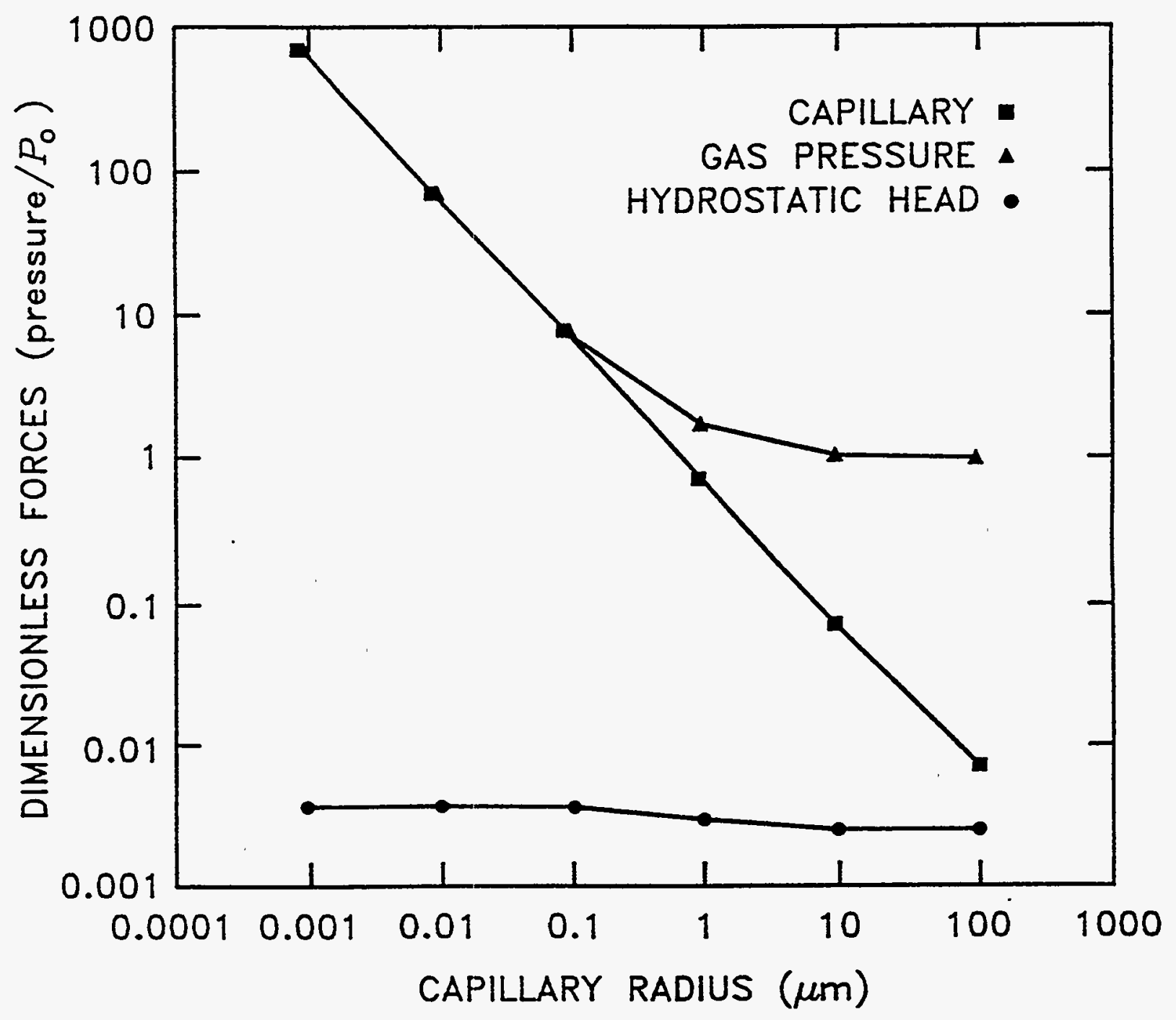

Fig. 3.18. Comparison between forces acting on liquid in a pore. 


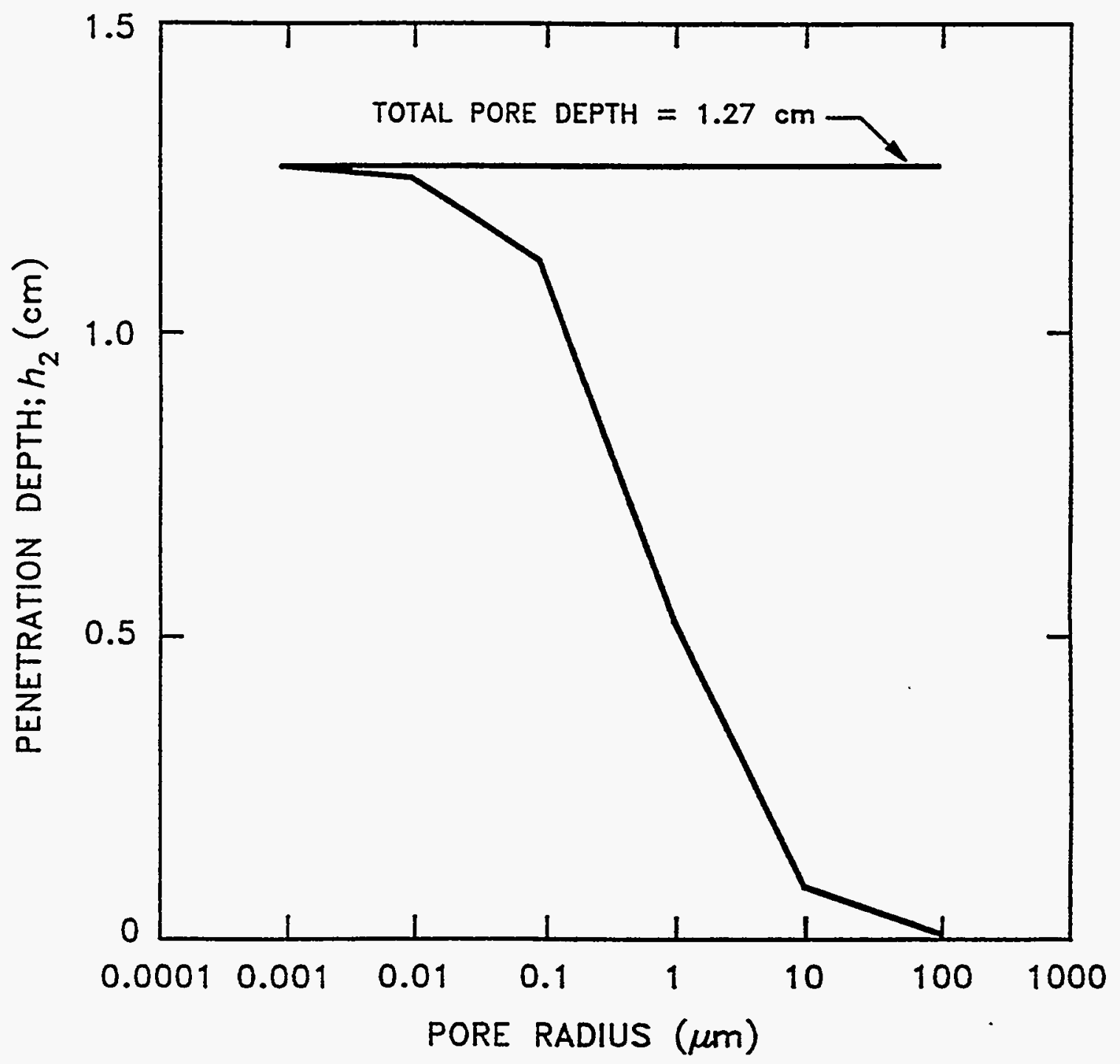

Fig. 3.19. Penetration of cylindrical closed-end pores. 
distance measured in the direction of gravity, $P_{\text {gos }}$ is the pressure of the gas in the closed-end pore, $N_{c}$ is the electrical Bond number (signifying the relative magnitude of electrical to surface forces), and $E_{n}$ is the normal component of the electrical field at the gas-liquid interface. A boundary integral representation of the Laplace equation is

$$
c(\underline{r}) U(\underline{r})+\int_{\partial V} U\left(\underline{r}^{\prime}\right) \frac{\partial G}{\partial n}\left(\underline{r}, \underline{r}^{\prime}\right) d S=\int_{\partial V^{\prime}} \frac{\partial U}{\partial n}\left(\underline{r}^{\prime}\right) G\left(\underline{r}, \underline{r}^{\prime}\right) d S,
$$

where $c$ is a constant depending on position, $U$ is the electrical potential, $\underline{r}$ and $\underline{r}^{\prime}$ are position vectors of points in the solution system, and $n$ is the unit normal to the surface, $S$. These two equations were solved simultaneously using the finite-element and boundary-element methods, respectively (Harris and Basaran 1993).

Equations (3.16) and (3.17) have been solved to yield the applied voltage that is necessary to cause the liquid interface in a pore to become unstable. This value represents the voltage necessary to cause the liquid to penetrate further into the pore. Some typical results are shown in Table 3.10. Critical potentials of approximately $10 \mathrm{kV}$ are required to enhance penetration of a liquid in $10-\mu \mathrm{m}$ pores. However, for pores smaller than $0.1 \mu \mathrm{m}$, potentials of less than $100 \mathrm{~V}$ are required to cause the liquid to migrate further into the pore. Because most of these smaller pores are filled with liquid by capillary forces in the absence of electrical forces, it is likely that smaller pores will be completely filled by liquid.

These calculations indicate that the voltage required to initiate the EK process may be as high as 1000 to $1500 \mathrm{~V}$. As the lixiviant penetrates the first few millimeters of concrete, the electrical path rapidly increases in conductivity and the required potential should decrease to $100 \mathrm{~V}$ or less. These results are useful for estimating and optimizing the equipment and power requirements during EK decontamination. 
Table 3.10. Results of electrohydrostatic computations

$\left(h_{\text {pore }}=1.27 \mathrm{~cm}\right)$

\begin{tabular}{ccc}
\hline Pore radius & Critical potential & Pressure due to electric stress \\
$(\mu \mathrm{m})$ & $(\mathrm{V})$ & $($ dyn $/ \mathrm{cm})$ \\
\hline 10.0 & 9070 & $1.17 \times 10^{6}$ \\
0.001 & 28.9 & $9.79 \times 10^{8}$ \\
\hline
\end{tabular}

\subsubsection{Contaminant Transport by EK}

Modeling efforts were focused on the development of a one-dimensional dynamic model of the EK. The model will be useful for estimating power requirements and the rate of contaminant transport during the application of EK to concrete.

\subsubsection{Equation Development}

One of the governing equations for EK is the equation of continuity, commonly called the convective diffusion equation. When parallel-plate electrodes are used, electrokinetic decontamination can be modeled as a one-dimensional problem. The resulting expression for the convective diffusion equation is given as (Shapiro 1990)

$$
\epsilon \frac{\partial c_{i}}{\partial t}=\epsilon \frac{D_{i} \partial^{2} c_{i}}{\tau^{2}} \frac{\epsilon x^{2}}{\tau^{2}} \frac{\partial\left[c_{i}\left(u_{e, i}+u_{c}\right)\right]}{\partial x}-(1-\epsilon) \rho_{b} \frac{\partial q_{i}}{\partial t}+R_{i}
$$

where

$$
\begin{aligned}
& \epsilon=\text { porosity of concrete; } \\
& c_{i}=\text { concentration of component } i \text { in the concrete pore; } \\
& t=\text { time; } \\
& \tau=\text { tortuosity; }
\end{aligned}
$$




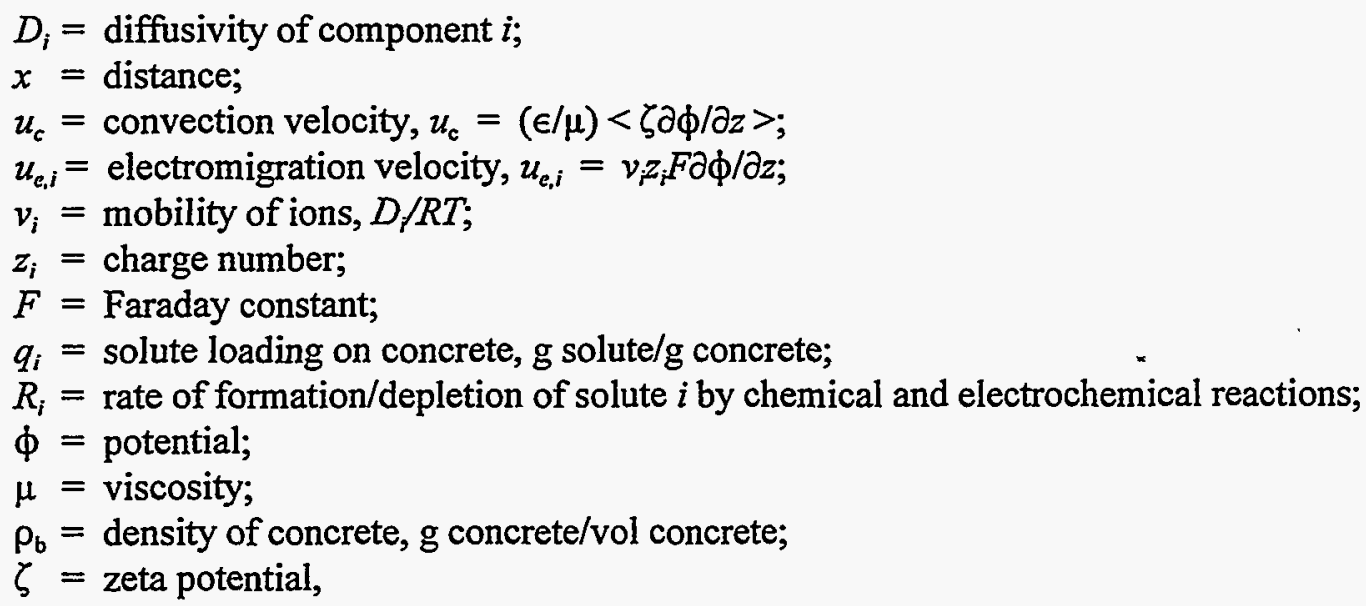

To simplify matters in the application of the solid-phase material balance, it is often possible to replace the adsorption/desorption kinetics with an overall linear rate expression (Santacesaria et al. 1982; Carta 1986). Then the adsorbed-phase mass balance for component $i$ is:

$$
\rho_{b} \frac{\partial q_{i}}{\partial t}=k_{i}^{\prime}\left(c_{i}-c_{i}^{*}\right)
$$

This expression assumes that the mass transfer resistances to the liquid film, surface diffusion, and internal pore diffusion can be "lumped" into a single rate constant. The overall mass transfer constant, $k_{i}^{\prime}$, can be estimated from the physical characteristics of the concrete and the diffusivities of the various solutes. An expression for equilibrium concentration, $c_{i}^{*}$, is required to solve Eq. (3.14). Such an expression is obtained by fitting experimental data to various adsorption isotherm models.

The following one-dimensional electrical current density expression is the second equation that governs the electrokinetic decontamination of concrete:

$$
i_{x}=\frac{1}{\tau^{2}}\left[-\kappa(x) \frac{\partial \phi}{\partial x}-F \sum_{i=1}^{m} z_{i} D_{i} \frac{\partial c_{i}}{\partial x}\right]
$$


It is assumed that the material conductivity is comprised of two components, surface conductivity and solution conductivity, added in parallel such that $\kappa(x)$ is the effective conductivity:

$$
\kappa(x)=F^{2} \sum_{i} z_{i}^{2} v_{i} c_{i}+\kappa_{\text {surface }}
$$

The surface conductivity must be measured experimentally.

In this work, the ions are assumed to be fully dissociated in the liquid phase. The law of electroneutrality applies and is incorporated in the model. Equations (3.13), (3.14), and (3.15) are expressed in dimensionless form as follows:

$$
\begin{gathered}
\frac{\partial \bar{c}_{i}}{\partial \bar{t}}=\alpha \frac{\partial^{2} \bar{c}_{i}}{\partial \bar{x}^{2}}+\beta\left[\frac{\partial \bar{c}_{i}}{\partial \bar{x}} \frac{\partial \bar{\phi}}{\partial \bar{x}}+\overline{c_{i}} \frac{\partial \bar{\phi}^{2}}{\partial \bar{x}^{2}}\right]-P e\left(\frac{\partial \bar{\phi}}{\partial \bar{x}}\right) \frac{\partial \bar{c}_{i}}{\partial \bar{x}}+\frac{\partial \bar{q}_{i}}{\partial \bar{t}}+D_{i} \bar{R}_{i}, \\
\frac{d \bar{q}}{d t}=\frac{k^{\prime} L^{2} \rho_{p}(1-\epsilon)}{\rho_{p} D_{i} \epsilon}\left(\bar{c}-\bar{c}^{*}\right), \\
\bar{i}_{x}=-\left[\sum_{i} \Lambda_{i}^{(1)} \overline{c_{i}}+\sum_{i} \Lambda_{i}^{(2)} \frac{\partial \overline{c_{i}}}{\partial \bar{x}}\right],
\end{gathered}
$$

where

$\bar{c}_{j}=$ dimensionless concentration of component $i, c_{i} / c_{\text {rej }}$

$\vec{c}_{1}=$ dimensionless equilibrium concentration of component $i, c_{i}^{*} / c_{r e j} ;$

$c_{\text {ref }}=$ reference concentration;

$\bar{t}=$ dimensionless time, $t D_{t} / L^{2}$;

$D_{l}=$ diffusion coefficient of reference species;

$L \quad=$ thickness of concrete slab;

$x=$ dimensionless axial distance, $x / L$;

$\Phi=$ scaled electrical potential, $\phi / \phi_{0}$;

$\phi_{0}=$ reference potential;

$\bar{R}_{i} \quad=$ scaled reaction rate, $R_{i} / R^{0}$;

$R^{0} \quad=$ reference reaction rate; 


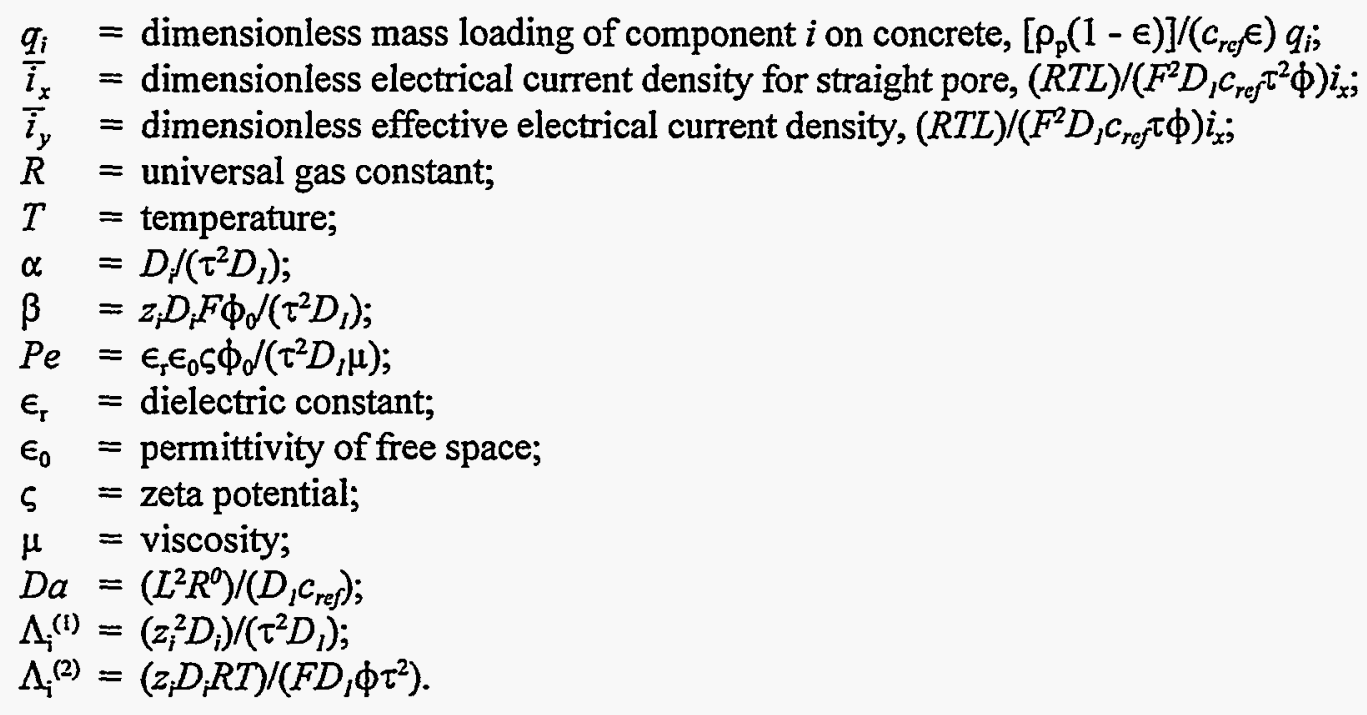

Two additional sets of equations are required to model the electrokinetic experiment. Mass balances must be done for the vessels containing the anodes and cathodes. If the vessels are stirred, the dimensionless form of the governing equation is given below:

$$
\frac{d \bar{c}_{i, \pm}}{d \bar{t}}=( \pm) A_{c}\left[\beta \frac{d \bar{\Phi}}{d \bar{z}}-\operatorname{Pe}\left(\frac{\partial \bar{\phi}}{\partial \bar{z}}\right)\right] \bar{c}_{i}
$$

where

$$
\begin{aligned}
& A_{c}=\text { dimensionless area, } \tau\left(\epsilon \pi L d^{2}\right) /\left(4 V_{\text {lank }}\right), \\
& d=\text { diameter of the concrete disk, } \\
& ( \pm)=+1 \text { for vessel containing the anode and }-1 \text { for vessel containing the cathode, } \\
& c_{i, \pm}=\text { molar concentration of species } i \text { in vessel containing the anode }(+) \text { and cathode }(-), \\
& V_{\text {tank }}=\text { volume of vessel containing the anode or cathode. }
\end{aligned}
$$

Boundary and initial conditions are used to approximate the state of the experimental system. The general initial and boundary conditions are as follows:

in the vessels containing the anode and cathode:

$$
\begin{aligned}
& c_{i,+}(0)=c_{i,+}^{0} \\
& c_{i,-}(0)=c_{i,-}^{0}
\end{aligned}
$$


in the concrete slab:

$$
\begin{aligned}
& c_{i}(0, x)=c_{i}^{0}(x) \text { and } q_{i}(0, x)=q_{i}^{0}(x), \\
& c_{i}(t, 0)=c_{i,+} \text { when }\left(u_{e, i}-u_{c}\right)>0, \\
& c_{i}(t, x)=c_{i,-} \text { when }\left(u_{c, i}-u_{c}\right)<0 .
\end{aligned}
$$

Subject to the appropriate boundary conditions, Eqs. (3.17), (3.18), and (3.19) are solved by the orthogonal collocation method. Time integrations are performed by the Euler method.

\subsubsection{Simulations .}

Figure 3.20 shows a schematic of the electrokinetic computer experiment that was performed to determine if uranyl tricarbonate anion, $\mathrm{UO}_{2}\left(\mathrm{CO}_{3}\right)_{3}{ }^{4-}$, could be removed by electromigration. These simulations were also done to evaluate the effect of the number of collocation points in the numerical solution system on (1) the variation of $\left[\mathrm{UO}_{2}\left(\mathrm{CO}_{3}\right)_{3}{ }_{3}\right]$ in the vessels containing the anode and cathode and (2) the axial variation of $\left[\mathrm{UO}_{2}\left(\mathrm{CO}_{3}\right)_{3}{ }^{4-}\right]$ in the liquid phase in the concrete.

In these simulations, no uranium was present initially in the anolyte or the catholyte; the only source of uranium was the concrete pore solution. In addition, all uranium was present in a $\mathrm{UO}_{2}\left(\mathrm{CO}_{3}\right)_{3}{ }^{4}$ state, with no sorption or precipitation. The initial concentrations of the uranyl tricarbonate and $\mathrm{Ca}^{2+}$ in the liquid phase were $2.06 \times 10^{-4}$ and $0.008 \mathrm{M}$, respectively. The current density was $5 \mathrm{~A} / \mathrm{m}^{2}$, and the diffusion coefficient for all ions was assumed to be $1.0 \times 10^{-9} \mathrm{~m} / \mathrm{s}^{2}$.

The stability of the model and the suitability of the solution method were determined by varying the number of collocation points in the solution system. Figures 3.21 through 3.24 present the results for simulations using 12,22 , and 32 collocation points. Figure 3.21 shows little effect of the number of collocation points on $\left[\mathrm{UO}_{2}\left(\mathrm{CO}_{3}\right)_{3}\right]^{4}$ in the vessels containing the anode and cathode. Figures 3.22 through 3.24 show a greater effect of the number of collocation points on the variation of $\left[\mathrm{UO}_{2}\left(\mathrm{CO}_{3}\right)_{3}\right]^{4-}$ along the axial position in the concrete slab. With a few collocation points, the solution oscillates. The oscillations 


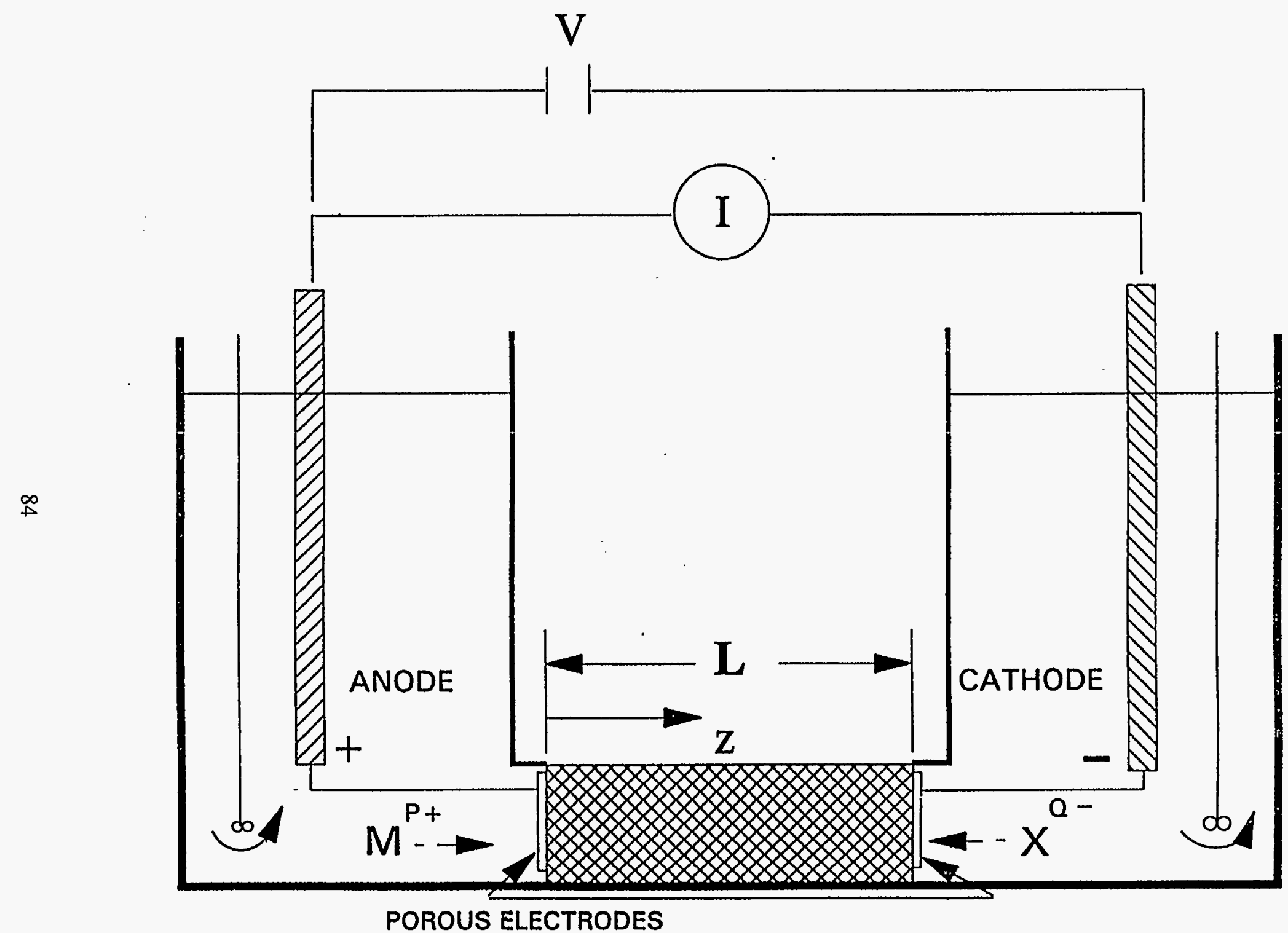

Fig. 3.20. Schematic of system used in the simulation of dynamic experiments. 


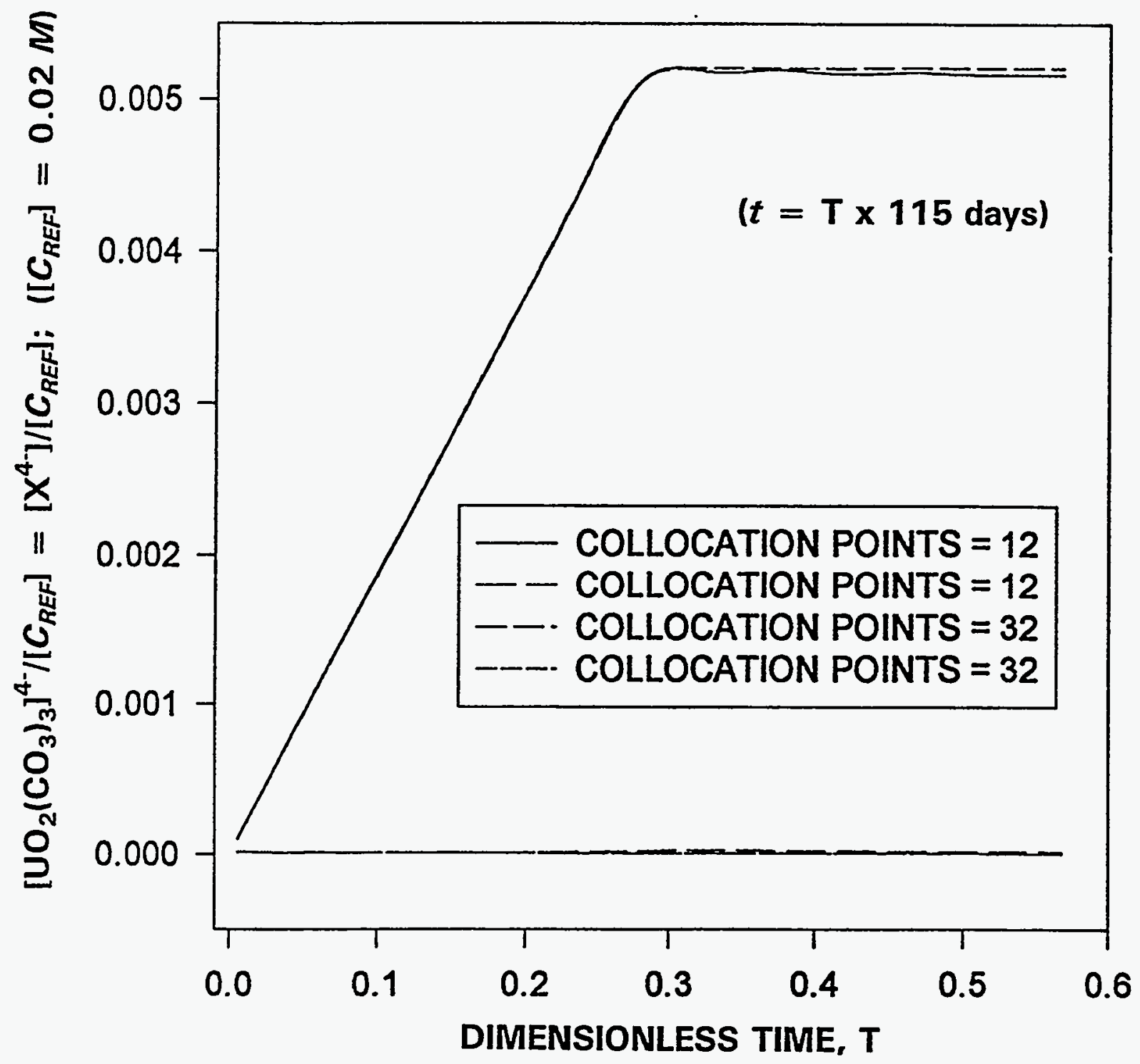

Fig. 3.21. Effect of number of collocation points on computed $\mathrm{UO}_{2}\left(\mathrm{CO}_{3}\right)_{2}{ }^{4-}$ concentrations in the anolyte and catholyte. $\left[\mathrm{Ca}^{2+}\right]_{+, c,-}=0.008 \mathrm{M} ;\left[\mathrm{UO}_{2}\left(\mathrm{CO}_{3}\right)_{3}{ }^{4-}\right]=2.06 \times 10^{-4} M ; D_{i}=1 \times 10^{-9} \mathrm{~m}^{2} / \mathrm{s}$; $i=5 \mathrm{~mA} / \mathrm{m}^{2} ; L=10 \mathrm{~cm} ; V_{1}=V_{2}=10 \mathrm{~cm}^{3} ; \tau=10$. 


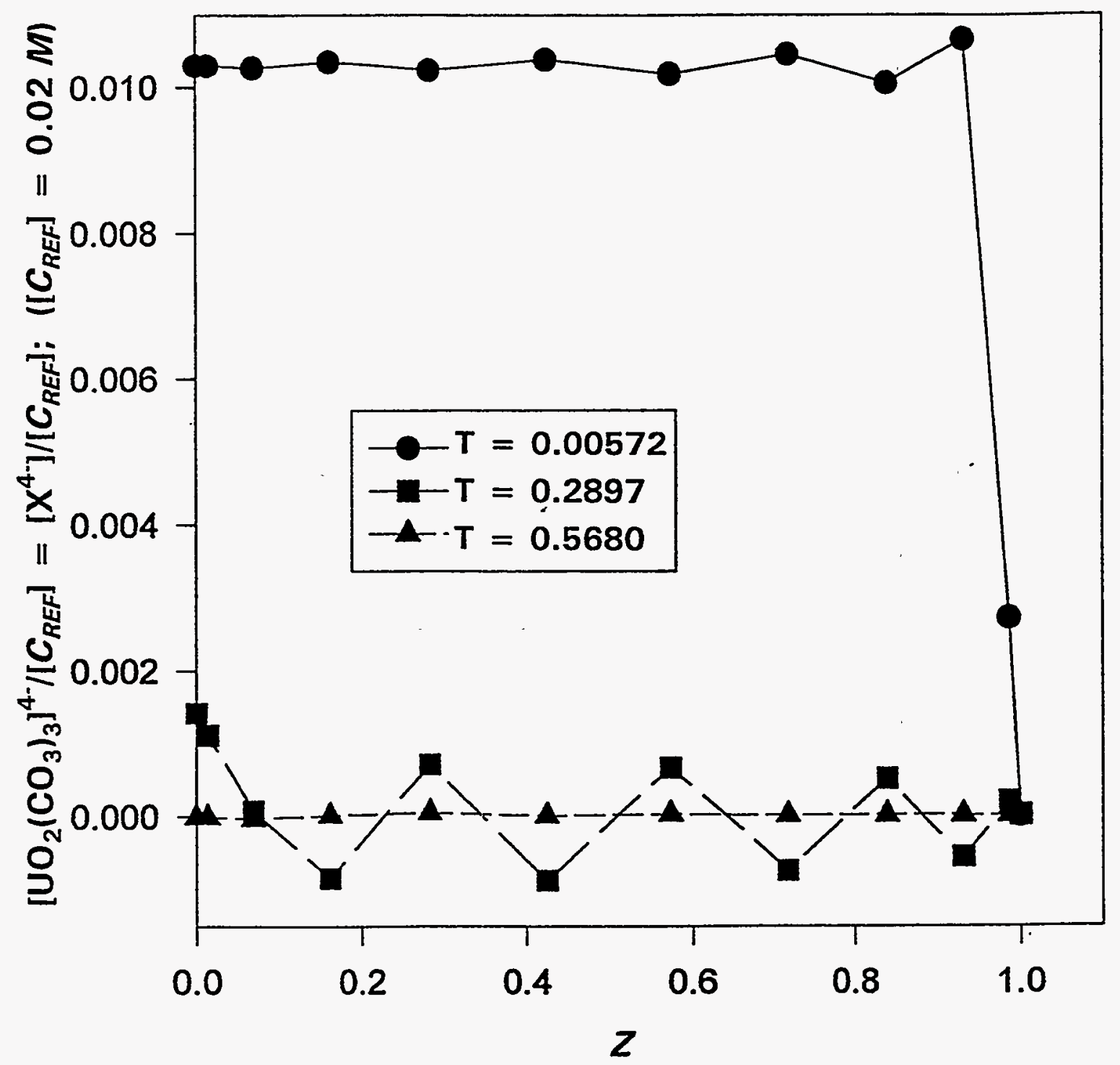

Fig. 3.22. Computed $\mathrm{UO}_{2}\left(\mathrm{CO}_{3}\right)_{2}{ }^{4}$ concentration profile in concrete for 12 collocation points. $\left[\mathrm{Ca}^{2+}\right]_{+, c_{-}}=0.008 M ;\left[\mathrm{UO}_{2}\left(\mathrm{CO}_{3}\right)_{3}{ }^{4}\right]=2.06 \times 10^{-4} M ; D_{i}=1 \times 10^{-9} \mathrm{~m}^{2} / \mathrm{s} ; i=5 \mathrm{~mA} / \mathrm{m}^{2} ; L=10 \mathrm{~cm} ; V_{1}=$ $V_{2}=100 \mathrm{~cm}^{3} ; \tau=10$. 


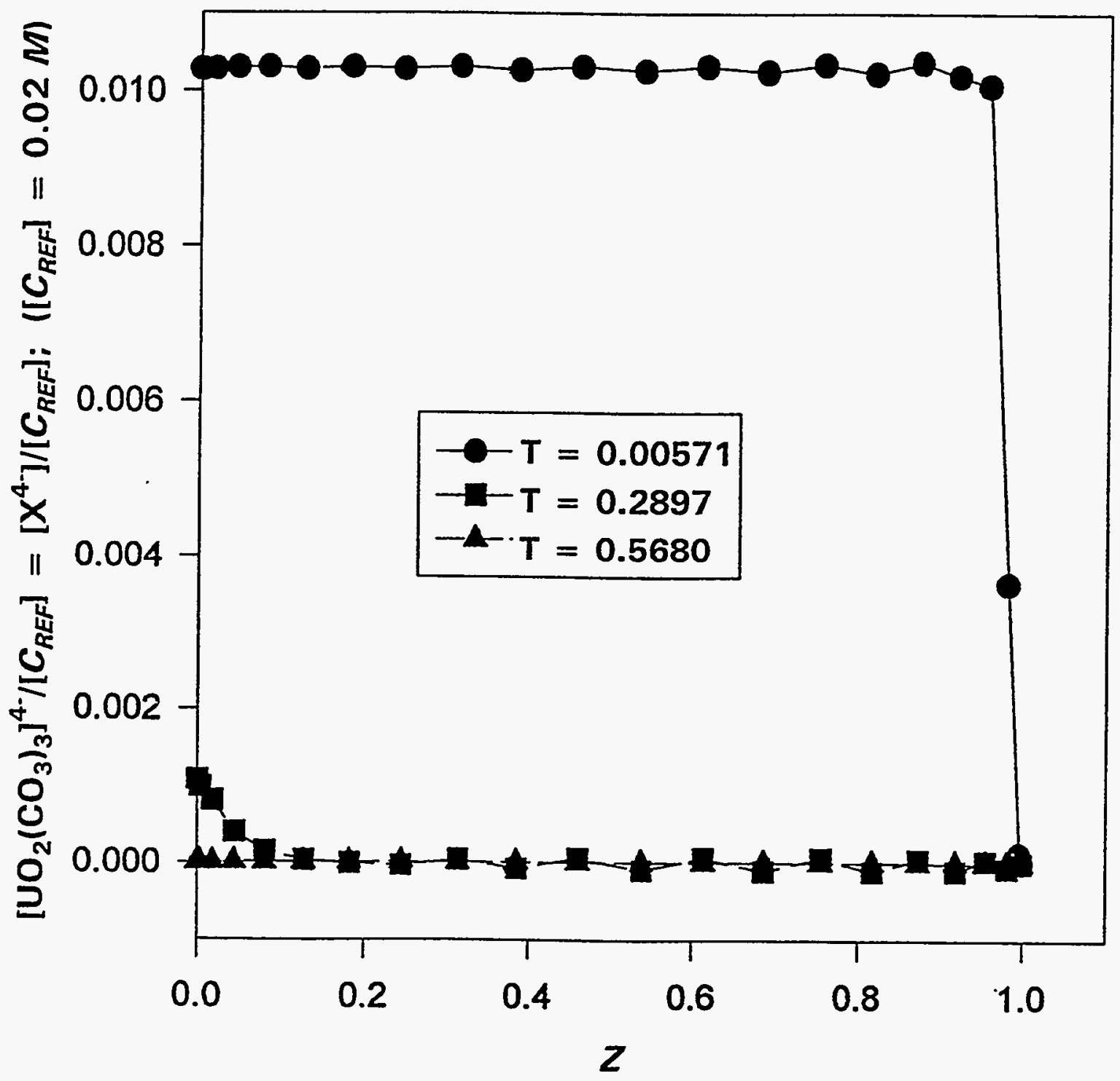

Fig. 3.23. Computed $\mathrm{UO}_{2}\left(\mathrm{CO}_{3}\right)_{2}{ }^{4}$ concentration profile in concrete for 22 collocation points. $\left[\mathrm{Ca}^{2+}\right]_{+, c_{-}}=0.008 \mathrm{M} ;\left[\mathrm{UO}_{2}\left(\mathrm{CO}_{3}\right)_{3}{ }^{4}\right]=2.06 \times 10^{-4} M ; D_{i}=1 \times 10^{-9} \mathrm{~m}^{2} / \mathrm{s} ; i=5 \mathrm{~mA} / \mathrm{m}^{2} ; L=10 \mathrm{~cm} ; V_{1}=$ $V_{2}=100 \mathrm{~cm}^{3} ; \tau=10$. 


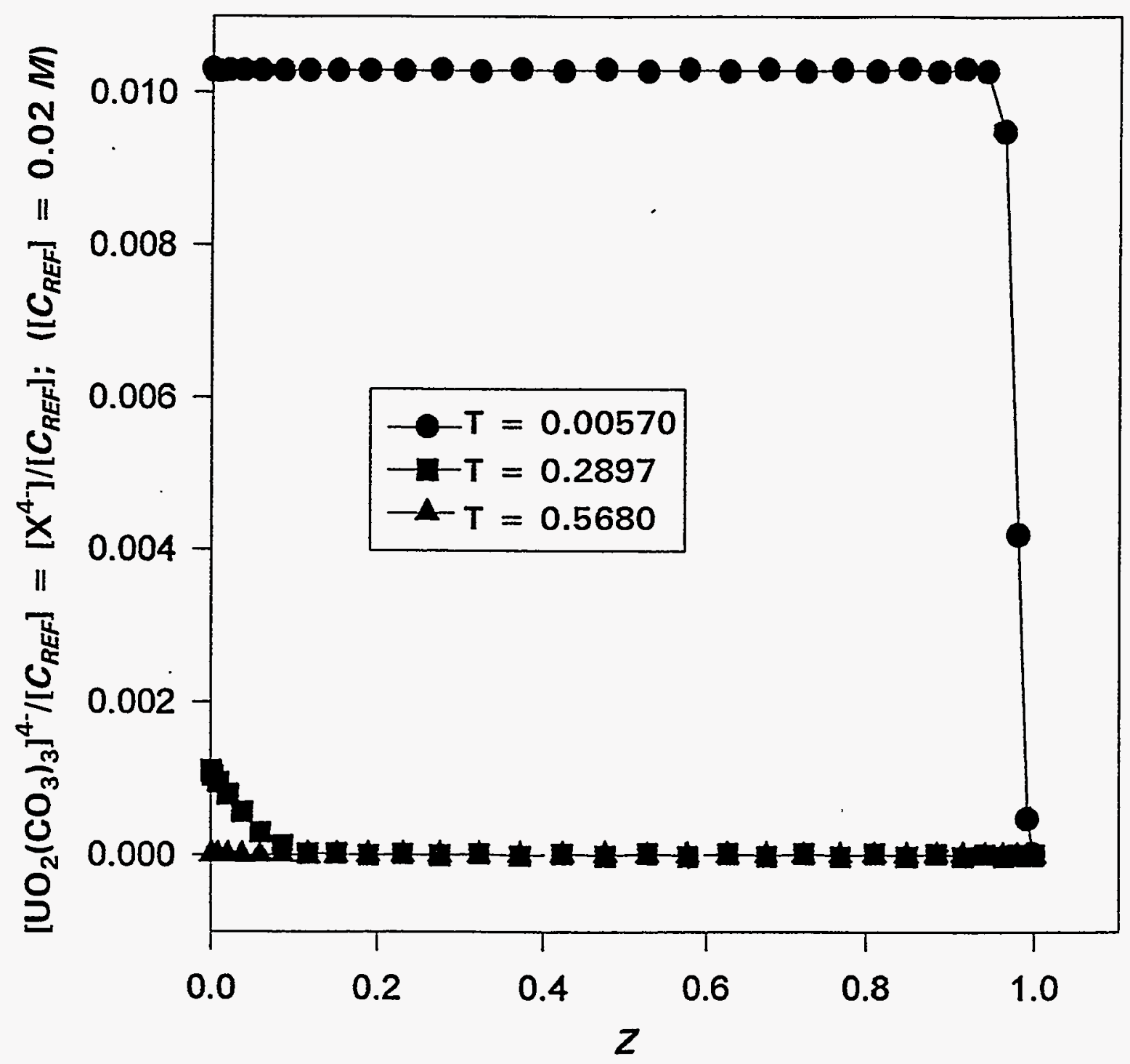

Fig. 3.24. Computed $\mathrm{UO}_{2}\left(\mathrm{CO}_{3}\right)_{2}{ }^{4}$ concentration profile in concrete for 32 collocation points. $\left[\mathrm{Ca}^{2+}\right]_{+, \mathrm{c}_{-}}=0.008 \mathrm{M} ;\left[\mathrm{UO}_{2}\left(\mathrm{CO}_{3}\right)_{3}{ }^{4}\right]=2.06 \times 10^{-4} M ; D_{i}=1 \times 10^{-9} \mathrm{~m}^{2} / \mathrm{s} ; i=5 \mathrm{~mA} / \mathrm{m}^{2} ; L=10 \mathrm{~cm} ; V_{1}=$ $V_{2}=100 \mathrm{~cm}^{3} ; \tau=10$. 
are suppressed as the number of collocation points are increased. These results suggest that only 12 collocation points are required when only the variation of $\left[\mathrm{UO}_{2}\left(\mathrm{CO}_{3}\right)_{3}\right]^{4}$ is to be computed. However, as many as 32 collocation points are required if the axial variation of $\left[\mathrm{UO}_{2}\left(\mathrm{CO}_{3}\right)_{3}\right]^{4-}$ is to be computed accurately.

Figures $3.25 a, 3.25 b, 3.26 a$, and $3.26 b$ present the results of simulations used to illustrate the effect of electroosmosis on the transport of $\mathrm{Cs}^{+}$and $\mathrm{UO}_{2}\left(\mathrm{CO}_{3}\right)_{3}{ }^{4}$ from the liquid phase in the concrete. The conditions for the $\mathrm{Cs}^{+}$simulation are similar to those for $\mathrm{UO}_{2}\left(\mathrm{CO}_{3}\right)_{3}{ }^{4}$; as with the previous simulations, the concrete pore liquid is the only source of the contaminants, and there are no sorption or precipitation effects. The thickness of the concrete slab, $\mathrm{L}$, was $0.635 \mathrm{~cm}$, and the initial concentration of $\mathrm{Ca}^{2+}$ was $0.008 M$. The current density was $47.8 \mathrm{~A} / \mathrm{m}^{2}$ for these simulations, and a zeta potential of $-20 \mathrm{mV}$ was used in the computations that included electromigration. As was shown in Sect. 3.2.5, the zeta potential varied from -40 to $20 \mathrm{mV}$ and depends on the presence of potential-determining ions such as sodium and calcium. Thus, the $-20-\mathrm{mV}$ value represents an intermediate zeta potential. A comparson of Figs. $3.25 a, 3.25 b, 3.26 a$, and $3.26 b$ shows that although electroosmosis enhances the transport of $\mathrm{Cs}^{+}$to the cathode and retards the migration of uranyl tricarbonate to the anode, electromigration is the dominant transport mechanism. These figures also demonstrate the effect of the charge number, $z_{i}$ on the electromigration of $\mathrm{Cs}^{+}$and $\mathrm{UO}_{2}\left(\mathrm{CO}_{3}\right)_{3}{ }^{4}$. The uranyl tricarbonate is transported to the anode much faster than the $\mathrm{Cs}^{+}$migrates to the cathode. The $\left[\mathrm{UO}_{2}\left(\mathrm{CO}_{3}\right)_{3}{ }^{4}\right]$ in the anolyte reaches steady state in approximately 0.4 dimensionless time unit, whereas the $\left[\mathrm{Cs}^{+}\right]$did not reach a steady-state value after 0.6 dimensionless time unit.

\subsubsection{Comparison of Computational and Dynamic Experiment Results}

Computer runs were conducted to simulate the conditions of the dynamic experiments that were performed with cesium and strontium. These simulations included sorption/ion-exchange effects on the concrete by incorporating the isotherms that were measured in the equilibration tests. 

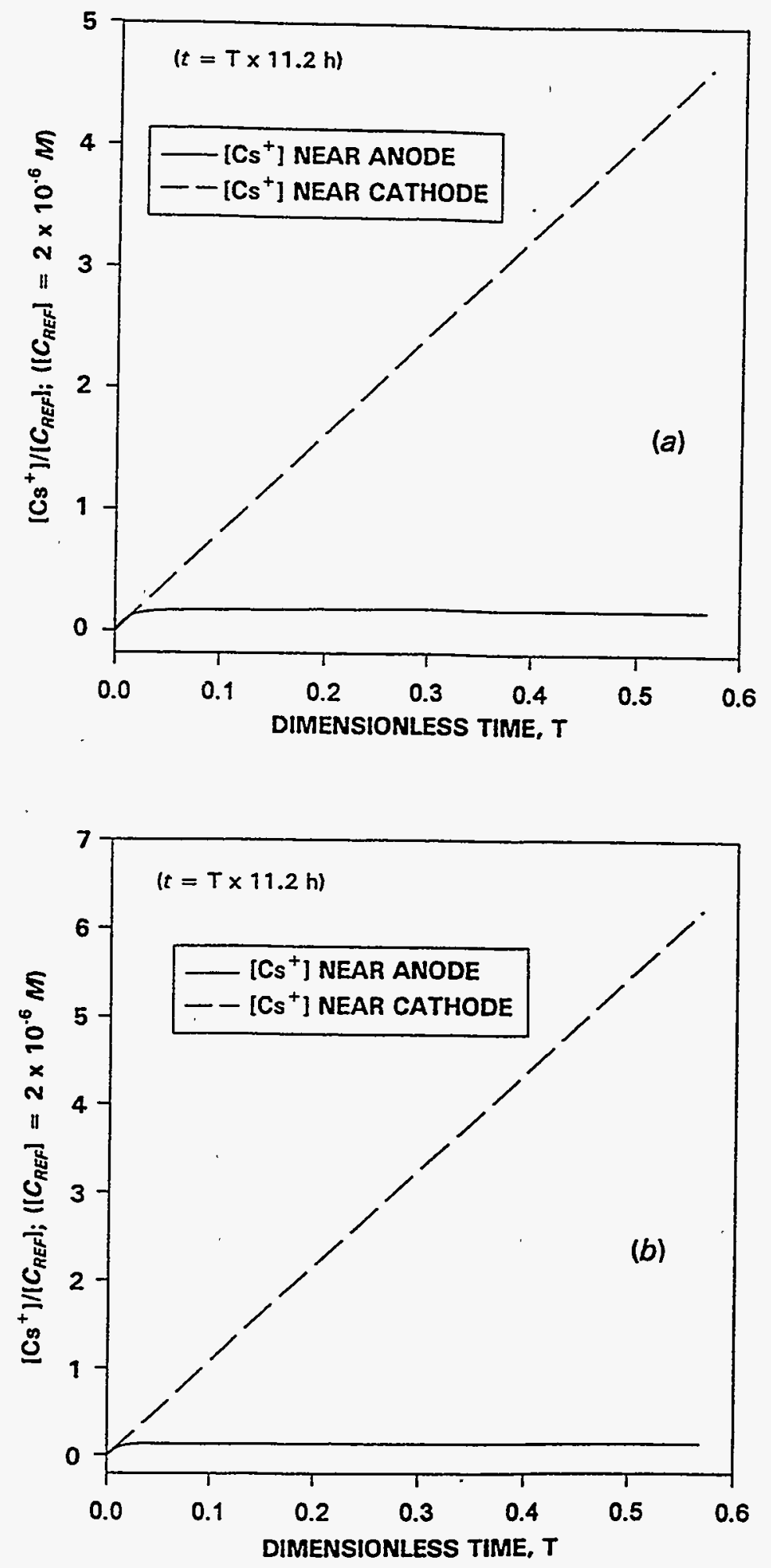

Fig. 3.25. Computed electrokinetic transport of $\mathrm{Cs}^{+}$ions through a concrete core: (a) without electroosmosis; (b) with electroosmosis. $\left[\mathrm{Ca}^{2+}\right]_{+, \mathrm{c}_{-}-}=0.008 \mathrm{M},\left[\mathrm{Cs}^{+}\right]_{\mathrm{c}}=4.52 \times 10^{-4} \mathrm{M},\left[\mathrm{UO}_{2}\left(\mathrm{CO}_{3}\right)_{3}{ }^{4}\right]=$ $2.06 \times 10^{-4} M, D_{i}=10^{-9} \mathrm{~m}^{2} / \mathrm{s}, i=5 \mathrm{~mA} / \mathrm{m}^{2}, L=10 \mathrm{~cm}, V_{1}=V_{2}=100 \mathrm{~mL} ; \tau=10$. 

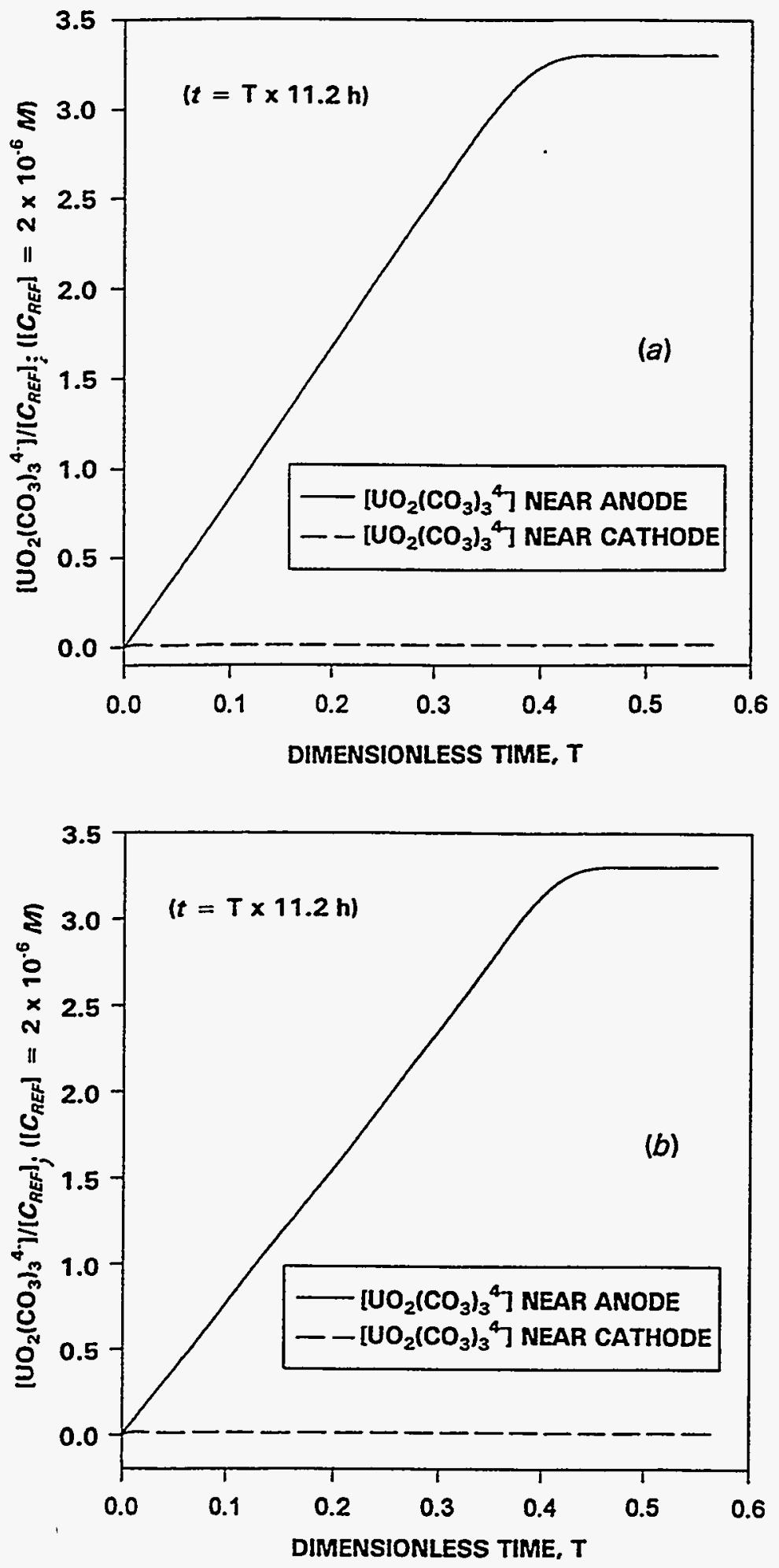

Fig. 3.26. Computed electrokinetic transport of $\mathrm{UO}_{2}\left(\mathrm{CO}_{3}\right)_{2}{ }^{4}$ ions through a concrete core: $(a)$ without electroosmosis; $(b)$ with electroosmosis. $\left[\mathrm{Ca}^{2+}\right]_{+, c_{-}}=0.008 \mathrm{M},\left[\mathrm{Cs}^{+}\right]_{\mathrm{c}}=4.52 \times 10^{-4} \mathrm{M}$, $\left[\mathrm{UO}_{2}\left(\mathrm{CO}_{3}\right)_{3}{ }^{4}\right]=2.06 \times 10^{-4} \mathrm{M}, D_{i}=1 \times 10^{-9} \mathrm{~m}^{2} / \mathrm{s} ; i=5 \mathrm{~mA} / \mathrm{m}^{2} ; L=10 \mathrm{~cm} ; V_{1}=V_{2}=100 \mathrm{~mL} ; \tau=10$. 


\subsection{Cesium}

As described in Sect. 3.2.3.1, bench-scale experiments were performed in which the initial anolyte solution was $0.016 M$ sodium hydroxide containing $0.00752 M$ cesium and the catholyte was $0.016 M$ sodium hydroxide. The concrete slab was $3.81 \mathrm{~cm}$ in diameter and $0.952 \mathrm{~cm}$ thick. The current was $0.1 \mathrm{~A}$, and the potential drop across the anode and cathode varied from approximately 50 to $100 \mathrm{~V}$. If it is assumed that the current flux is across the entire cross-sectional area of the concrete, the current density, $i_{\rightarrow}$, was $87.7 \mathrm{~A} / \mathrm{m}^{2}$. Since the porosity of concrete is approximately 0.2 to 0.4 (Taylor 1990), the current density in the pores would be approximately 438 to $219 \mathrm{~A} / \mathrm{m}^{2}$. Table 3.11 shows a listing of the ions included in the simulations and their assumed initial concentrations in the anolyte, catholyte, and concrete pore solution; Table 3.12 lists the parameter values that were used.

A comparison of the experimental and the simulation results is shown in Figs. 3.27 through 3.29. The concentrations of cesium and sodium hydroxide are $0.00752 \mathrm{M}$ in the vessel containing the anode and $0.016 M$ throughout the system, respectively. The cesium cations are transported by electromigration from the anolyte, through the concrete slab, to the catholyte. Sorption is allowed to occur in the concrete slab. A current density of $219 \mathrm{~A} / \mathrm{m}^{2}$ was used in the computer simulations. Figure 3.27 shows the transport of $\mathrm{Cs}^{+}$from the anolyte, through the concrete, and to the catholyte. The computer model accurately predicts the rate of transport of $\mathrm{Cs}^{+}$from the anolyte and into the concrete; however, the computer code overpredicts the rate of transport of $\mathrm{Cs}^{+}$to the catholyte. The dimensionless mass transfer coefficient for the transport of $\mathrm{Cs}^{+}$from the liquid to the solid phase is 10 .

Figure 3.28 shows the computed and experimental variations of the $\mathrm{pH}$ during the electrokinetic decontamination of concrete. The computer model captures the trend in the variation of the $\mathrm{pH}$; however, quantitative agreement between the computed and experimental results is only fair. The discrepancy between the two results is possibly due to the assumption in the model that the $\left[\mathrm{Ca}^{2+}\right]$ in the pore liquid is constant over the entire simulation. Future improved versions of this model should include the desorption/ 
Table 3.11. Initial concentrations of ions for simulation of cesium dynamic experiment

\begin{tabular}{lccc} 
Ion & $\begin{array}{c}\text { Anolyte } \\
(M)\end{array}$ & $\begin{array}{c}\text { Pore solution } \\
(M)\end{array}$ & $\begin{array}{c}\text { Catholyte } \\
(M)\end{array}$ \\
\hline $\mathrm{Ca}^{2+}$ & 0 & 0.005 & 0 \\
$\mathrm{Na}^{+}$ & 0.016 & 0 & 0.016 \\
$\mathrm{H}_{3} \mathrm{O}^{+}$ & $6.3 \times 10^{-13}$ & $1.0 \times 10^{-13}$ & $6.3 \times 10^{-13}$ \\
$\mathrm{OH}^{-}$ & 0.016 & 0.010 & 0.016 \\
$\mathrm{NO}_{3}^{-}$ & 0.0075 & 0 & 0 \\
$\mathrm{Cs}^{+}$ & 0.0075 & 0 & 0 \\
\hline
\end{tabular}

Table 3.12. Parameter values for simulation of cesium dynamic experiment

\begin{tabular}{cc}
\hline Parameter & Value \\
\hline $\mathrm{Da}$ & 0 \\
$\mathrm{Pe}$ & 0 \\
$\alpha_{\mathrm{i}}$ & 0.030 \\
$\beta_{\mathrm{Ca}}$ & 2.322 \\
$\beta_{\mathrm{Na}}, \beta_{\mathrm{H}}, \beta_{\mathrm{Cs}}$ & 1.161 \\
$\beta_{\mathrm{OH}}, \beta_{\mathrm{NO} 3}$ & -1.161 \\
$\Lambda^{(1)} \mathrm{Ca}$ & 0.120 \\
$\Lambda^{(2)} \mathrm{Ca}$ & 0.00155 \\
$\Lambda^{(1)}{ }_{\mathrm{Na}}, \Lambda^{(1)} \mathrm{Cs}$ & 0.030 \\
$\Lambda_{\mathrm{Na}}^{(2)} \Lambda^{(2)} \mathrm{Cs}_{\mathrm{N}}$ & $7.77 \times 10^{4}$ \\
$\Lambda_{\mathrm{NO}}^{(1)}, \Lambda^{(1)} \mathrm{OH}_{\mathrm{O}}$ & 0.030 \\
$\Lambda^{(2)}{ }_{\mathrm{NO}}, \Lambda^{(2)} \mathrm{OH}$ & $-7.77 \times 10^{-4}$ \\
$\tau$ & $-7.77 \times 10^{-4}$ \\
\hline
\end{tabular}




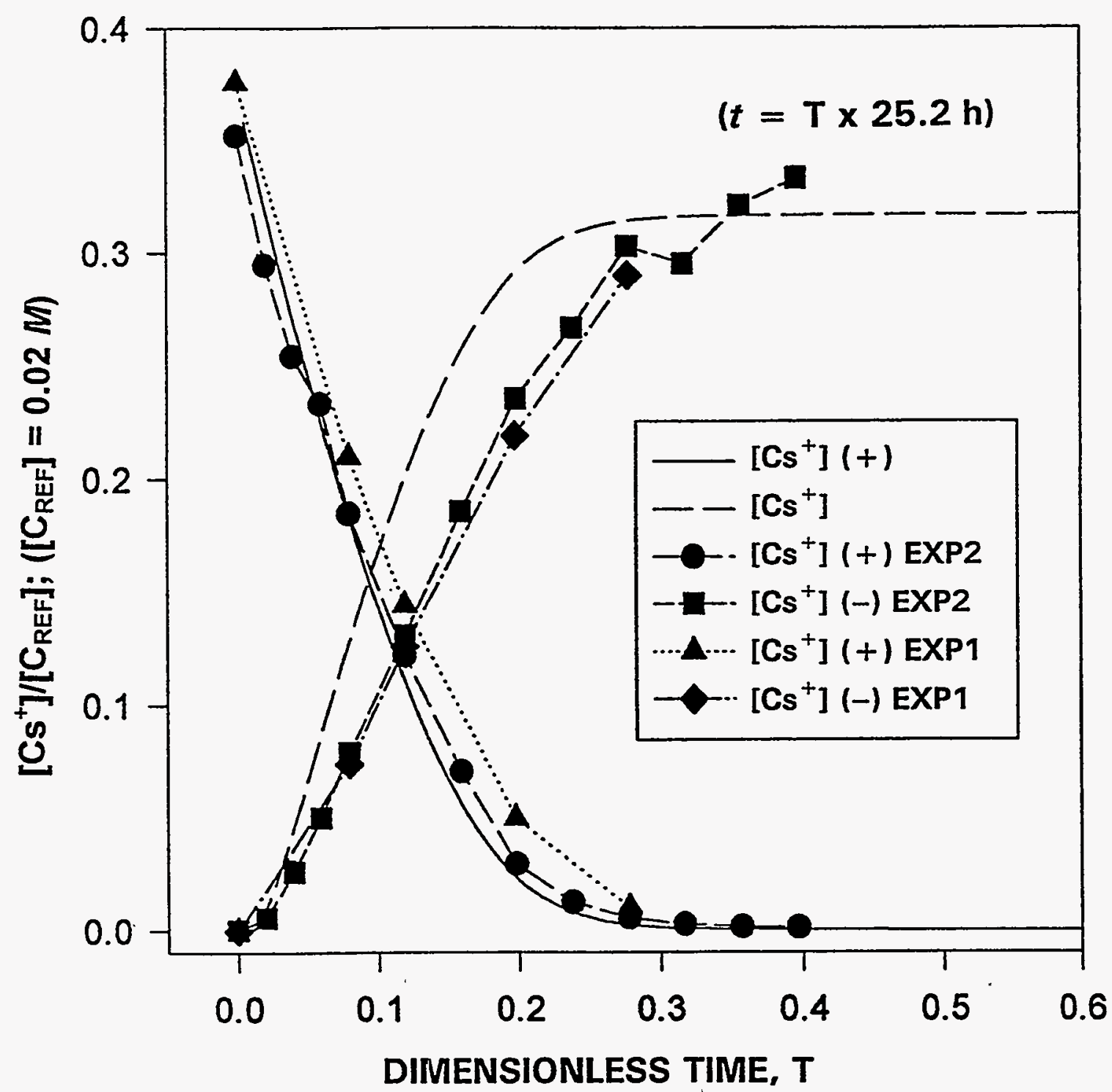

Fig. 3.27. Comparison of computed and experimental cesium concentrations in anolyte and catholyte. $D_{i}=1 \times 10^{-9} \mathrm{~m}^{2} / \mathrm{s} ; i=0.834 \mathrm{~mA} / \mathrm{m}^{2} ; L=0.952 \mathrm{~cm} ; V_{l}=V_{2}=200 \mathrm{~mL} ; \epsilon=0.4 ; A_{C}=0.1252$; $k^{\prime}=10 ; \tau=5.77 ; q^{\prime}(0, z)=0.0$. 


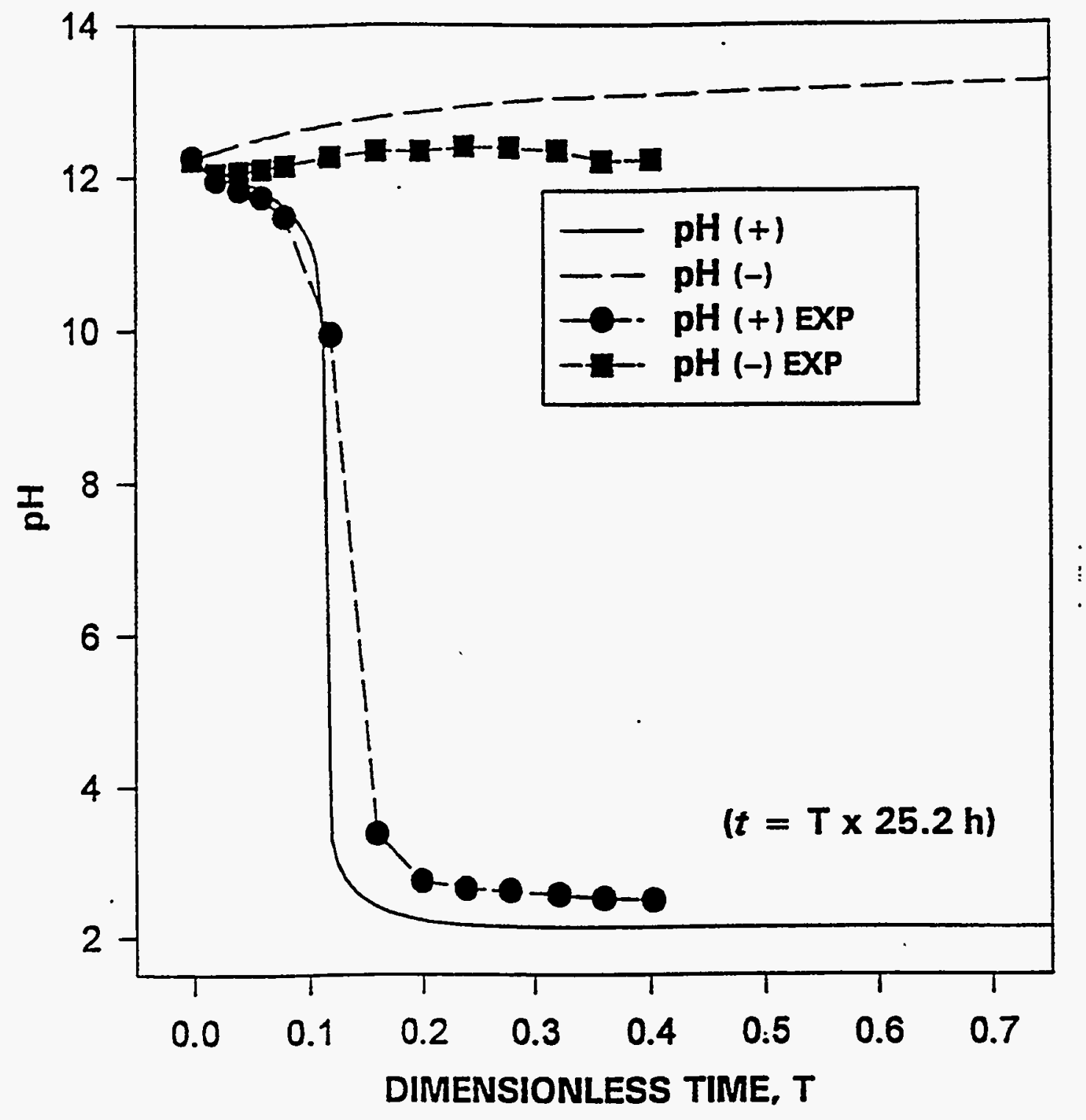

Fig. 3.28. Comparison of computed and experimental $\mathrm{pH}$ levels during cesium transport. 


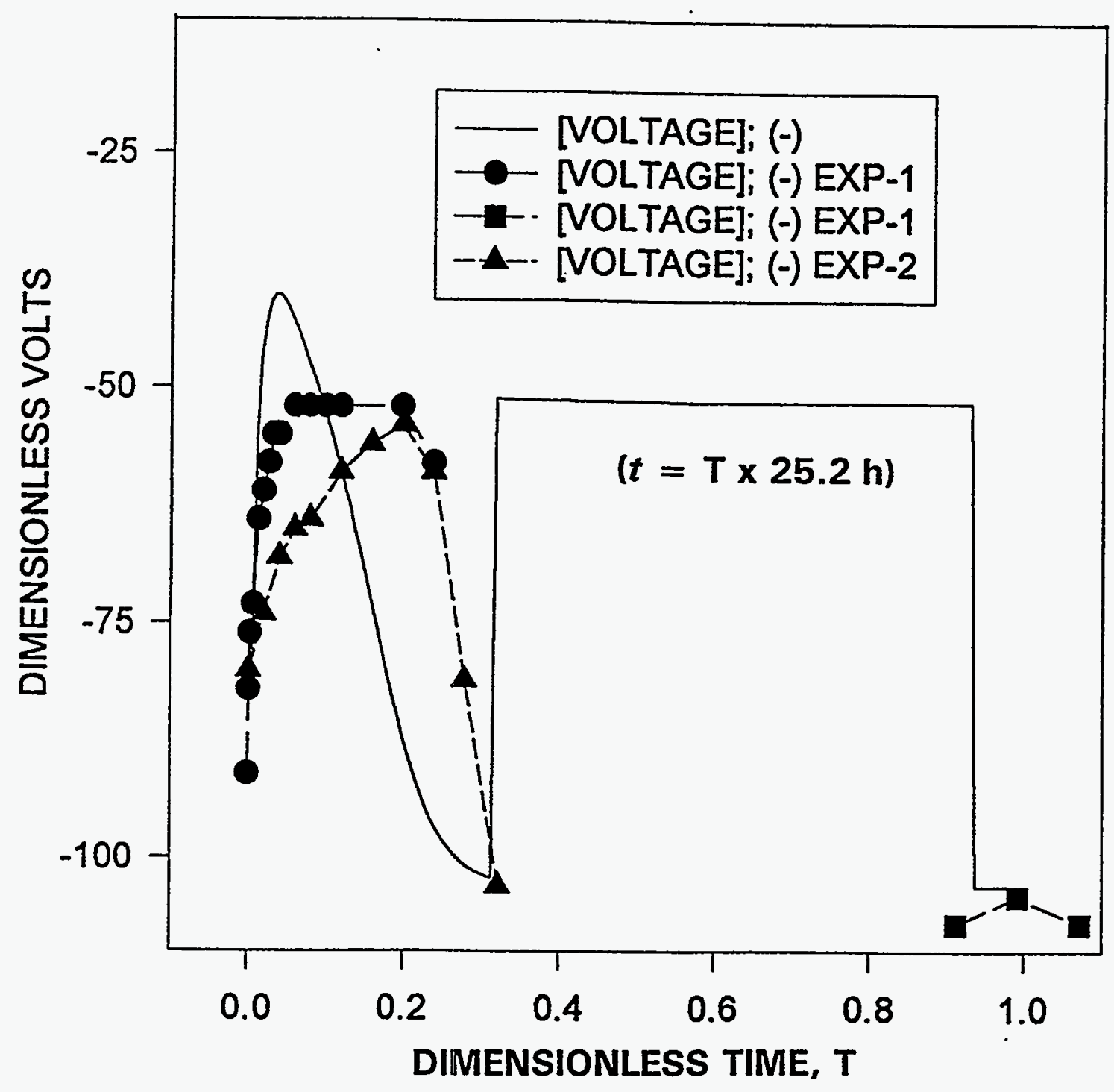

Fig. 3.29. Comparison of computed and experimental voltage drops across concrete disk during cesium transport. 
dissolution of $\mathrm{Ca}^{2+}$ from pore walls in the concrete.

The variation of the voltage drop, $\Delta \mathrm{V}$, across the concrete core is illustrated in Fig. 3.29. Like the $\mathrm{pH}$ results, the computer model predicts the trend in $\Delta \mathrm{V}$; however, there is only semiquantitative agreement between the data. Similar to the $\mathrm{pH}, \Delta \mathrm{V}$ depends on the concentration of ions in pores of the concrete. Thus, it is expected that the agreement between the experimental and computed results would improve if better models were used for the sorption/dissolution/ion exchange of ions in the pores of the concrete.

\subsection{Strontium}

As described in Sect. 3.2.3.2, a bench-scale experiment was performed in which the initial anolyte solution was $0.016 M$ sodium hydroxide containing $0.0114 M$ strontium nitrate and the catholyte was $0.016 \mathrm{M}$ sodium hydroxide. The experimental setup and operating conditions ( $i=100 \mathrm{~mA}$ ) were similar to those used in the cesium dynamic experiments.

Strontium will either exist as $\mathrm{Sr}(\mathrm{OH})^{+}$or will precipitate as a carbonate in the very alkaline $(\mathrm{pH}>13)$ pore liquid in the concrete. Thus, the simulations were performed as if strontium existed in the monovalent hydroxide state. The major ions in the pore liquid are assumed to be same as those given in Table 3.11, except for the replacement of $\mathrm{Sr}(\mathrm{OH})^{+}$for $\mathrm{Cs}^{+}$. Since the size of the strontium monohydroxide is approximately twice that of the cesium cation, the diffusivity $\left(5 \times 10^{-9} \mathrm{~m}^{2} / \mathrm{s}\right)$ for the strontium monohydroxide ion is approximately half that of cesium. The initial concentrations of the ions and parameter values for the simulation of electrokinetic transport of strontium through concrete are given in Tables 3.13 and 3.14, respectively. The simulation results are presented in Figs. 3.30 through 3.32. Figure 3.30 shows a comparison of the simulated and experimental results for the variation of the strontium concentrations in the anolyte and catholyte. As observed, the simulated and experimental results are in good agreement.

The simulated and experimental $\mathrm{pH}$ and voltage-drop data are presented in Figs. 3.31 and 3.32, 
Table 3.13. Initial concentrations of ions for simulation of strontium dynamic experiment

\begin{tabular}{cccc} 
Ion & $\begin{array}{c}\text { Anolyte } \\
(M)\end{array}$ & $\begin{array}{c}\text { Pore solution } \\
(M)\end{array}$ & $\begin{array}{c}\text { Catholyte } \\
(M)\end{array}$ \\
\hline $\mathrm{Ca}^{2+}$ & 0 & 0.008 & 0 \\
$\mathrm{Na}^{+}$ & 0.016 & 0 & 0.016 \\
$\mathrm{H}_{3} \mathrm{O}^{+}$ & $6.3 \times 10^{-13}$ & $6.3 \times 10^{-13}$ & $6.3 \times 10^{-13}$ \\
$\mathrm{OH}^{-}$ & 0.016 & 0.016 & 0.016 \\
$\mathrm{NO}_{3}^{-}$ & 0.0228 & 0 & 0 \\
$\mathrm{Sr}(\mathrm{OH})^{+}$ & 0.0114 & 0 & 0 \\
\hline
\end{tabular}

Table 3.14. Parameter values for simulation of strontium dynamic experiment

\begin{tabular}{cc}
\multicolumn{2}{c}{ of strontium dynamic experiment } \\
\hline Parameter & Value \\
\hline $\mathrm{Da}$ & 0 \\
$\mathrm{Pe}$ & 0 \\
$\alpha_{\mathrm{Sr}(\mathrm{OH})}$ & 0.015 \\
$\alpha_{i}\left(i=\mathrm{Ca}^{2+}, \mathrm{Na}^{+}, \mathrm{NO}_{3}^{-}\right)$ & 0.030 \\
$\beta_{\mathrm{Ca}}$ & 2.322 \\
$\beta_{\mathrm{Na}}, \beta_{\mathrm{H3O}}$ & 1.161 \\
$\beta_{\mathrm{Sr}(\mathrm{OH})}$ & 0.581 \\
$\beta_{\mathrm{OH}}, \beta_{\mathrm{NO}}$ & -1.161 \\
$\Lambda^{(1)}{ }_{\mathrm{Ca}}$ & 0.120 \\
$\Lambda^{(2)}{ }_{\mathrm{Ca}}$ & 0.00155 \\
$\Lambda^{(1)}{ }_{\mathrm{Na}}$ & 0.030 \\
$\Lambda_{\mathrm{Na}}^{(2)}$ & $7.77 \times 10^{-4}$ \\
$\Lambda_{\mathrm{Sr}(\mathrm{OH})}^{(1)}$ & 0.015 \\
$\Lambda_{\mathrm{Sr}(\mathrm{OH})}^{(2)}$ & $3.89 \times 10^{-4}$ \\
$\Lambda_{\mathrm{NO},}^{(1)} \Lambda^{(1)} \mathrm{OH}^{(2)}$ & 0.030 \\
$\Lambda_{\mathrm{NO},}^{(2)}, \Lambda_{\mathrm{OH}}^{(2)}$ & $-7.77 \times 10^{-4}$ \\
$\tau$ & 5.77 \\
\hline
\end{tabular}




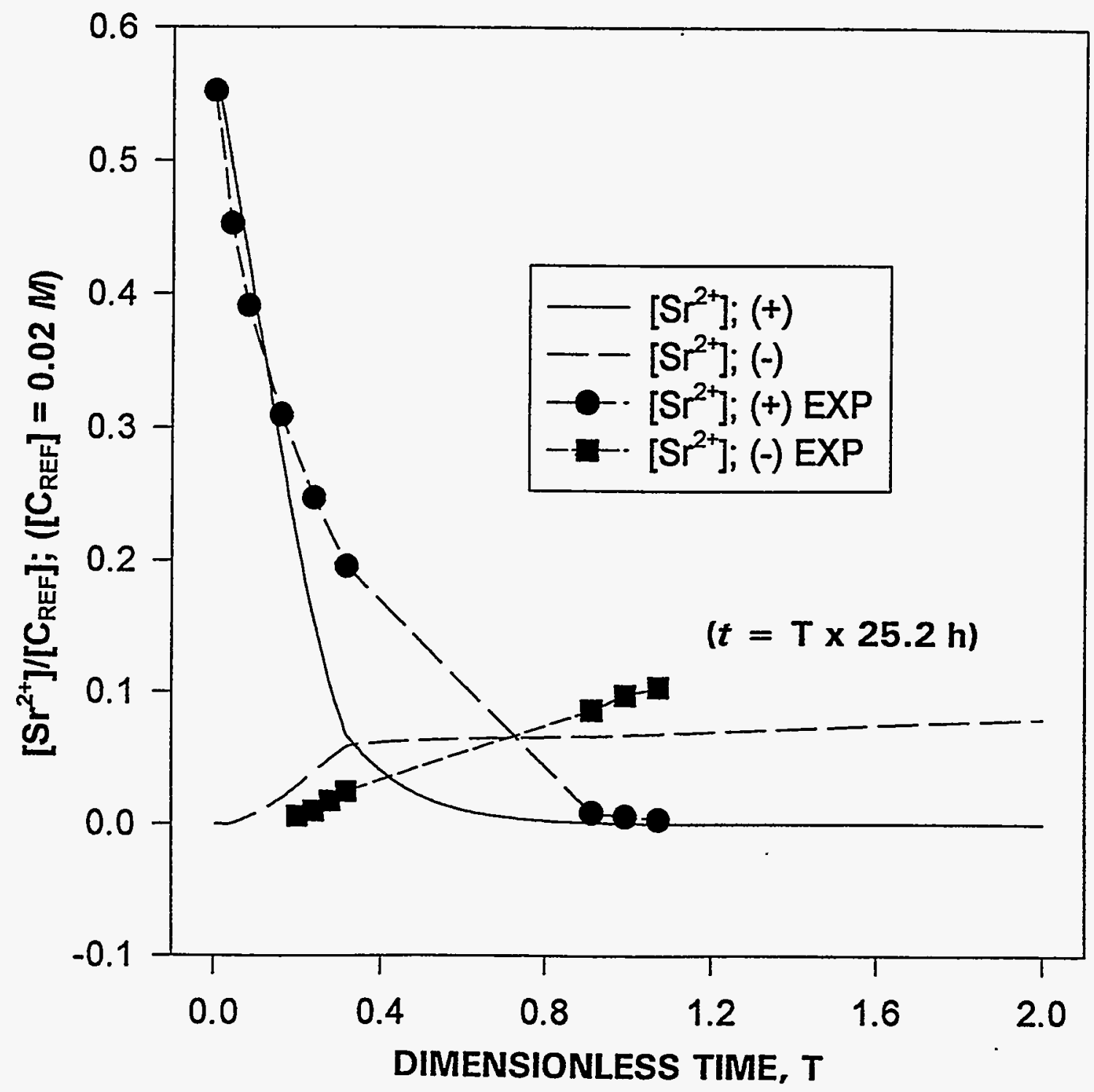

Fig. 3.30. Comparison of computed and experimental strontium concentrations in anolyte and catholyte. $D_{i}=5 \times 10^{-10} \mathrm{~m}^{2} / \mathrm{s} ; i=0.834 \mathrm{~mA} / \mathrm{m}^{2} ; L=0.952 \mathrm{~cm} ; V_{1}=V_{2}=200 \mathrm{~mL} ; \mathrm{A}_{\mathrm{c}}=0.1252$; $k^{\prime}=40 ; q^{\prime}(0, z)=0.0 ; \epsilon=0.4 ; \tau=5.77$. 


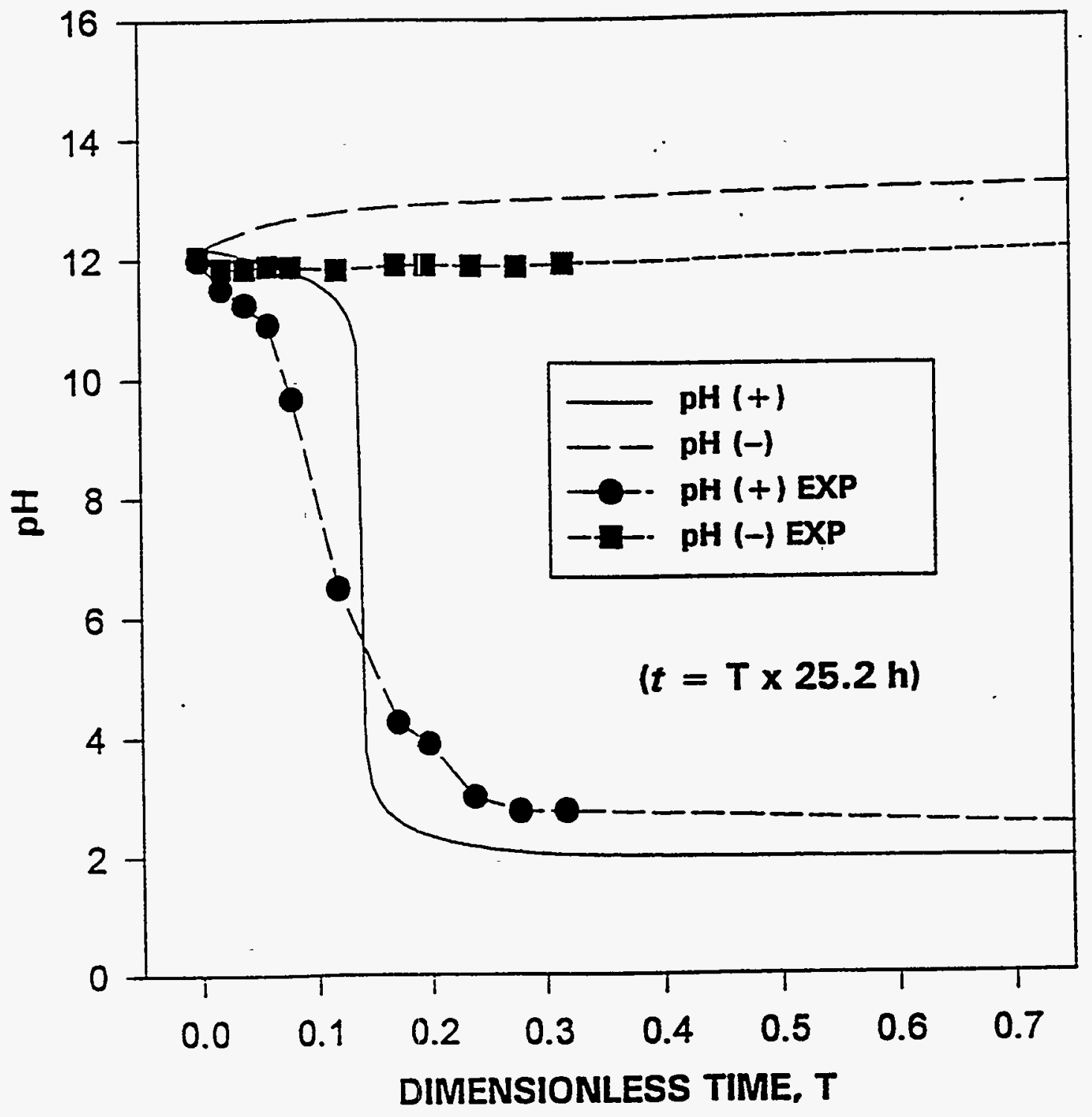

Fig. 3.31. Comparison of computed and experimental $\mathrm{pH}$ levels during strontium transport. 


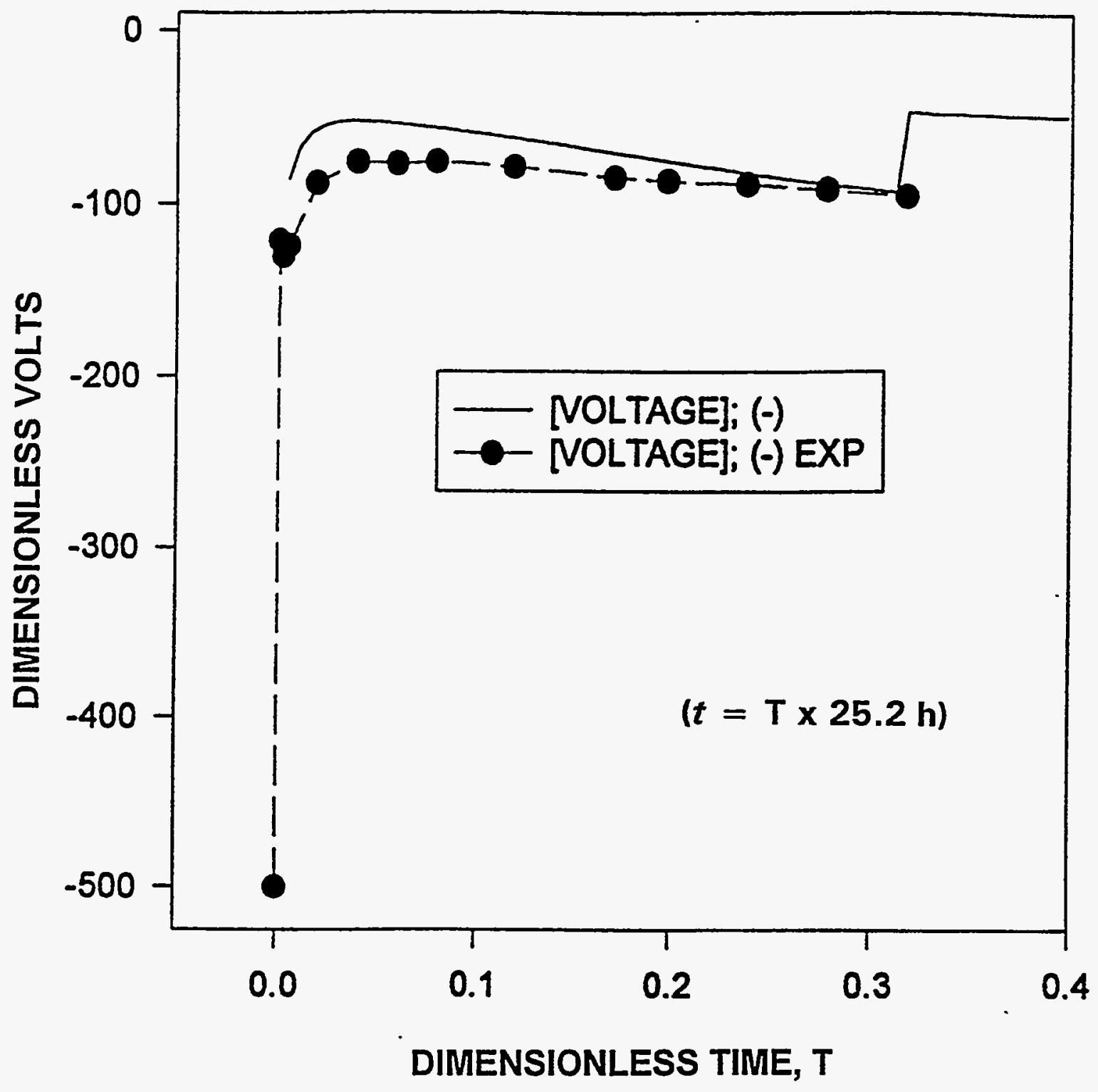

Fig. 3.32. Comparison of computed and experimental voltage drops across concrete disk during strontium transport. 
respectively. These figures illustrate that, similar to the cesium data, the computer model captures the trend in the experimental $\mathrm{pH}$ and voltage data. Again, more accurate models are required to account for the fate of ions in the pores of the concrete.

\subsubsection{Discussion of Modeling Results}

A one-dimensional model has been developed for the EK of concrete. This model shows that electromigration is the dominant transport mechanism for the removal of cations and anions such as $\mathrm{Cs}^{+}$and $\mathrm{UO}_{2}\left(\mathrm{CO}_{3}\right)_{3}^{4}$. Electromigration is strongly affected by the charge number of the ions. Furthermore, the results from the simulations suggest that even if ions are sorbed onto the solid cement particles or pore walls and for favorable sorption isotherms, electrokinetics can still be used to decontaminate concrete. When the results obtained using the model were compared with bench-scale experimental data for cesium and strontium, good agreement was found.

Additional modifications are required for more accurate prediction of contaminant transport using EK. One recommended revision to this one-dimensional model is a mechanism for the desorption of $\mathrm{Ca}^{2+}$ from the solid phase. Further valuable revisions would include expansion to a two-dimensional domain, which would allow modeling of dual-reservoir EK systems. 


\section{EVALUATION OF THE ELECTROKINETIC DECONTAMINATION OF CONCRETE}

Although many advances have been made regarding the EK of soil, this technology is not mature and cannot be directly translated to concrete; therefore, many uncertainties remain. As discussed in Sect. 1.3, several questions must be resolved in order to evaluate EK relative to other decontamination technologies. The required information includes capability for removal of contaminants, secondary waste production, cost considerations, and overall safety (including protection of the environment).

The work reported here has been aimed primarily toward the technical feasibility of EK. As such, no information regarding cost, overall safety, and operability has been collected. More reliable information of this type will be obtained during field demonstrations. Only limited information regarding the characteristics of secondary waste can be surmised from this work; for nonprecipitating species such as cesium and strontium, the secondary waste is expected to be in the form of a somewhat dilute, basic solution of the contaminants (and a possibly contaminated acidic waste stream), while for precipitating species, such as cobalt and uranium, the secondary waste will likely be an acidic waste containing complexing agents. The electrical current could be a significant cost concern, while generation of hydrogen and oxygen gas at separate electrodes is a safety concern in confined areas.

The performance of EK in concrete appears to be dominated by the chemical interactions between the concrete, pore solution, and contaminants; these interactions are dependent on (1) $\mathrm{pH}$ and (2) sorption/ion exchange. Equilibration isotherms provide a good indication regarding the relative capability for transporting and removing the contaminants from concrete. For instance, the rate of contaminant transport through the concrete in dynamic tests followed the same order as that predicted by loading in equilibration tests; cesium had the lowest loading and was the most mobile, while strontium was more strongly loaded and

was less mobile, and cobalt and uranium were not mobile due to formation of precipitates. The removal by EK of nonprecipitating species, such as cesium and strontium, to meet specifications defined by standard 
cleanup criteria appears achievable.

Lixiviant solutions containing complexing agents appear to be necessary in order to achieve significant removal rates by EK for precipitating contaminants such as cobalt and uranium. Results of the dynamic tests showed that it is possible to transport both a charged complexant and a complexed contaminant through concrete; thus, electrokinetic removal using complexing agents appears feasible. Some difficulties encountered with carbonate solutions indicate that this complexant must be used with care for removal of uranium from concrete. Through evaluation of the results of this work, it is recommended that a dualreservoir system be used for application of complexing lixiviants for removal of precipitating contaminants. When a lixiviant containing negative complexant ions (such as carbonate or EDTA) is used, the anolyte reservoir (containing the positive electrode) should be positioned over the contaminated area, while the catholyte reservoir (containing the negative electrode) should be placed in a clean zone. Several reasons make this configuration desirable. The negative complexant ions would be transported by electromigration through the concrete from the catholyte to the anolyte. Contaminants in the path between reservoirs would be solubilized and transported toward the anolyte; however, because of the equilibrium between the precipitation and complexation reactions, some of the contaminant might be precipitated as it travels through the bulk concrete. For this reason, the catholyte reservoir should be placed on clean concrete to minimize the distance over which the contaminant could be "smeared." Acidic conditions in the catholyte reservoir would act to speed the dissolution of surface contamination. This configuration should be tested in demonstrations; in addition, a two-dimensional model is needed for optimization of the dual-reservoir approach.

This work has not resolved several potential technical problems. The possibility and extent of concrete damage due to gas generation (in single-reservoir systems) and/or precipitation reactions have not been determined. Heat generation could be significant, especially if lixiviant solutions of lower conductivity are used. In addition, the use of a single-reservoir system for removal of cations could result in significant 
corrosion of rebar, possibly degrading the concrete performance.

The results of the work reported here indicate that EK has the capability for removing many ionizable contaminants from concrete. At this point, the available information is insufficient to evaluate EK relative to other decontamination technologies. Further work, particularly well-characterized demonstrations that are conducted in conjunction with laboratory tests and modeling, are needed to develop the technology to the extent necessary to permit a fair evaluation. 


\section{CONCLUSIONS AND RECOMMENDATIONS}

These fundamental studies were conducted to provide a more complete understanding of the processes that govern the EK of concrete. Results indicated that electroosmosis is not likely to be the dominant transport mechanism in most cases; rather, most species will be transported by electromigration. This finding is important because it indicates that high voltages (and resulting large currents) may not be necessary to drive the process; thus, large power consumption and difficulties encountered due to resistive heating may be avoided. Batch equilibration tests have shown that the removal of each contaminant will be governed largely by the chemistry of the concrete, contaminant, and lixiviant; in particular, precipitation of species such as cobalt and uranium will limit transport in the normally high-pH concrete pore solution. Dynamic experiments have indicated that it is possible to transport nonprecipitating species, such as cesium, through concrete using electrolyte lixiviants, while it appears to be necessary to apply complexing agents to mobilize precipitating species. The results of a one-dimensional computational model have been shown to be in good agreement with dynamic experiments; therefore, this model will provide a valuable tool for further investigation and optimization of the application of EK of concrete.

These studies have indicated that the technology is worthy of further consideration by DOE for decontamination of concrete. The experimental and theoretical work that has been conducted during this project has served to answer several questions regarding the technical feasibility of the process; however, the ultimate utility of the process must be determined through demonstration. The following recommendations are made toward future demonstrations of EK:

1. Evaluation of the effectiveness of a demonstration can only be made with a material balance. Future demonstrations should include coring and analysis prior to and following the operation. The analysis should determine the concentrations of the contaminants as a function of depth. 
2. This work has indicated that the chemistry of the contaminant and lixiviants in concrete controlling the fate of contaminants can be complicated. Future demonstrations should include laboratory testing - both determination of site-specific isotherms and dynamic desorption tests. The isotherm work could be performed by crushing cores from the site and performing batch equilibrations with different lixiviant solutions. Isotherm testing would provide several benefits: (1) difficulties with the site-specific chemistry could be predicted, (2) an optimum lixiviant solution could be determined, and (3) the isotherms would provide input for model predictions of contaminant removal. Dynamic experiments conducted with actual contaminated cores would determine the efficacy of the proposed EK operation and would allow evaluation of model performance prior to predicting field performance.

3. Because of the difficulties encountered in the laboratory and in previous field demonstrations with uranium, it may be preferable to perform a demonstration at a site contaminated with a more mobile contaminant, such as cesium, with subsequent demonstrations to deal with more troublesome contaminants.

4. The operating conditions for a demonstration should be optimized by simulation using a model such as that developed in this work. This model would allow estimation of the amount of contaminant removed and the time required for cleanup for a given applied voltage/current. Simulation would be vitally important if the operation is aimed at removal of a precipitating species using a single electrolyte reservoir. In such an operation, the power is applied for a period to drive lixiviant into the concrete and then the polarity is reversed to remove the contaminants. One example might involve transporting negative carbonate ions into concrete by applying the negative side of the power supply to the surface electrode and the positive side within the concrete, followed by a polarity reversal to force the negatively charged uranium/carbonate complex to the positive electrode at the surface. A 
model would be necessary to estimate the distances traveled via electromigration by the differently charged ions; this would allow adjustment of the operating times to prevent driving complexed uranium ions farther into the concrete.

5. Further development of EK technology should be primarily focused on dual-reservoir systems. These systems would allow monitoring and control of the environment surrounding both electrodes. Such capability would be valuable in avoiding potential problems for electrodes submerged in the concrete, including corrosion of rebar and cracking of the concrete due to gas production; also, simultaneous removal of oppositely charged contaminants would be possible. A dual-reservoir system would be preferable for removal of precipitating contaminants; it would be most advantageously applied if the catholyte containing negatively charged complexants (such as EDTA) were placed over clean concrete and the anolyte were in contact with a contaminated zone.

6. Further development of EK models is urged. A two-dimensional model is necessary to determine the capabilities and limitations of dual-reservoir process designs. Two-dimensional modeling would result in a mapping of the spatial distribution of electrical current under different geometries. This would aid in system design by helping to avoid short-circuit current flow along the surface between electrolyte reservoirs and to ensure that current flow is significantly deep to encompass the entire contamination zone. 


\section{REFERENCES}

Acar, Y. B., and Alshawabkeh, A. W. 1993. "Principles of Electrokinetic Remediation," Environ. Sci. Technol. 27, 2638.

Acar, Y. B., Alshawabkeh, A. W., and Gale, R. J. 1993. "Fundamentals of Extracting Species from Soils by Electrokinetics," Waste Manage. 13, 141.

Acar, Y. B., Gale, R. J., Putnam, G. A., Hamed, J., and Wong, R. L. 1990. "Electrochemical Processing of Soils: Theory of $\mathrm{pH}$ Gradient Development by Diffusion, Migration, and Linear Convection," J. Environ. Sci. Health A25, 687.

Acar, Y. B., Li, H., and Gale, R. J. 1992. "Phenol Removal from Kaolinite by Electrokinetics," J. Environ. Eng. 118, 1837.

Alshawabkeh, A. W., and Acar, Y. B. 1992. "Removal of Contaminant from Soils by Electrokinetics: A Theoretical Treatise," J. Environ. Sci. Health A27, 1835.

Andrade, C., Sanjuan, M. A., Recurero, A., and Rio, O. 1994. "Calculation of Chloride Diffusivity in Concrete from Migration Experiments, in Non-Steady-State Conditions," Cem. Concr. Res. 24, 1214.

Archibald, K. E. 1995. Concrete Decontamination Scoping Tests (draft), Idaho National Laboratory, Idaho Falls, Idaho.

Atkins, P. W. 1982. Physical Chemistry, W. H. Freeman, San Francisco, Calif.

Baes, C. F., Jr., and Mesmer, R. E. 1976. The Hydrolysis of Cations, John Wiley and Sons, New York.

Bibler, J. P., and Meaker, T. F. 1994. "Field Demonstration of Electrokinetic Migration Technology at Old TNX Seepage Basin," p. 355 in Proceedings.of the EPRI Workshop on In Situ Electrochemical Soil and Water Remediation, Electric Power Research Institute Report EPRI TR-104170.

Bibler, J. P., Osteen, A. B., and Meaker, T. F. 1993. "Application of Electrokinetic Migration Technology for Removal of Chromium and Uranium from Unsaturated Soil at SRS," p. 855 in Proceedings of the 1993 Symposium on Waste Management, Tucson, Arizona, February 28-March 4, 1993.

Bockris, J. O., and Reddy, A. K. N. 1977. Modern Electrochemistry, Plenum Press, New York.

Bostick, W. D., et al. 1993. Electroosmotic Decontamination of Concrete, K/TCD-1054, Martin Marietta Energy Systems, Inc., Oak Ridge, Tennessee.

Bruell, C. J., Segall, B. A., and Walsh, M. T. 1992. "Electroosmotic Removal of Gasoline Hydrocarbons and TCE from Clay, " J. Environ. Eng. 118, 68. 
Carta, G. 1986. FXCOLFRF.F77: A FORTRAN 77 Computer program, University of Virginia.

Casagrande, L. 1952. "Electro-osmotic Stabilization of Soils," J. Boston Soc. Civ. Eng. 39, 51.

Casagrande, L. 1983. "Stabilization of Soils by Means of Electro-osmosis, State-of-the-Art," J. Boston Soc. Civ. Eng. 69, 255.

Cocke, D. L., and Mollah, M. Y. A. 1991. "The Chemistry and Leaching Mechanisms of Hazardous Substances in Cementitious Solidification/Stabilization Systems,"' Proceedings of the Symp. Chemistry . and Microstructure of Solidified Waste Forms, ACS National Meeting, New York, Aug. 25-30.

Connor, J. R. 1990. Chemical Fixation and Solidification of Hazardous Wastes, Van Nostrand Reinhold, New York.

Dickerson, K. S., Wilson-Nichols, M. J., and Morris, M. I. 1995. Contaminated Concrete: Occurrence and Emerging Technologies for DOE Decontamination, DOE/ORO-2034, prepared by Oak Ridge National Laboratory for the U.S. Department of Energy, Office of Environmental Restoration and Waste Management, Office of Technology Development, Washington, D.C.

Evans, D. F., and Wennerstrom, H. 1994. The Colloidal Domain: Where Physics, Chemistry, Biology and Technology Meet, VCH Publishers, Inc., New York.

Francis, C. W., Mattus, A. J., Farr, L. L., Ellis, M. P., and Lee, S. Y. 1995. Selective Leaching of Uranium Contaminated Soils: Progress Report $I_{z}$ ORNL/TM-12177, Oak Ridge National Laboratory, Oak Ridge, Tenn.

Gucker, F. T., and Meldrum, W. B. 1950. Physical Chemistry, American Book Company, New York.

Hamed, J., Acar, Y. B., and Gale, R. J. 1991. "Pb Removal from Kaolinite by Electrokinetics," J. Geotechnical Eng. 117, 241.

Harris, M. T., and Basaran, O. A. 1993. "Capillary Electrohydrostatics of Conducting Drops Hanging from a Nozzle in an Electric Field," J. Colloid Interface Sci. 161, 389.

Hicks, R. E., and Tondorf, S. 1994. "Electrorestoration of Metal Contaminated Soils," Environ. Sci. Technol. 28, 2203.

Jacobs, R. A., Sengun, M. Z., Hicks, R. E., and Probstein, R. F. 1994. "Model and Experiments on Soil Remediation by Electric Fields," J. Environ. Sci. Health A29, 1933.

Kaufman, J., Luethi, T., Flisch, A., and Link, J. 1992. "First Results from the Measurement of the Distribution of Water in Building Concrete by Means of MRI and X-Ray Computer Tomography," presented at DGZfP Annual Meeting-Innovative Nondestructive Testing-A Challenge to All Sectors of Industry, Fulda, Germany, April 27-29. 
Khan, L. I., and Alam, M. S. 1994. "Heavy Metal Removal from Soil by Coupled Electric-Hydraulic Gradient," J. Environ. Eng. 120, 1524.

Kong, F. K., Evans, R. H., Cohen, E., and Roll, F., eds., 1983. Handbook of Structural Concrete, McGrawHill, New York.

Lageman, R., Pool, W., and Seffinga, G. 1989. "Electro-Reclamation: Theory and Practice," Chem. Ind. 18, 585.

Lockhart, N. C. 1983a. "Electroosmotic Dewatering of Clays I. Influence of Voltage," Colloids Surf. 6, 229.

Lockhart, N. C. 1983b. "Electroosmotic Dewatering of Clays II. Influence of Salt, Acid, and Flocculants," Colloids Surf. 6, 239.

Lockhart, N. C. 1983c. "Electroosmotic Dewatering of Clays. III. Influence of Clay Type, Exchangeable Cations, and Electrode Materials," Colloids Surf. 6, 253.

Lomasney, H. L. 1993. Electrokinetic Decontamination of Concrete, Research by Isotron Corporation, New Orleans, La.

Lomasney, H. L. 1994. "Russian Experience with Electrokinetic Cleanup of Groundwater Zones Associated with Uranium Leach Mining Sites," p. 347 in Proceedings of the EPRI Workshop on In Situ Electrochemical Soil and Water Remediation, Electric Power Research Institute Report EPRI TR-104170.

Morgan, I. L., and Gilbert, V.P. 1994. Testing of Non-Destructive Concrete Decontamination Techniques for the Solar Basins at the Hanford Site (draft), Oak Ridge National Laboratory, Oak Ridge, Tenn.

Murphie, W. E. 1992. "Decommissioning of Radioactive Facilities," p. 9 in Proceedings of the International. Conference of the Institution of Mechanical Engineers, London, United Kingdom, Feb. 17-19, 1992.

Nagele, E. 1985. "The Zeta-Potential of Cement," Cem. Concr. Res. 15, 453.

Nagele, E. 1987. "The Zeta-Potential of Cement. II: Effect of pH Value," Cem. Concr. Res. 16, 853.

Nagele, E. 1991. "The Zeta-Potential of Cement. III: The Non-Equilibrium Double Layer on Cement," Cem. Concr. Res. 17, 573.

Nagele, E., and Schneider, U. 1987. "The Zeta-Potential of Cement. IV: Effect of Simple Salts," Cem. Concr. Res. 17, 977.

Nagele, E., and Schneider, U. 1988. "The Zeta-Potential of Cement. V: Effect of Surfactants," Cem. Concr. Res. 18, 257.

Nagele, E., and Schneider, U. 1989a. "The Zeta-Potential of Blast Furnace Slag and Fly Ash," Cem. Concr. Res. 19, 811 . 
Nagele, E., and Schneider, U. 1989b. "From Cement to Hardened Paste - An Electrokinetic Study," Cem. Concr. Res. 19, 978.

Peters, D. G., Hayes, J. M., and Hieftje, G. M. 1974. Chemical Separations and Measurements, W. B. Saunders, Philadelphia.

Ramachandran, V. S., ed., 1984. Concrete Admixtures Handbook: Properties, Science, and Technology, Noyes Publications, Park Ridge, N.J.

Roy, D. M., 1989. "Relationships between Permeability, Porosity, Diffusion and Microstructure of Cement Pastes, Mortar, and Concrete at Different Temperatures, Mater. Res. Symp. Proc. 137, 179-89.

Roy, D. M., and Scheetz, B. E. 1991. "The Chemistry of Cementitious Systems for Waste Management: the Penn State Experience," Proceedings of the Symposium on Chemistry and Microstructure of Solidified Waste Forms, ACS National Meeting, New York, August 25-30.

Runnels, D. D., and Patterson, C. G. 1994. "Electromigration as a Method for In-Situ Remediation of Sulfate and Other Highly Soluble Contaminants in Groundwater," p. 85 in Proceedings of the EPRI Workshop on In Situ Electrochemical Soil and Water Remediation, Electric Power Research Institute Report TR-104170.

Santacesaria, E. M., et al. 1982. "Separation of Xylenes on Y Zeolites 2. Breakthrough Curves and Their Interpretation," Ind. Eng. Chem. Process Des. Dev. 21, 446.

Segall, B. A., and Bruell, C. J. 1992. "Electroosmotic Contaminant-Removal Processes," J. Envron. Eng. 118,84 .

Shapiro, A. P. 1990. Electroosmotic Purging of Contaminants from Saturated Soils, Ph.D. thesis, Massachusetts Institute of Technology.

Shapiro, A. P., and Probstein, R. F. 1993. "Removal of Contaminants from Saturated Clay by Electroosmosis," Environ. Sci. Technol. 27, 283.

Sheludko, A. 1966. Colloid Chemistry, Elsevier, New York.

Slater, J. E., Lankard, D. R., and Moreland, P. J. 1976. "Electrochemical Removal of Chlorides from Concrete Bridge Decks," Mater. Perform. 15, 21-26.

Taylor, H. F. W. 1990. Cement Chemistry, Academic Press, Inc., Orlando, Fla.

Thornton, R. F., and Shapiro, A. P. 1994. "Modeling of In-Situ Electrokinetic Remediation of Cr(VI)Contaminated Soil and Estimating Remediation Costs," p. 329 in Proceedings of the EPRI Workshop on In Situ Electrochemical Soil and Water Remediation, Electric Power Research Institute Report EPRI TR104170.

Trombly, J. 1994. "Electrochemical Remediation Takes to the Field," Environ. Sci. Technol. 28, 289A. 
Troxell, G. E., Davis, H. E., and Kelly, J. W. 1956. Composition and Properties of Concrete, McGraw-Hill, New York.

U.S. NRC 1994. Generic Environmental Impact Statement in Support of Rulemaking on Radiological Criteria for Decommissioning of NRC-Licensed Facilities (draft), NUREG-1496, Vol. 2, U.S. Nuclear Regulatory Commission.

Vennesland, O., and Opsahl, O. A. 1986. "Removal of Chlorides from Concrete," European patent number 0200428. 



\section{INTERNAL DISTRIBUTION}

1-5. M. R. Ally

6. C. E. Benson

7. B. A. Berven

8. C. H. Byers

9. A. G. Croff

10-14. D. W. DePaoli

15. M. E. Ellis

16-20. M. T. Harris

21. H. W. Hayden

22. D. W. Hovis

23. A. P. Malinauskas

24. L. E. McNeese
25. M. I. Morris

26. D. Pfifer

27. S. M. Robinson

28. C. Tsouris

29. J. S. Watson

30. D. F. Williams

31. ORNL Central Research Library

32. ORNL Laboratory Records- $\mathrm{RC}$

33. ORNL Patent Section

34. ORNL Y-12 Technical Library Document Reference Section

\section{EXTERNAL DISTRIBUTION}

35. K. Abbott, DOE/SF, 1301 Clay Street, Room 700N, Oakland, CA 94612-5208

36. G. Allen, SNL, P. O. Box 5800, Dept. 6607, MS-0756, Albuquerque, NM 87185-0756

37. C. L. Anderson, Department of Chemistry, Dabney/Buehler Hall, University of Tennessee, Knoxville, TN 37996

38. W. E. Austin, WSRC, WMER/ER, MS-992W-4, P. O. Box 6161, Aiken, SC 29803

39. R. W. Bailey, WHC, P. O. Box 1970, MS-S6-15, Richland, WA 99352

40. C. E. Baldwin, RFETS, P. O. Box 464, Bldg. 881, Golden, CO 80401-0464

41. R. Bedick, METC, 3610 Collins Ferry Road, Morgantown, WV 26507-0880

42. J. Berger, WHC, P. O. Box 1970, MS LO-18, Richland, WA 99352

43. W. Bliss, REECo-NV, P. O. Box 98521, Las Vegas, NV 89193-8521

44. S. Bossart, METC, 3610 Collins Ferry Road, Morgantown, WV 26507-0880

45. J. Boudreaux, Florida International University, Department of Mechanical Engineering, ECS 458, Miami, FL 33199

46. T. Bramlette, SNL/CA, P. O. Box 969, Dept. 8240, Livermore, CA, 94550

47. C. H. Brown, ORNL/Rocky Flats, P. O. Box 928, T1124, C26, Golden, CO 80402-0928 
48. R. D. Bundy, Battelle, 151 Lafayette Dr., Suite 110, Oak Ridge, TN 37830

49. N. E. Cate, 821 Volunteer Boulevard \#414, Knoxville, TN 37916

50. R. F Christensen, DOE/RL, P. O. Box 550, Richland, WA 99352

51. T. R. Clark, FERMCO, CERCLA/RCRA Unit 3, P. O. Box 398704, MS 52-3, Cincinnati, OH 45239-8704

52. J. T. Coleman, WSRC, Savannah River Site, Bldg. 773-A, A208, Aiken, SC 29802

53. J. Crockett, ORISE, P. O. Box 117, Oak Ridge, TN 37831

54. K. S. Dickerson, ORNL/Rocky Flats, P. O. Box 4013, T124A, C34, Golden, CO 80401-0014

55. M. Edleson, Ames Laboratory, 110 Spedding Hall, Iowa State University, Ames, IA 50011

56. N. S. Egan, MSE, Inc., P. O. Box 3767, Butte, MT 59702

57. D. Emilia, RUST Geotech, P. O. Box 14000, Grand Junction, CO 81502-2567

58. B. Erdal, LANL, ET-AET, MS D446, Los Alamos, NM 87545

59. E. M. Franz, BNL, P. O. Box 5000, Bldg. 830, Upton, NY 11973

60. B. Frazee, Lockheed Idaho Technologies Corp., P. O. Box 1625, MS 5229, Idaho Falls, ID 83415

61. S. Grace, DOE/RF, P. O. Box 928, Bldg. 116, Golden, CO 80402-0928

62. R. Grubb, Parsons Engineering Science, 111 Union Valley Rd., Suite 100, Oak Ridge, TN 37830

63. B. Gupta, NREL, 1617 Cole Blvd., Golden, CO 80401

64-68. J. Harness, USDOE/ORO, P. O. Box 2001, Oak Ridge, TN 37830-8620

69. P. Hart, METC, 3610 Collins Ferry Road, Morgantown, WV 26507-0880

70. K. Heath, Department of Chemical Engineering, Dougherty Hall, University of Tennessee, Knoxville, TN 37996

71. F. Heckendorn, WSRC, P. O. Box 616, Rd. 1, Bldg. 773-A, Aiken, SC 29802

72. J. E. Helt, ANL, 9700 South Cass Ave., Argonne, IL 60439-4837

73. D. Herman, FERMCO, P. O. Box 538704, MS 81-2, Cincinnati, OH 452538704

74. J. Hyde, USDOE, EM-54, 19901, Germantown Road, Germantown, MD 20874-1298

75. R. Jacobson, Desert Research Institute, P. O. Box 19040, Las Vegas, NV 89132-0040

76. D. Kaback, CCEM, 999 18th Street, Suite 2750, Denver, CO 80202

77. G. W. Kabalka, Department of Chemistry, Dabney/Buehler Hall, University of Tennessee, Knoxville, TN 37996

78. R. Keller, EMEC Consultants, R. D. 3, Roundtop Road, Export, PA 15632

79. R. K. Kibbe, Battelle, 151 Lafayette Drive, Suite 1110, Oak Ridge, TN 37830

80. N. E. Korte, ORNL/GJO, P. O. Box 2567, Bldg. 56, Grand Junction, CO 81502

81. B. J. Krall, ORNL/GJO, P. O. Box 2567, Bldg. 53B, Grand Junction, CO 81502 
82. D. R. Kuespert, W. R. Grace \& Co., Washington Research Center, 7500 Grace Drive, Columbia, MD 21044-4098

83. S. Larson, PPPL, P. O. Box 451, Princeton, NJ 08543

84. W. LaVeille, DOE/SR, Savannah River Operations Office, 703 A, Rm. B 202, Aiken, SC

85. S. C. T. Lien, USDOE, EM-53, 1000 Independence Ave., SW, Washington, DC, 20585

86. C. A. Little, ORNL/GJO, P. O. Box 2567, Bldg. 53B, Grand Junction, CO 81502

87. D. Maynor, DOE/Ohio, P. O. Box 3020, Miamisburg, OH 45343-3020

88. D. MacArthur, LANL, NIS-6, MS J561, Los Alamos, NM 87545

89. M. Mazzotti, Dipartimento Di Chimica, Pelitecnico di Milano, Via Mancinelli 7, I-20131 Milano, ITALY

90. R. McCallister, DOE/RF, P. O. Box 928, Bldg. T124A, Golden, CO 804020928

91. L. W. McClure, WINCO, P. O. Box 4000, Idaho Falls, ID 83415-2202

92. K. Merrill, Lockheed, P. O. Box 1625, MS 3710, Idaho Falls, ID 83415-3710

93. J. O. Moore, USDOE/ORO, P. O. Box 2001, FOB, EW-92, Oak Ridge, TN 37831-8620

94. D. A. Olona, DOE/AL, P. O. Box 5400, Albuquerque, NM 87185

95. K. Ortego, Raytheon Services of Nevada, P. O. Box 95487, Las Vegas, NV 89193-5487

96. J. P. Perl, HQ AFCEE/ERC, 8004 Chennault Road, Brooks AFB, TX 782355359

97. J. L. Peterson, P. O. Box 464, Bldg. T130B, Golden, CO 80402-0464

98. P. J. Pettit, FERMCO, P. O. Box 538704, MS 81-2, Cincinnati, OH 452538704

99. L. Rogers, EG\&G Measurements, Inc., P. O. Box 1912, MS RSL-11, Las Vegas, NV 89125

100. M. D. Salazar, LANL, P. O. Box 1663, MS 773, SM30, Los Alamos, NM 87545

101. M. Shupe, DOE/PETC, P. O. Box 3462, Butte, MT 59702

102. S. Slate, PNL, P. O. Box 999, MS IN K9-14, Richland, WA 99352

103. R. Smiecinski, DOE/NV, P. O. Box 98518, Las Vegas, NV 89193-8518

104. K. Stevenson, DOE, 376 Hudson Street, New York, NY 10014-3621

105. G. Subbaraman, ETEC, P. O. Box 1449, D/030, T038, Canoga Park, CA 91304

106. C. Tang, Department of Chemistry, Dabney/Buehler Hall, University of Tennessee, Knoxville, TN 37996

107. C-F. Tsang, LBL, Earth Sciences Division, Lawrence Berkeley Lab., Bldg. 50E, Berkeley, CA 94720

108. C. L. Valle, Allied Signal Aerospace KCP, P. O. Box 419159, D/272, FV43, Kansas City, MO 64141-6159 
109. R. Warner, P. O. Box 538705, Cincinnati, OH 45253-8705

110. S. Webster, DOE/CH, 9800 South Cass Ave., Argonne, IL 60439

111. T. E. Williams, DOE/ID, 785 DOE Place, MS1219, Idaho Falls, ID 83402

112. M. J. Wilson-Nichols, ORNL/GJO, P. O. Box 2567, Bldg. 53C, Grand Junction, CO 81502

113. J. Ziagos, LLNL, P. O. Box 808, MS L-207, Livermore, CA 94550

114-115. Office of Scientific and Technology Information, U.S. DOE, P. O. Box 62, Oak Ridge, TN 37831 